\title{
THE INFLUENCE OF SHIP RATS (RATTUS RATTUS) ON THE HABITAT PREFERENCES OF THE HOUSE MOUSE (MUS MUSCULUS)
}

By

Benjamin Hancock

2008 


\title{
THE INFLUENCE OF SHIP RATS (RATTUS RATTUS) ON THE HABITAT PREFERENCES OF THE HOUSE MOUSE (MUS MUSCULUS)
}

By

Benjamin Hancock

\author{
A thesis \\ submitted to the Victoria University of Wellington \\ in fulfilment of the requirements for the degree of \\ Master of Science \\ in Ecology and Biodiversity
}

Victoria University of Wellington

2008 


\section{Abstract}

As methods and successes of Rattus rattus (ship rat) control progress, particularly in island environments, the importance of managing Mus musculus (house mouse) increases. M. musculus can negatively impact on a variety of native fauna and flora, potentially creating long term cascading effects. M. musculus populations benefit with the reduction in $\mathrm{R}$. rattus abundance and recover sooner from pest control programs. This three-part study investigated the habitat utilisation of M. musculus and how their relationship with R. rattus influences their habitat preferences. Firstly, hypotheses about the habitat preferences of M. musculus were tested over a landscape scale to determine the features of the environment most important to their distribution. Then the direct effect of $\mathrm{R}$. rattus presence on $\mathrm{M}$. musculus habitat-use was investigated in arena trials. Lastly, in the same arenas, canopy cover was tested as an indirect cue for M. musculus to evaluate the presence of R. rattus. Across 32 sites, M. musculus were the most abundant in warm dry habitats. North facing slopes and rank grass cover were the features of the environment that had the strongest relationship with abundance. In arenas M. musculus foraging activity was $52 \%$ lower in patches of short grass when R. rattus scent was present but foraging in rank grass and bare ground was not altered, suggesting activity was suppressed not competitive displacement. There were no significant changes in M. musculus foraging behaviour between different canopy treatments. Although a trend of nocturnal foraging activity dropping $26 \%$ when high canopy cover was over short grass compared to short grass patches with lower or no canopy treatments may indicate a risky habitat. M. musculus use of dense ground cover was common theme in this study and in the literature. R. rattus do influence the habitat selection of $\mathrm{M}$. musculus though this was with direct presence more than indirect cues. 


\section{Acknowledgments}

My supervisor Dr. Wayne Linklater and my co-supervisor Dr. Angela Moles for all their guidance and support throughout my master's study. John and Liz Hancock for allowing the use of their farm, "Rapaki", for the arena trials, plus their financial support and equipment use. The Murray King Memorial scholarship and the Rural Women New Zealand (Wairarapa) scholarship. The land owners that granted me access across their properties to study sites for Chapter 2. Juken Nisho Limited for the plywood sheets needed to construct the arenas. Members of the School of Biological Sciences at Victoria University of Wellington for the support, knowledge and resources. Darren Peters of the Department of Conservation and Raewyn Empson of the Karori Sanctuary for thier comments and advice. The Department of Conservation Wairarapa Area Office for lending of equipment. 
Contents

Page

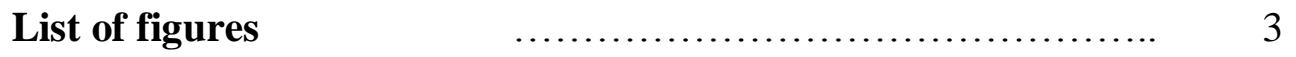

List of tables

Chapter 1: Introduction $\quad$ …................................ 4

Chapter 2: Landscape habitat preferences of house mice (Mus musculus) 12

Abstract $\quad$.................................... 13

Introduction $\quad$..................................... 14

Methods $\quad$................................... 16

Analysis $\quad$.................................. 25

Results $\quad$.

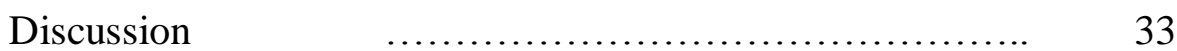

Chapter 3: Ship rats (Rattus rattus) alter house mouse (Mus musculus) habitat

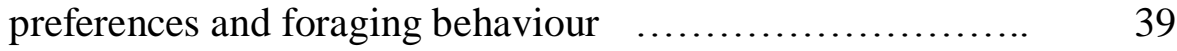

Abstract $\quad$................................... 40

Introduction $\quad$................................... 41

Methods $\quad$...................................... 43

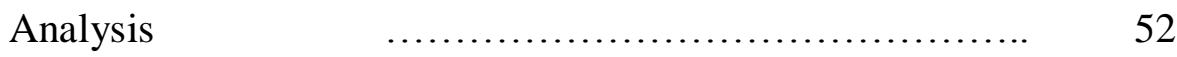

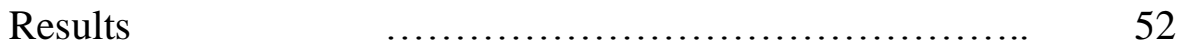

Discussion $\quad$.................................. 53

Chapter 4: The role of canopy as an indirect cue in house mouse (Mus

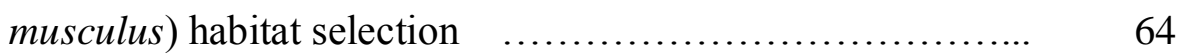

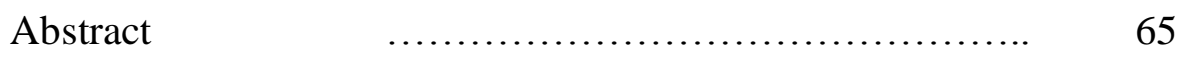

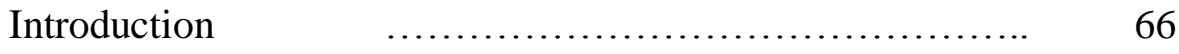

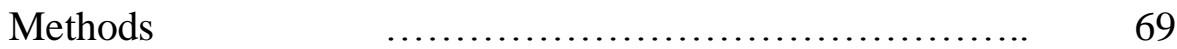

Analysis $\quad$................................... 78 
Results $\quad$.................................. 79

Discussion $\quad$ (n................................. 85

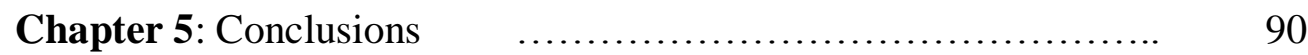

References $\quad$................................... 99 


\section{Figures}

Chapter 2:

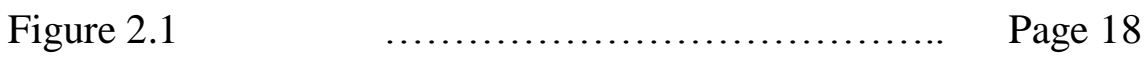

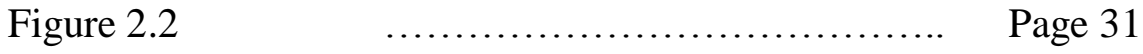

Chapter 3:

Figure 3.1

Page 46

Figure 3.2

Page 47

Figure 3.3

Page 48

Figure 3.4

Page 55

Figure 3.5

Page 56

Figure 3.6

Page 57

Chapter 4: 
Figure 4.1

Page 72

Figure 4.2

Page 73

Figure 4.3

Page 74

Figure 4.4

Page 75

Figure 4.5

Page 82

Figure 4.6

Page 83

Figure 4.7

Page 84

Figure 4.8

Page 85

\section{Tables}

Chapter 2:

Table 2.1

Page 32

Table 2.2

Page 32 
Chapter 1:

Introduction 
Communities are complex networks of interacting species where even measuring and understanding the relationship between two species is a challenge to ecologists. Yet understanding how species interact and how those interactions mediate their individual relationships with the physical environment is key to advancing ecological science. Predator-prey and competitor relationships are known to modify the distribution and abundance of species (Nicholson 1933, Brand et al. 1976, Legendre and Fortin 1989, Lima 1998). Often these relationships are obvious but there are many other relationships that are too subtle and difficult to measure in natural systems.

New Zealand poses a unique opportunity to investigate vertebrate species interactions in a comparatively simple system because a limited number of exotic species were introduced during human colonisation. Ordinarily these species live in more biodiverse and complex communities (Schoener 1983, Blackwell and Linklater 2003, Blackwell 2005). As such, New Zealand provides a grand natural laboratory to investigate community dynamics in a way not available elsewhere. Furthermore, experiments with these invasive species are not as limited as work with native species, and the work has the practical application for improving invasive species management.

Invasive species are a global problem in ecosystems whether they are aquatic or terrestrial, island or continental (Dulloo et al. 2002, Andersen et al. 2004, Buckley 2008). Not only are native environments threatened but they have social and economic implications for human communities (Juliano and Philip Lounibos 2005, Pimentel et al. 2005). Approximately $6 \%$ of species on the IUCN Red List are known to be negatively impacted by naturalised exotic species, habitat loss is the main contributor (33\%) to species decline, followed by exploitation (7.5\%) (Gurevitch and Padilla 2004). Commensal rodents are particularly successful invasive species 
(Atkinson 1996), their historical proximity with humans has meant that they have spread throughout the world and occur in every terrestrial region except polar regions (Ruscoe and Murphy 2005). Although, rodents have impacted on native species worldwide, they have been particularly damaging in island ecosystems (Towns et al. 2006).

New Zealand has been severely impacted by the arrival of rodents. Terrestrial mammals were absent from New Zealand prior to human arrival, except for three species of bats (Daniel 1990). The native species of New Zealand were vulnerable to introduced mammals because of the absence of mammalian predators and competitors in their evolutionary history (Holdaway 1989). Rodents contributed to and caused species decline, extinctions and habitat restrictions (Saunders and Norton 2001) and many native species became restricted to mammal-free offshore islands (Diamond and Veitch 1981, Towns and Daugherty 1994).

Four species of rodents became established in New Zealand, all from the Murid family. The first species, Rattus exulans (Polynesian rat, kiore, 60-80 g), arrived with Maori settlers as the first exotic mammal (Wilmshurst and Higham 2004), although the timing of this is debated (Holdaway and Beavan 1999, Wilmshurst and Higham 2004). McGlone (1989) proposes that predation by $R$. exulans was one of four main pre-European anthropogenic impacts on New Zealand's native species. With the arrival of Europeans three more species colonised New Zealand from approximately 1770 onwards (O'Donnell 1996): R. norvegicus (Norway rat, 200-300 g), R. rattus (ship rat, 120-160 g), and Mus musculus (house mouse, 15$20 \mathrm{~g})$.

The house mouse in New Zealand was thought be M. musculus (Ruscoe and Murphy 2005) but shares characteristics with Mus domesticus (Efford et al. 1988) and 
this uncertainty has yet to be resolved (Ruscoe and Murphy 2005). M. musculus and $R$. rattus are the most widespread rodent species throughout New Zealand (Innes 2005b, Ruscoe and Murphy 2005). R. norvegicus distribution is more restricted being usually commensal or in proximity to bodies of water (Innes 2005a) and the range of $R$. exulans is probably restricted through competition with the other three rodent species (Taylor 1975).

The decline and extinction of some of New Zealand's flora and fauna is largely attributed to $R$. rattus. For example, in 1962 when $R$. rattus invaded Big South Cape Island off the coast of Stewart Island (Bell 1978) it caused the complete extinction of the Xenicus longipes variabilis (Stead's bush wren), Coenocorypha aucklandica iredalei (Stewart Island snipe), and Mystacina robusta (greater shorttailed bat). Additionally, four bird species and one bat species became locally extinct. $R$. rattus also eat invertebrates, birds, eggs and plant material, and destroy flowers and seeds (Ecroyd et al. 1995, Innes and Barker 1999). The direct and severe impact of $R$. rattus has meant that they have been a particular focus of pest management and eradication in New Zealand and globally (Murphy et al. 1998b, Basse et al. 2003, Towns et al. 2006), and over the last forty years the methods for controlling, eradicating and excluding $R$. rattus have improved (Towns and Broome 2003, Towns et al. 2006, Day and MacGibbon 2007).

M. musculus populations have repeatedly been shown to benefit from the removal of $R$. rattus (Innes et al. 1995, Miller and Miller 1995, Caut et al. 2007) because they rebound from control techniques sooner than other species due to their shorter life history (Innes et al. 1995, Ruscoe and Murphy 2005). R. rattus are generally considered not to be predators but dominant competitors of M. musculus (Brown et al. 1996, Yom-Tov et al. 1999, Sweetapple and Nugent 2005, Caut et al. 
2007), they rarely occur in $R$. rattus diet even when $M$. musculus has been provided as food in captivity (Daniel 1973, Miller and Miller 1995). There is considerable overlap in the two species diets including seeds, invertebrates and plant matter (Miller and Miller 1995, Ruscoe 2001, Sweetapple and Nugent 2007) but an apparent habitat separation in New Zealand forests. $R$. rattus occupy arboreal habitats with continuous canopy and M. musculus are abundant in habitats with dense ground cover and broken canopy (Hooker and Innes 1995, King et al. 1996).

While there has been an emphasis on $R$. rattus control because of the damage they do, M. musculus are not innocuous. M. musculus are seed predators which can have large scale implications for ecosystems by limiting the recruitment of some plant species and altering the regeneration and succession dynamics of native forests (Wilson et al. 2007). Their competition for seed and depredation of native seed dispersers like Hemidenina crassidens (tree weta) may also limit dispersal of seeds (Duthie et al. 2006). M. musculus also impact on a variety of New Zealand's species, depredating and depressing lizard populations (Newman 1994, Lettink and Cree 2006), destroying bird eggs (Alterio et al. 1999), preying on invertebrates (Miller and Miller 1995, Fitzgerald et al. 1996) and the large Paryphanta busbyi watti (kauri snail) (Stringer and Montefiore 2000), and even eat the eggs of Galaxias maculatus (inanga, whitebait) (Baker 2006).

M. musculus impacts can also be indirect. A common example is the increased predation of Mohoua ochrocephala (mohua, yellowhead) after mast seeding years in Nothofagus forest (King 1983, O'Donnell et al. 1996, O'Donnell and Phillipson 1996, White and King 2006). Nothofagus forests have heavy seeding years (mast years) with little seed production during the intervening years (Schauber et al. 2002). On Nothofagus mast years there are irruptions of $M$. musculus populations, although this 
may not be directly due to seed predation but an abundance of Tingena epimylia, a litter feeding moth that features commonly in M. musculus diet (Fitzgerald et al. 1996). The Mustela erminea (stoat) population increases with the abundance of $M$. musculus for prey but after the mast seeding ends the M. musculus population declines rapidly (King 1983, King and White 2004). With the numerical increase of $M$. erminea, a greater portion of the threatened endemic M. ochrocephala population is affected causing a short-term, but catastrophic, decline in their survival and nesting success (King 1983, O'Donnell 1996, O'Donnell and Phillipson 1996).

Population increases of $M$. musculus with the reduction in $R$. rattus, coupled with the host of threats that $M$. musculus present, mean they should be considered a serious threat to native ecosystems. With the control of introduced mammals, particularly $R$. rattus, the implications throughout the exotic mammal community and flow-on effects from manipulating these species need to be considered (Zavaleta et al. 2001). The dynamics between $M$. musculus and $R$. rattus need to be investigated further (Innes et al. 1995, Brown et al. 1996, King et al. 1996, Sweetapple and Nugent 2005, Caut et al. 2007) to clarify whether habitat-use by M. musculus is altered by $R$. rattus direct displacement, or if $M$. musculus take indirect cues from features of the habitat to avoid encounters with $R$. rattus (Orrock et al. 2004). The investigation of habitat selection cues by rodents has often been related to predators (Kotler et al. 1988, Brown 1992, Dickman 1992, Arthur et al. 2004) not competitors (Schoener 1983, Abramsky et al. 2001, Jones et al. 2001, Kotler et al. 2001).

To further our knowledge of the competitive dynamics between $R$. rattus and M. musculus a three part study was undertaken to; 1) establish the habitat preferences of M. musculus on a landscape scale across a variety of habitat types in a natural setting, 2) observe how the presence of direct $R$. rattus cues affect the habitat 
preferences of $M$. musculus, and 3) whether M. musculus mediate interactions with $R$. rattus by using features of their environment, particularly the canopy, as an indirect cue of $R$. rattus presence.

In Chapter 2 M. musculus habitat selection was investigated. I set out survey sites across the South Wairarapa District in a variety of exotic and native habitats. I used covered and uncovered feed trays to measure giving up densities (GUDs) (Brown 1988) at each site. Trapping was used to index M. musculus abundance at each site and features of the habitat measured so that preferences could be related to aspects of their ecology and their surrounding environment. I used an information theoretic approach to test hypotheses about the habitat preferences of $M$. musculus.

In Chapter 3 the influence of $R$. rattus scent on M. musculus habitat-use was examined in large outdoor arenas. Six arenas were built to house a single mouse each with three even sized patches of different ground cover within them: long rank grass, short trimmed grass, and bare ground. Quitting harvest rates (QHR) were used to gauge changes in foraging activity in each habitat patch with and without $R$. rattus scent.

In Chapter 4 the same six arenas were used to investigate the use of indirect cues by $M$. musculus to evaluate $R$. rattus presence. The $R$. rattus scent was removed and varying heights of canopy treatments placed over arenas: high canopy ( $2 \mathrm{~m}$ approx.), low cover (1 m approx.), and no canopy cover. QHRs were used to test whether M. musculus used canopy cover as an indirect cue for evaluating $R$. rattus presence.

My overall hypothesis is that the direct presence of $R$. rattus will alter $M$. musculus habitat-use and that to a lesser degree M. musclus will use high canopy as an indicator of $R$. rattus presence. $R$. rattus influence $M$. musclus populations (Innes et 
al. 1995, Miller and Miller 1995, Caut et al. 2007) so it would seem highly likely that the presence of $R$. rattus would alter their behaviour. Although Dickman (1992) stated that $M$. domesticus did not value vegetation over $1 \mathrm{~m}, R$. rattus are aboreal (Hooker and Innes 1995) and play an important role in M. musclus ecology so it could be beneficial for $M$. musclus to consider canopy cover as an indicator of $R$. rattus occurrence. 
Chapter 2:

Landscape habitat preferences of house mice (Mus musculus) 


\section{Abstract}

Knowledge of the relationships within a community is useful when managing a species, whether for improving, maintaining or removing a population. Mus musculus (house mouse) is an introduced rodent that detrimentally affects New Zealand's native flora and fauna. Management of M. musculus can improve with further understanding how they use their surrounding environment. The giving up density (GUD) method was used to give values relative to predation risk and food availability in the surrounding environment. GUDs, M. musculus abundance, and physical features habitat of the habitat were measured at 32 sites across the South Wairarapa District. Unfortunately, GUD values were found not to be representative of M. musculus activity. Using Akaike's information criterion (AIC), the strength of hypothetical models of M. musculus ecology for explaining the abundance patterns of M. musculus were compared. The use of rank grass model was the strongest accounting for almost $60 \%$ of the support of the models. The next two strongest models were the suitable breeding habitat and topography models $(12.5 \%$ and $12.1 \%$ of the support respectively). Models of low and high ground cover were the next models. No single model clearly explained $M$. musculus abundance variation but rank grass cover and slope aspect both featured strongly in the four strongest models. Rank grass ground cover at $0.25 \mathrm{~m}$ and north facing slopes were positively correlated with abundance and sites facing northeast around to the west were negatively correlated. This is likely due to more exposure to the sun and the warm dry north-west wind. This study presents rank grass cover and north facing slopes as the strongest predictors of $M$. musculus abundance from the parameters examined. Further work is required on how other species affect $M$. musculus distribution and behaviour. 


\section{Introduction}

How species are influenced by their environment is a key question in ecology. Biotic and abiotic factors modify population dynamics, predator-prey relationships, interspecific competition, and even the physical habitat itself (Ricklefs and Miller 1999). Understanding the relationships of a single species to its environment contributes to the overall knowledge of a community and benefits species management, whether for conserving, harvesting or eradication.

Invasive pests are a global problem but especially in island ecosystems (Towns et al. 2006). Rodents are adept at colonising new ecosystems and New Zealand is a prime example of this (Atkinson 1996). Management of exotic mammals is an ongoing and costly process (Innes and Barker 1999, Brown and Urlich 2005) with labour costs making up a large portion of pest control programs (Innes et al. 1995, Brown and Urlich 2005). Increasing the efficiency and scope of pest animal management could be achieved with improved understanding of the target species to enhance the implementation of tools such as poisoning and trapping.

Rattus rattus (ship rats) and Mus muculus (house mice) both negatively impact on New Zealand's native flora and fauna through predation and competition (King 1983, Newman 1994, Fitzgerald et al. 1996, Baker 2006), although more pest management effort is targeted at $R$. rattus (Towns et al. 2006). M. muculus populations have been reported to increase after $R$. rattus control in New Zealand forests (Innes et al. 1995, Ruscoe 2001, Sweetapple and Nugent 2005, Caut et al. 2007, Sweetapple and Nugent 2007). As the management of $R$. rattus improves, the importance of effective M. musculus control increases (Towns and Broome 2003, Caut et al. 2007). To increase the efficiency of $M$. musculus control programs, their habitat preferences and population success in different habitats should be understood. 
The giving up density (hereafter GUD) method (Brown 1988) can be used to compare the habitat preferences of $M$. musculus. Trays are filled with a substrate with food mixed through. As the forager depletes the food resource greater search effort is required to find the same quantity of food. The method assumes that an individual will no longer feed from the tray when the food reward does not justify the effort or risk of further searching compared to foraging in the surrounding environment (Charnov 1976, Brown 1988). The GUD is the level at which the harvester quits searching in the tray, in this way the GUD reflects the habitat preferences of M. musculus because in better quality or higher risk habitat the GUD will be higher.

Linking the observed patterns of $M$. musculus abundance, perceived predator risk and food availability to particular features of the environment improves our understanding about which elements of their environment play important roles in their habitat-use behaviour. Hypothetical models can be made from the habitat features that pertain to a certain aspect of $M$. musculus ecology. Parameters within the hypothetical models (predictors) that are strongly supported by the observation data may become apparent as habitat preferences.

It would be useful to know the habitat preferences of M. musculus when eradicating M. musculus. For example, assume dense rank grass was positively related to $M$. musculus abundance and negatively to predation risk, then management plans could then focus on habitats with high grass cover because they could be reservoirs of M. musculus and sources of immigrants during population expansion.

I expect that sites with plentiful ground cover will have higher numbers of $M$. musculus, lower perceived predation risk (Dickman et al. 1991, Dickman 1992, King et al. 1996, Arthur et al. 2004), and potentially high food availability because the cover provides a substrate to accommodate invertebrates (Miller and Miller 1995, 
Fitzgerald et al. 1996). Variations in this association are expected to be caused by the presence of mature fruiting trees that provide food and aerial cover that would also restrict avian predators, and features that provide a less severe micro-climate and lower rates of habitat disturbance.

\section{Methods}

\section{Study Area}

The South Wairarapa District in the south eastern corner of North Island, New

Zealand (Figure 2.1) has a seasonally mild, temperate climate with an average annual rainfall of $979 \mathrm{~mm}$ and 1915 sunshine hours. In spring and summer Wairarapa weather is dominated by winds from mountain ranges to the north-west and west that are warm and dry. During the autumn and winter cool and wet weather arrives from the south and east. Average January and July temperatures are $17.8^{\circ} \mathrm{C}$ and $7.5^{\circ} \mathrm{C}$ respectively (Tait et al. 2002, National Climate Database, National Institute of Water and Atmospheric Research Ltd (NIWA)).

The South Wairarapa has three distinct areas; mountain ranges to the west with peaks reaching to $1571 \mathrm{~m}$ above sea level (Mitre peak) in the Tararua Forest Park, an eastern hill range which reaches $983 \mathrm{~m}$ above sea level (Mt Ross) in the Aorangi Forest Park, and the central Wairarapa Valley running between the two ranges (Marra 2003). The Rimutaka and Tararua Forest Parks comprise the western boundary. These are forested by mixed podocarp-broadleaf species with areas of Nothofagus species (Moffat and Minot 1994, Rogers and McGlone 1994). Catchments on the Wairarapa side of these ranges drain east into the main Wairarapa 


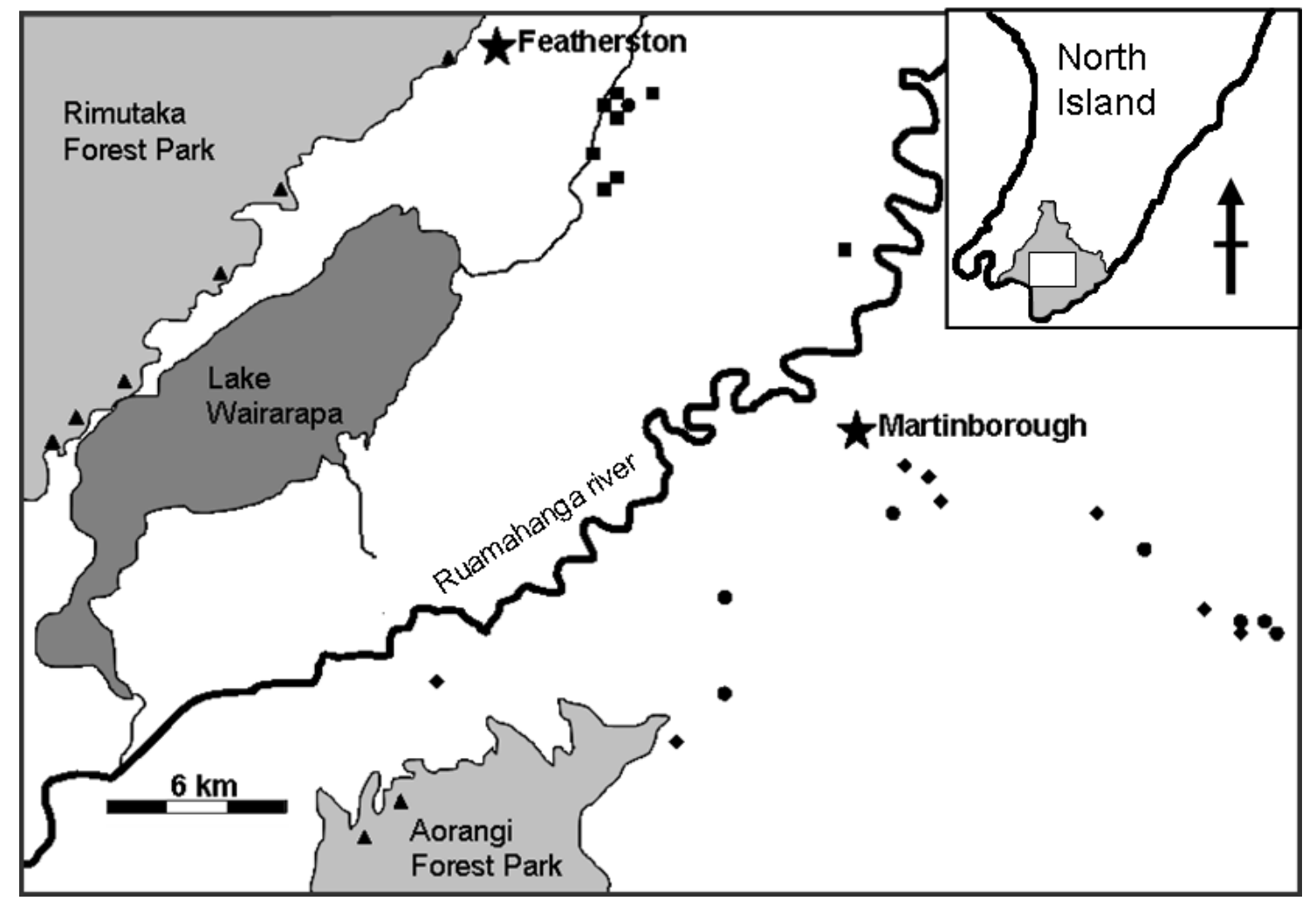

Figure 2.1 Distribution of survey sites across the South Wairarapa District (location in North Island, New Zealand, shown in top-right insert). Rimutaka Forest Park is in the north-western corner with Lake Wairarapa below. The Ruamahanga runs from northeast to south-west. The Aorangi Forest Park is bottom centre and Martinborough is east of centre. Exotic pine forest $(\diamond)$, farm shelter belt $(\bullet)$, native forest fragment $(\boldsymbol{\square})$, and continuous native forest $(\boldsymbol{\Delta})$ sites are indicated. 
Valley to contribute to the Ruamahanga River and Lake Wairarapa. The eastern hills range from the edge of the main valley to the eastern coastline of the province, gradually building from gentler foothills in the west to higher and steeper hills on the coast. Dry stock farming is the dominant land use in the eastern hills with a scrub belt running along the coastal edge of the range. The Ruamahanga River is the main river that flows the length of the valley and is chiefly fed by tributary rivers from the western mountain ranges. The Wairarapa Valley is low lying area made up of remnant river terraces, fans and drained floodplains and is principally modified for agriculture and horticulture.

\section{Habitat types and survey sites}

Two exotic and two native vegetative community types varying in history, conditions and size were used for the study. These types were; (1) exotic pine forest, (2) farm shelter belts, (3) native forest fragments, and (4) continuous native forest (Figure 2.1).

Exotic pine forests were defined as uniform man-made forests of conifers exotic to New Zealand. Pinus radiata was the most prevalent species used in the Wairarapa and all of the exotic pine forest survey sites used occurred in forests of this species. Sites were chosen in pine plantations greater than $100 \mathrm{~m}$ wide so that sites were representative of the habitat and influence from neighbouring habitats was reduced (Young and Mitchell 1994, Herbst et al. 2007). These forests are generally in the eastern hills and sparse in the main valley or western ranges. Pine forests were often fenced to exclude livestock though some were grazed sporadically. The trees were planted in large cohorts and then thinned and pruned such that under more established forests there was often debris from branches and surplus trees.

Farm shelter belts were plantings a few metres wide of hardy exotic and some native species along pasture boundaries between fields. Sites selected were uniform in 
width and livestock were excluded with fences. Shelter belts were planted from the eastern hills to the western side of the main valley on arable land and widely used to protect agricultural and horticultural land from strong winds and to provide shelter for livestock.

Native forest fragments were areas with a minimum radius of $50 \mathrm{~m}$ that were predominantly podocarp-broadleaf native bush surrounded by modified land. Fifty metres was considered to be a sufficient distance to reduce the influence of neighbouring habitats (Young and Mitchell 1994, Herbst et al. 2007). All of these areas were fenced to exclude livestock. A majority of the native forest fragments used are designated "key native ecosystems" by the Greater Wellington Regional Council as part of a program managing remnant native habitats on privately owned land. All of these fragments occur in the central Wairarapa Valley. The number and distribution of remnants were limited because of the low number of remnants that remained and access across private land was not always granted.

Continuous native forests were defined as predominantly native forest that was part of, or continuous, with the Rimutaka Forest or Aorangi Forest Parks. These sites were usually Nothofagus sp. forest but not exclusively. Some sites were broadleaf forest and earlier successional forest.

Thirty-two survey sites were distributed amongst the four different habitat types throughout the South Wairarapa District (Figure 2.1). For each of these habitat types, eight survey sites were spread as much as possible across the landscape such that all could be sampled within a day to reduce the weather variation within sampling events. In a pilot trial, 10 sites for each habitat type were initially selected but it was not possible to sample each of these sites in one day so eight sites were selected for each habitat type. No survey sites were located in the same forest remnant, plantation or 
shelter belt. It was not possible to use separate unconnected habitat patches for the continuous native forest survey sites. Nevertheless, $1 \mathrm{~km}$ was used as a minimum distance between each site as mice are unlikely to travel this distance and use more than one survey site in a night such that sample sites are independent (Fitzgerald et al. 1981, Krebs et al. 1995). Once a suitable forest, remnant, plantation or shelter belt was selected the survey site was identified by using random compass bearings and numbers for short distances to locate a site at least $50 \mathrm{~m}$ from the habitat edge.

\section{Survey site layout}

At each survey site two round trays were placed $10 \mathrm{~m}$ apart (Hughes and Ward 1993, Kotler et al. 2001). The distance between trays ensured that an individual mouse would assess and feed from each individually but close enough so that the mouse could visit both trays over the period of a trial. Feed trays were cut from $200 \mathrm{~mm}$ diameter dark green plastic buckets at approximately $35 \mathrm{~mm}$ depth so the volume of trays was slightly larger than 1 litre.

If the survey site was on sloping ground then the trays were placed laterally across the slope. On negligible slopes the trays were organised parallel to the nearest habitat edge. Each tray was dug into the ground so that its upper edge was level with the ground surface and so the tray provided no additional cover, thus removing the possibility that the tray provided an unintended refuge for mice (Gray et al. 2000). On sloping ground, the tray was dug down until tray was level with the ground down slope. The soil was removed upslope of the tray so that animals could approach from all sides.

One tray was left open while the other was covered. The covered tray was randomly selected then covered with an approximately $400 \mathrm{~mm}$ branch of dry Kunzea ericoides (kanuka) and six $300 \mathrm{~mm}$ fronds of Pteridium esculentum (bracken). The 
stalk of the kanuka branch was wedged into the ground so that its foliage overhung the tray and supported the sprigs of bracken. This created a gap $>30 \mathrm{~mm}$ between the cover and tray substrate so that mice could manoeuvre once under the cover (Kotler et al. 1991).

Three Victor ${ }^{\circledR}$ professional mouse traps were placed at each survey site (Wiener and Smith 1972). One trap was placed centrally between the feed trays and the other two within $1 \mathrm{~m}$ of each feed tray. Each mouse trap was wired onto a piece of untreated kiln dried timber. A $105 \times 70 \times 50$ mm cage made of fine aluminium $12.5 \times$ $12.5 \mathrm{~mm}$ mesh was placed over each trap. A $35 \times 25 \mathrm{~mm}$ opening in the cage at the trigger-pedal end of the trap (King et al. 1996, Choquenot and Ruscoe 2000) was made so that the mice could only enter the trap from the trigger end. The cage prevented non-target animals getting caught in the trap. The traps were baited with quarter of a button of Nestle ${ }^{\circledR}$ chocolate melts fixed onto the pedal of the trap, and then the trigger pin was set to sensitive on the trigger pedal. All pieces of equipment were placed unset at least five days prior to the trials beginning to allow rodents to habituate to them (Brown et al. 1996).

\section{Feed trial protocol}

M. musculus GUDs were used to gauge M. musculus perception of predation risk and the food availability of the surrounding habitat (Brown 1988). Trays were filled with a mix of substrate and a known amount of particulate food. Substrate limits the rate at which M. musculus find and harvest the food. As the ratio of food to substrate decreases, the rate of harvesting decreases exponentially to an asymptote. The final amount of seed that was left in the substrate was the density of seeds at which $M$. musculus quit searching the trays, i.e. the giving up density. The GUD for individual trays was influenced by the value and risk of the surrounding environment. The 
method assumes that if a habitat patch has low predation risk then individuals will be inclined to remain there longer and deplete the food resource further. Conversely, if the surrounding environment has high food availability then individuals will deplete the tray less because of the other feeding opportunities available. Both scenarios are preferable situations though they would create opposing GUDs.

By pairing trays at the site and reducing predation risk with added cover at one of the trays the influence of perceived predation risk on foraging behaviour can be investigated. At trays where there was no added cover, mice are prone to the inherent predation risk of the surrounding environment. Predation risk can be inferred from the difference in GUDs between uncovered and covered trays, and food availability from GUDs of covered trays where predation risk is reduced.

Feed trays were filled with 1 litre of Hudson® attapulgite pet litter, mixed with $5 \mathrm{~g}$ of Sharpes ${ }^{\circledR}$ feed wheat. The pet litter was used because it limited the feed tray filling with water and was easier to sort through when wet compared to other substrates like sand. Care was taken to disturb the surrounding area as little as possible when approaching and leaving the trays. All feed trays were stocked on the same day and left for five consecutive nights in each trial. The wheat was sifted out of every tray on the day after the fifth night and seeds put into an individual ziplock $®$ bag labelled with the trays identity number and date. The litter was returned to the tray. Trials lasting five nights were used to give ample opportunity for the feed trays to be depleted to the GUD.

\section{Preliminary trial}

A preliminary trial was conducted for three nights from 13 September 2008 to test how many survey sites could be sampled in a day and whether there would be any activity at the feed trays at each site. The methods previously described were followed 
except the wheat was not mixed through the litter but 10 seeds instead placed on top of the litter. In this preliminary trial ten survey sites were placed in each of the four habitat types. It proved not possible to visit all 40 survey sites in one day. Five survey sites that took too much time to access were removed and three were randomly selected for removal to reduce the total number of survey sites to 32 . Twenty-eight of the 32 sites had some activity with at least a few of the seeds removed.

\section{Timeline}

Trials were conducted during September and October 2007. Feed trays were stocked on 16 September for the first trial and remaining seeds collected on 21 September. A second trial was conducted immediately after the first trial, with each tray being restocked. The second trial was completed on 26 September. Three nights of mouse trapping began after the second trial on the night of 27 September. Seeds that were removed during each of the three trials were dried in an oven at $60{ }^{\circ} \mathrm{C}$ for seven hours and weighed to the nearest $0.01 \mathrm{~g}$ (Orrock et al. 2004).

\section{Habitat surveys}

A range of micro-habitat features were measured (King et al. 1996) at each of the 32 survey sites to determine the habitat preferences of $M$. musculus. Surveys were done using a modified reconnaissance plot of 15 m diameter (King et al. 1996). Surveys of shelter belt sites were truncated where they met the habitat's edge. Canopy height, canopy cover, altitude, slope aspect, slope gradient, the percentage and type of ground cover, and distance from survey site to the nearest change in ecotype were the features measured.

Average canopy height was initially measured by using a clinometer to the nearest metre. The canopy height was gained by walking away from the tree forming 
part of the canopy until the sighting angle through the clinometer was $45^{\circ}$. The measured distance from the base of the tree plus the height of the observer was equal to the height of the canopy.

Canopy density was measured with a convex densiometer by recording the percentage of open sky blocked by vegetation at $1.35 \mathrm{~m}$ above the ground. A random bearing was taken by throwing a pen in the air and following which direction it pointed. From this direction another three readings were taken at $90^{\circ}$ from each other at the same spot. Twenty-four even squares were etched into the face of the densiometer. Four equally spaced points were visualised in each square and every point that was covered by vegetation was counted. The count was averaged over the four readings and then multiplied by 1.04 to give percent canopy cover.

Altitude in metres above sea level was recorded from the handheld Global Positioning System (GPS) (Garmin etrex) and confirmed against a topographical map. Slope aspect was gauged by estimating the general direction of the slope by eye and then taking a compass bearing to the nearest whole degree.

Slope gradient was taken on the same bearing as the aspect of the slope using a clinometer. Measurement was taken by standing $2.5 \mathrm{~m}$ up the slope from the centre of the survey site and looking through the clinometer at a reference point at eye level 2.5 $\mathrm{m}$ downhill of the survey site. If no reference point was available, then a stick that reached eye level was anchored in the ground as a guide.

Percentage ground cover was estimated at $0.25 \mathrm{~m}$ and $1 \mathrm{~m}$ heights for; vascular plants, rank grasses $(>150 \mathrm{~mm})$, short grasses $(<150 \mathrm{~mm})$, leaf litter, and exposed rock or soil. 
Distance to the next ecotype was measured from the centre of the survey site to the nearest boundary of the next ecotype with the handheld GPS. Half the width of a shelter belt was measured in place of the distance to nearest ecotype.

\section{Analysis}

\section{Giving up densities}

The use of GUDs as measure of perceived predation risk and food availability for $M$. musculus was checked by conducting Student's t-tests in Microsoft Excel®.

Comparing the GUDs of covered with uncovered trays and sites with and without $M$. musculus would clarify if the GUDs were representative of $M$. musculus foraging activity and if the additonal cover reduced predation risk. The second GUD trial was discarded because some trays were disturbed so the sample set was not complete.

\section{Mouse abundance}

An index of abundance (IA) was used to gain a value of mouse abundance at each site (Cunningham and Moors 1993). Based on the percentage of mice caught per possible trapping effort, a measure of relative abundance was obtained.

Trapping effort and rodents caught per 100 trapping nights is calculated by:

$\begin{array}{lll}\text { Index of abundance }(\mathrm{IA}) & = & \frac{\text { Captures } \times 100}{\text { Corrected trap nights }} \\ \text { Total trap nights } & = & \text { No\# traps set } \times \text { No\# of nights } \\ \text { Trap nights lost } & = & \frac{(\text { Captures }+ \text { Sprung, empty traps })}{2} \\ \text { Corrected trap nights } & = & \text { Total trap nights }- \text { Trap nights lost }\end{array}$




\section{Habitat models}

Eight a priori candidate models were developed from hypotheses using combinations of habitat features as predictors of M. musculus habitat preferences. These models were then ranked in order based on the predicted importance of the model in $M$. musculus habitat selection. The eight hypotheses were;

1. Rank grass use. This hypothesis only included rank grass cover at $0.25 \mathrm{~m}$ as a predictor of dense ground cover which has been ascribed as being important for providing cover from predation (Dickman et al. 1991, Dickman 1992) and correlated with M. musculus abundance (King et al. 1996).

2. High ground cover. This hypothesis included the percentage of ground covered at $1 \mathrm{~m}$ by short grass, rank grass and vascular foliage as predictors. The model provides the benefits of ground cover as well as immediate aerial cover from predators of M. musculus.

3. Food availability. This hypothesis included habitat type, canopy height, and leaf litter cover and rank grass cover measured at $0.25 \mathrm{~m}$ as predictors in the model. The type of habitat and age of forest could influence the type and amounts of foods available and the seed bank can be affected by the age and stage of succession of the site (Bossuyt et al. 2002). Leaf litter provides a substrate for M. musculus to forage for invertebrates and rank grass is another source of seeds. Both seeds and invertebrates have been shown to be large components of M. musculus diet (Fitzgerald et al. 1996). With more food available, a denser population would be able to be sustained within the habitat.

4. Low ground cover. The hypothesis included percentage of ground covered at $0.25 \mathrm{~m}$ by short grass, rank grass and vascular foliage as predictors. These three habitat features measure cover from predators and competitors on the ground that a 
mouse could move through. This is a similar model to the high ground cover model but without the low aerial cover and includes information on more types of ground cover than the rank grass model.

5. Cover from aerial predators. This hypothesis included vascular ground cover at $1 \mathrm{~m}$, canopy height, canopy density, and habitat type as predictors. These variables would provide some protection from aerial predators except for habitat type. Shelter belts may have had dense canopy cover directly above but little cover would be provided from the edges because they were often narrow strips so habitat type was included in the model.

6. Suitable breeding habitat. This hypothesis included slope gradient, slope aspect, percentage of ground cover at $250 \mathrm{~mm}$ by rank grass and woody debris as estimable variables. These factors included aspects that contribute to a warm, dry and stable habitat. A moderate gradient would offer drainage and stability, and north facing sites would receive more sunlight, creating a location where nests could be warmer, dryer and remain intact until the young leave.

7. Topographical features. This hypothesis included the aspect of the slope, slope gradient, and altitude as predictors. Aspect is used as gauge for exposure to different prevailing weather conditions with dry warmer air arriving from the northwest and colder wet weather from the south (Tait et al. 2002). The slope gradient gives information of the sites drainage ability which may have been important for a small ground dwelling mammal.

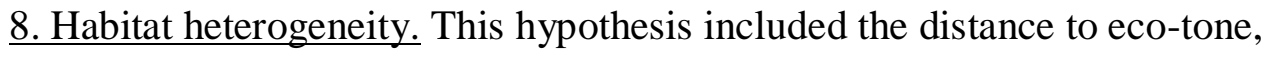
next eco-type, percentage of canopy made up by the dominant species, canopy density, and number of species present in the canopy as predictors. These habitat 
features contributed to the physical variability and biodiversity of the site which may promote mouse abundance with a more complex habitat structure and composition.

\section{Information theoretic analysis}

An information theoretic analysis was used to find the candidate model that best explains abundance of $M$. musculus or habitat preference with the information available (Burnham and Anderson 2002). Each survey site was treated as a single replicate. GUDs were used as a measure of $M$. musculus habitat preference and IA as a measure of $M$. musculus abundance at each survey site. A general linear model (GLM) was conducted using R 2.7.2 (R Foundation for Statistical Computing, Vienna, Austria) for each hypothesis to acquire an Akaike's information criterion (AIC) for each candidate model.

Due to the small sample size of the candidate models $(n=32)$ a second order Akaike's information criterion $\left(\mathrm{AIC}_{\mathrm{c}}\right)$ was used because $\mathrm{n} / \mathrm{K}<40$ (range $1<\mathrm{K}<11$ ) (Burnham and Anderson 2002). Each model was then ranked using the lowest difference in $\mathrm{AIC}_{\mathrm{c}}\left(\Delta \mathrm{AIC}_{\mathrm{c}}\right)$ from the model with the smallest $\mathrm{AIC}_{\mathrm{c}}$. The lower the $\Delta \mathrm{AIC}_{\mathrm{c}}$ value the more comparative strength the model has. Where $\Delta \mathrm{AIC}_{\mathrm{c}} \leq 2$ models have convincing support from the data (Burnham and Anderson 2002). The Akaike weight $\left(w_{i}\right)$ is the relative support for each of the models and conveys the likelihood of the model explaining variation in $M$. musculus abundance between the survey sites (Burnham and Anderson 2002).

The IA and GUDs were entered as scale dependent variables. The habitat features that were used in the model were treated as scale data, except for the data from the "next eco-type" and "habitat type" measurements that were treated as categorical. The raw bearing measurements for the aspect of a slope were transformed into categorical data because of the nonlinear nature of compass bearings. Slope 
aspect bearings were placed into eight categories of $45^{\circ}$; north $\left(338-022^{\circ}\right)$, northeast $\left(023-067^{\circ}\right)$, east $\left(068-112^{\circ}\right)$, southeast $\left(113-157^{\circ}\right)$, south $\left(158-202^{\circ}\right)$, southwest $(203-$ $\left.247^{\circ}\right)$, west $\left(248-292^{\circ}\right)$, northwest $\left(293-337^{\circ}\right)$. Each category of data counted as an explanatory variable for the models they were used in. Slope aspect was not treated as 1 explanatory variable but 8 for each of the data categories.

\section{Results}

GUDs were not different between covered and uncovered trays in the presence or absence of M. musculus (paired two sample for means Student's $t$-test, mice present $\mathrm{P}$ $=0.413$, no mice present $\mathrm{P}=0.370$ ). There was also no significant difference in GUDs between the sites with and without M. musculus (one tailed two sample assuming unequal variances Student's $t$-test, $P=0.179$ ) (Figure 2.2). Thus, GUD values are not conclusively representative of $M$. musculus foraging and could not be used as an indicator of mice habitat preference.

All models had some degree of support from the mouse abundance data except the aerial cover and food availability models $\left(\Delta \mathrm{AIC}_{\mathrm{c}}>10\right)$. Rank grass use was the strongest model, accounting for over half of Akaike weight $\left(w_{i}=0.580\right)$ though not clearly dominant compared to the other models $\left(w_{i}<0.9\right)$. The next two 

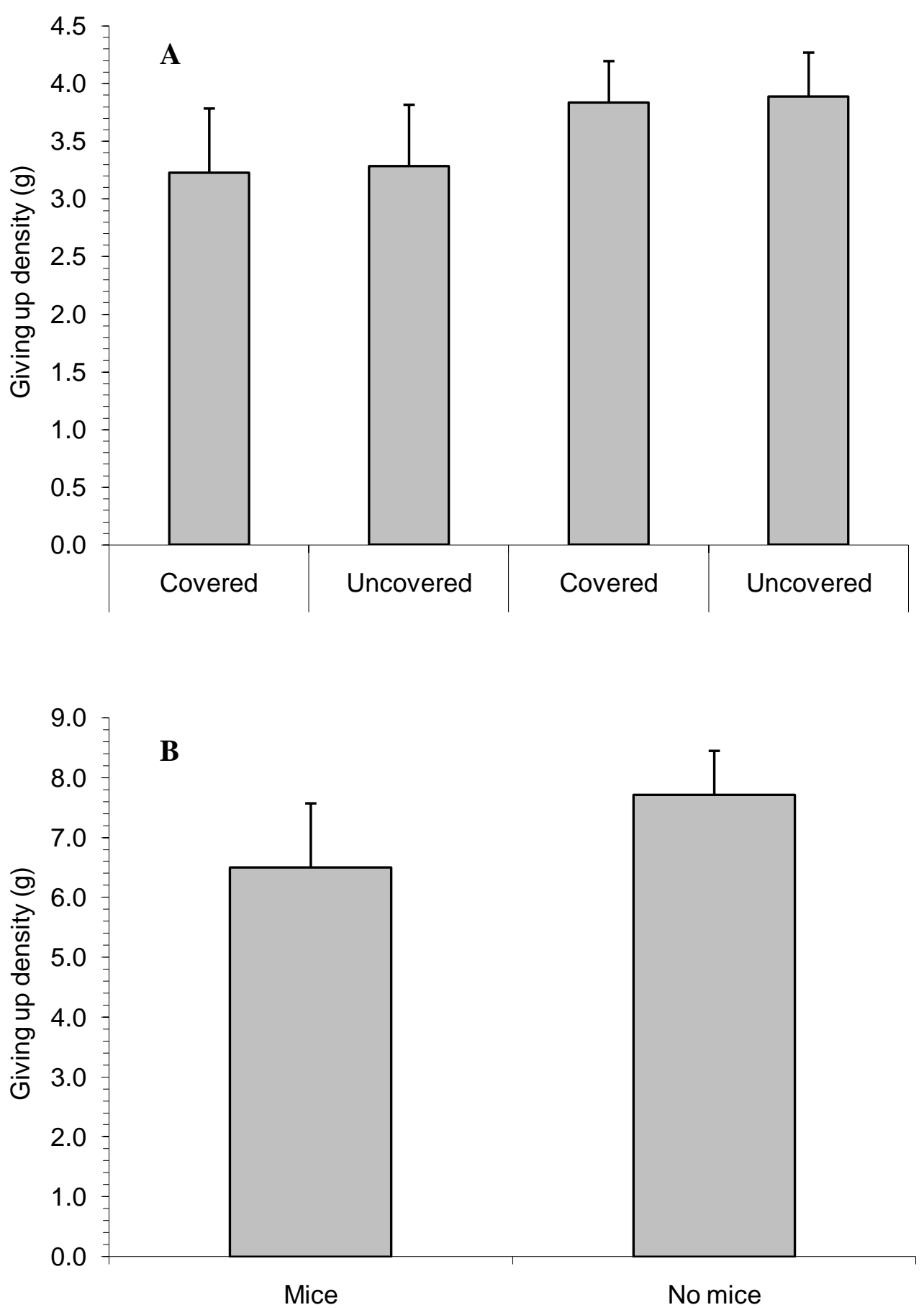

Figure 2.2. Giving up densities (GUD) across the South Wairarapa District of paired trays at 32 sites. A) The effect of additional cover over the tray at sites with $M$. musculus present and sites without M. musculus present. B) Combined covered and uncovered GUDs between sites with and without $M$. musculus present. 
Table 2.1. Predicted rankings of candidate models against the actual ranking from lowest second order Akaike's information criterion $\left(\mathrm{AIC}_{\mathrm{c}}\right)$ values. Models with lower $\mathrm{AIC}_{\mathrm{c}}$ values were supported more by the $M$. musculus abundance data. The models are not absolute explanations of habitat features or aspects of $M$. musculus ecology that are conducive to $M$. musculus abundance, they are the best explanation from the information gathered and hypothesis constructed.

\begin{tabular}{clcccc}
\hline $\begin{array}{c}\text { Predicted } \\
\text { ranking }\end{array}$ & Candidate models & $\mathrm{K}^{\mathrm{a}}$ & $\mathrm{AlC}_{\mathrm{c}}$ & $\Delta \mathrm{AlC}_{\mathrm{c}}$ & $\boldsymbol{w}_{i}$ \\
\hline 1 & Rank grass & 1 & 250.333 & 0.000 & 0.580 \\
6 & Breeding habitat & 11 & 253.400 & 3.067 & 0.125 \\
7 & Topographical features & 10 & 253.476 & 3.143 & 0.121 \\
4 & Low ground cover & 3 & 254.057 & 3.724 & 0.090 \\
2 & Higher ground cover & 3 & 254.557 & 4.224 & 0.070 \\
8 & Habitat heterogeneity & 6 & 258.460 & 8.127 & 0.010 \\
5 & Aerial cover & 7 & 261.366 & 11.033 & 0.002 \\
3 & Food availability & 7 & 262.466 & 12.133 & 0.001 \\
\hline
\end{tabular}

Notes: $\triangle \mathrm{AIC}_{\mathrm{c}}$ is the difference between the smallest $\mathrm{AIC}_{\mathrm{c}}$ and the models $\mathrm{AIC}_{\mathrm{c}}$ $w_{i}$ is Akaike weight or relative probability that the model was the best for predicting M. musculus abundance

${ }^{a}$ the number of explanatory variables in the candidate model.

If categorical data was used then each data category was counted as an explanatory variable.

Table 2.2. Second order Akaike's information criterion $\left(\mathrm{AIC}_{\mathrm{c}}\right)$ of the common estimable parameters of the breeding habitat and topographical features models.

\begin{tabular}{lccc}
\hline Estimable parameter & $\mathrm{K}^{\mathrm{a}}$ & $\mathrm{AlC}_{\mathrm{c}}$ & $\Delta \mathrm{AlC}_{\mathrm{c}}$ \\
\hline Aspect $^{\mathrm{b}}$ & 8 & 240.563 & 0.000 \\
Slope $^{\mathrm{c}}$ & 1 & 255.943 & 9.252 \\
\hline
\end{tabular}

Notes: ${ }^{a}$ the number of explanatory variables in the candidate model

${ }^{b} 45^{\circ}$ categories of aspect for the slope

${ }^{c}$ gradient of the slope. 
models best fitted to the data were suitable breeding habitat $\left(\Delta \mathrm{AIC}_{\mathrm{c}}=3.067, w_{i}=\right.$ $0.125)$ and topographical features $\left(\Delta \mathrm{AIC}_{\mathrm{c}}=3.143, w_{i}=0.121\right)$, with similar support from the data. Suitable breeding habitat and topographical features had a similar number of explanatory variables (Table 2.1$)$ and share 9 parameters ( 8 were categories of slope aspect). Low and high ground cover models followed next $\left(\Delta \mathrm{AIC}_{\mathrm{c}}\right.$ $=3.724, w_{i}=0.090$ and $\Delta \mathrm{AIC}_{\mathrm{c}}=4.224, w_{i}=0.070$ respectively). Both models shared the same habitat features though were measured at different heights from the ground. The order of strength of these two models was reversed from what was predicted (Table 1), with low ground cover only having $2 \%$ higher weight of support. The data partially supported the habitat heterogeneity model as well $\left(2 \leq \Delta \mathrm{AIC}_{\mathrm{c}}<10\right)$.

Rank grass was clearly the strongest single parameter for predicting $M$. musculus abundance (Table 2.1). It is probable that the explanatory strength for low and high ground cover models comes from their respective rank grass measures. The rank grass use model only featured the estimable variable for percentage of rank grass from $0.25 \mathrm{~m}$ and had $58 \%$ of the estimated explanatory power. Aspect of the slope and slope gradient were the common variables in the next two strongest models. A linear regression was conducted for both variables in R 2.7.2 (R Foundation for Statistical Computing, Vienna, Austria) to determine which or if indeed both parameters provided support to the two models. The large $\triangle \mathrm{AICc}$ of the slope gradient $(\triangle \mathrm{AICc}=9.252)$ asserts that slope aspect lends greater support to the topographical and breeding habitat models (Table 2.2), despite slope aspect having a larger number parameters $(\mathrm{K}=8)$. From the regression, north facing slopes were positively correlated with M. musculus abundance and the six slopes facing northeast around to west were all negatively correlated $(\mathrm{P}<0.01)$. 
The four models best supported by the data were predominantly driven by the inclusion of slope aspect and rank grass cover as predictors. The cumulative Akaike weights of these four models was above the $0.9\left(\Sigma w_{i}=0.916\right)$ threshold for explaining the majority of the variation in the data. While the cumulative weights was not as sound as model averaging (Burnham and Anderson 2002) this does indicate that the combination of slope aspect and rank grass cover from $0.25 \mathrm{~m}$ are the best estimable parameters of $M$. musculus abundance data.

\section{Discussion}

The hypothesis most supported was the model of rank grass that only estimated rank grass cover at $0.25 \mathrm{~m}$. The four models best supported by the data had a cumulative Akaike weight that would be sufficient to be a clear expression of $M$. musculus abundance. Each of those four models was largely contributed to by either the percentage of rank grass cover at $0.25 \mathrm{~m}$ or aspect of the slope at the survey sites. Only two of the candidate models, aerial cover and food availability, were not supported by the data to some extent ( $\triangle \mathrm{AICc}>10)$ (Burnham and Anderson 2002).

Because slope aspect data was entered as 8 categories of data, each category was treated as a separate explanatory variable in the models. The only category of slope aspect not significantly correlated with $M$. musculus abundance was northwest facing sites. The north facing slopes were the only significant categories with positive correlations, likely due to these slopes being warmer and dryer. These conditions would not just be produced by higher exposure to the sunlight but the frequent dry northwest wind, particularly in October (Tait et al. 2002) when the trials were conducted. The other six significant aspect categories had negative correlations. The 
lack of exposure to the sun and northwest wind would have made the environment colder and damper on these slope aspects.

$R$. rattus have been shown to be abundant on warmer steeper slopes (King et al. 1996). An overlap in use of warm, dry habitats by M. musculus and $R$. rattus could be mediated in two ways. King et al. (1996) established that in Pureora Forest Park, $M$. musculus and $R$. rattus used separate habitats: broken canopy and dense ground cover for M. musculus and continuous canopy for $R$. rattus. M. musculus were not found to be abundant on the warm dry slopes in King et al. (1996). This may have been caused by competitive exclusion by $R$. rattus (Brown et al. 1996, Caut et al. 2007) or M. musculus selecting micro-habitats that would limit direct interactions where their ranges overlapped with $R$. rattus (Dickman 1992, Orrock et al. 2004). The use of dense cover by M. musculus and other rodent species is widely documented (Dickman et al. 1991, Dickman 1992, King et al. 1996, Mandelik et al. 2003, Arthur et al. 2004).

The possible competition of these two species for warm and dry locations may have serious implications for native plants and animals adapted to these warmer dryer slopes (Holland and Steyn 1975, Wilson et al. 2007). The impacts of M. musculus on native species may have been under-estimated previously because $M$. musculus were competitively excluded by $R$. rattus (Caut et al. 2007). Removal of $R$. rattus from these warm dry locations may not provide relief for the native species communities because $M$. musculus could replace the $R$. rattus. Previously unregistered negative impacts of M. musculus may become prominent if activity in these areas increases after $R$. rattus eradication.

The suitable breeding habitat model may not have necessarily been a model exclusively explaining breeding habitat. The two significant estimable parameters of 
the model could relate to fitness of the individual as well, particularly if one considers the timing of the study. The positive correlation with the warm dryer slopes may relate to the survival of individuals and the population during the colder period of the year (Hamilton 1942). The similarity between the suitable breeding habitat and topographical models is understandable considering the breeding habitat model contained 9 of the 10 explanatory variables of the topography model. The combination of amiable climate and refuge in rank grass provided the model with the second strongest correlation with M. musculus abundance. It was predicted that including features of ground cover and disturbance rates into a model with topography would create a model with more support than the topography model, though this increase was minimal.

Comparing both models that focussed on degrees of ground cover at different heights $(0.25 \mathrm{~m}$ and $1 \mathrm{~m})$ showed that $M$. musculus abundance had a stronger correlation with lower patterns of ground cover. In Dickman (1992), vegetative cover above $1 \mathrm{~m}$ high did to provide cover for mice. The support from the mouse abundance data for the low ground cover model over higher ground cover supports Dickman (1992). Measurements for ground cover percentages mainly differed by more vascular cover being included at $1 \mathrm{~m}$ high. This was initially thought to have provided supplementary cover over the grass cover. If the vascular cover was not associated with M. musculus abundance and grass cover was (Table 2.1), then vascular cover over the grass would reduce the strength of the model by lowering the amount of grass represented.

Food availability and aerial cover were two models that were predicted to be strongly related to $M$. musculus occurrence (predicted rank: 3 and 5 respectively), but were the least supported by the abundance data (actual rank: 8 and 7 respectively). 
Perhaps more direct measurements of food sources like invertebrate and seed densities were needed than inferences from indirect elements of habitat. Seed fall traps and invertebrate traps would involve more effort as tools for estimating M. musculus abundance than gauging aspects of the habitat, making them less practical as tools for pest managers. It is understandable that the aerial cover model did not correlate with M. musculus abundance considering high ground cover was supported less than low ground cover, providing more support for that cover over $1 \mathrm{~m}$ is not valued by $M$. musculus (Dickman 1992). Though the positive relationship of lower direct cover was important there was still scope for a negative correlation with aerial cover. As the canopy or sub-canopy became more continuous less light would be available in the undergrowth, thus limiting the extent of low ground cover growth. However, I found no evidence that canopy cover played a role in this study.

Inferences could not be made on the habitat preferences of M. musculus because GUD values that would have given insight to predation risk and food availability at each site were not different at sites with or without $M$. musculus. The trapping index gives an indication of $M$. musculus abundance across habitats but no insight to the mechanisms and behaviours that produce the resulting pattern. It may be possible for certain habitat conditions to produce a situation where a habitat is preferred by M. musculus but the species is numerically lower than in another habitat, i.e. lower predation risk but lower food availability creating a safe but low carrying capacity habitat. This would be akin to source-sink population dynamics, where a stable population with positive population growth (source) is connected to and maintains a population that is not self-sustaining (sink) (Pulliam 1988), creating a net flow of individuals from the source population to the sink population. Dickman et al. 
(1991) displayed a possible example of this with Mus domesticus on Boullanger Island, Western Australia.

The likely explanation for the feed trays not being representative of GUDs was activity from other species of rodents and the avifauna. $R$. rattus have been shown to prohibit M. musculus access to resources (Brown et al. 1996) and it would be expected that birds such as Turdus merula (common blackbirds) and Turdus philomelos (song thrushes) (pers. obs.) would not be excluded by M. musculus due to their larger size. It was assumed from similar studies (Brown 1988, Kotler et al. 2001) that smaller species would have had lower GUDs but this did not appear to be correct. Another possible explanation to the lack of difference for GUDs between covered and uncovered trays at sites with $M$. musculus present could be that a dominant mouse was excluding other con-specifics which may have forced them to use the riskier tray, therefore removing the difference between covered and uncovered trays. This is unlikely, however, because it has not occurred in other similar studies of rodents using GUDs that were available to multiple individuals (Brown 1988, Abramsky et al. 2001, Ylönen et al. 2002, Arthur et al. 2004). Brown (1988) explained that the GUD will be representative of the individual with the lowest GUD, which is relative to environment not the number of individuals. If an individual reaches a tray that has already been depleted, they are not going to take the same amount of food from the tray as the prior visitor. The individual will search for the food until it is depleted to a level where the effort and risk of foraging in that patch outweighs the return.

A potential limitation for using the trapping index as a measure of $M$. musculus abundance was the potential decrease in trapping efficiency when $M$. musculus are in preferable conditions (Weihong et al. 1999). If food was plentiful or 
competition for resources was minimal then individuals may be less inclined to visit the traps, though generally this has not been the case (Innes et al. 1995, Fitzgerald et al. 1996, Choquenot and Ruscoe 2000, Ruscoe et al. 2001).

From this investigation, two features of the habitat were shown to positively relate to M. musculus abundance: north facing slopes and higher amounts of rank grass cover. These two features provide practical tools for estimating M. musculus abundance for they can be gauged quickly and easily. This does not suggest that these were the best possible estimable parameters, but the best of those measured in this study.

If a correlation between suitable breeding habitat and habitat preferences of $M$. musculus was made, then their population dynamics may be consistent with sourcesink dynamics. It may be possible that the strongest two estimable parameters could indicate potential source populations of $M$. musculus, making ongoing management of M. musculus logistically simpler. Studies of the occurrence of source-sink dynamics between M. musculus populations could have beneficial outcomes for managing this pest.

Understanding M. musculus habitat selection would give important insight to management of this pest species. Investigation into whether the apparent habitat segregation was due to M. musculus selection or R.rattus interference forcing $M$. musculus away would improve the knowledge of this small mammal community. Higher vegetation may play some degree in M. musculus habitat selection if other aspects of the habitat are equal. It would be expected that higher vegetation would likely play a minor role compared to the levels of ground cover. 


\section{Chapter 3:}

Change in house mouse (Mus musculus) habitat preferences and foraging behaviour with the removal of ship rat (Rattus rattus) 


\section{Abstract}

Rattus rattus (ship rats) play a major role in Mus musculus (house mouse) ecology as a dominant competitor affecting their distribution and population dynamics, so mechanisms of this relationship are examined here. The scent of $R$. rattus was used in a series of arena trials investigating how the presence of a direct cue of $R$. rattus affected M. musculus habitat preferences and foraging behaviour. Quitting harvest rates (QHR) were used to measure changes in M. musculus activity in the arenas. Regardless of scent treatment, nocturnal foraging was $78 \%$ higher than diurnal foraging. In the absence of the rat scent, $M$. musculus clearly preferred dense cover over the intermediate short grass cover by $47 \%$ and used a bare ground the least. The short grass cover became preferred the least in the presence of the $R$. rattus cue dropping 52\% with little change in the other two ground cover treatments. The preference of bare ground over the intermediate cover in the presence of $R$. rattus scent was an unexpected result. This pattern was likely due to improved vigilance and swifter movement in the bare ground patch. Foraging behaviour was suppressed in the intermediate cover without a shift to harvesting more food in other habitats. Suppression of M. musculus activity supports some of the literature and has implications for the success and distribution of their populations. The findings improve the understanding of rodent community interactions and imply how they may help with pest management, although further investigations are needed of interactions of the relationship of these species and the small mammal communities they occupy. 


\section{Introduction}

Inter-specific competition can reduce a subordinate species survival (Valone and Brown 1995) and fecundity (Arthur et al. 2004), and a populations range (Abramsky et al. 2001) through its impacts on the fitness of individuals (Dickman et al. 1991, Dickman 1992, Orrock et al. 2004). A dominant competitor can impact subordinate species similarly to a predator (Valone and Brown 1995). By removing a dominant species from an eco-system a subordinate species experiences the benefits of competitive release (Yeaton and Cody 1974, Heske et al. 1994).

Direct cues are signs of a species presence like calls, scent markings or visual territory markings. Usually a direct cue would only be present if the species was actually there. Subordinate species can use the direct cues of a dominant species as a proxy to avoid competition (Orrock et al. 2004, Nunes 2007). If the dominant species was removed then there would be a response from the subordinate species because the former's cue was also removed. An indirect cue is unlike a direct cue because it is not created by the dominant species, but indicators that the subordinate associated with increased vulnerability or coincidence with the dominant species such as brighter moonlight, lack of refuge, or at locations preferred by the other species (Dickman 1992, Abramsky et al. 2001, Orrock et al. 2004). Moreover, responses to indirect cues still occur even if the dominant species is absent. Brown et al. (1999) stated that predators change how prey use habitat by altering the time they spend in low versus high risk habitats or increasing time individuals spend vigilant at the expense of other behaviours. It is possible that this may also be true of an individual's response to a competitor (Valone and Brown 1995). 
Rattus rattus (ship rats) and Mus musculus (house mouse) are the most widespread invasive rodents in New Zealand (Innes 2001, Ruscoe and Murphy 2005), competitors divergent in their use of habitat. M. musculus are more abundant in habitat with broken canopy and dense ground cover while $R$. rattus are more prevalent in forest with continuous canopy (Hooker and Innes 1995, King et al. 1996). R. rattus are often the focus of pest control programs which has lead to cases of $M$. musculus populations responding positively after the removal of $R$. rattus (Innes et al. 1995, Miller and Miller 1995, Sweetapple and Nugent 2005, Caut et al. 2007). The two species relationship has not been intensely investigated (Caut et al. 2007), and the need to examine this relationship has been repeatedly highlighted (Innes et al. 1995, Brown et al. 1996, Sweetapple and Nugent 2005, 2007). The response of M. musculus to the removal of $R$. rattus may depend on the type of cues which M. musculus use to evaluate the presence. If the interactions between these two species are reliant on direct cues and $R$. rattus was removed then the flow on effects of removing a competitor would reach their full extent more immediately. Managers may be able to incorporate this into the management of other pest species or predict further long-term distribution and population patterns.

If the presence of $R$. rattus displaced M. musculus then a shift in temporal activity or allocation of foraging activity from one habitat to a safer habitat would be observed. It would be expected that foraging activity would decrease without increased activity in alternative times or habitats if $M$. musculus were changing their behaviour, by expending more effort into other activities, like vigilance, and reducing the time spent foraging (Brown 1988, Abramsky et al. 2002).

I conducted simultaneous arena trials with $M$. musculus in the presence of $R$. rattus scent as a direct cue treatment to test if M. musculus use direct cues to avoid $R$. 
rattus and to clarify how $R$. rattus displace $M$. musculus temporally or spatially, or alter their investment in foraging behaviours. I would expect that in the presence of $R$. rattus scent $M$. musculus would decrease foraging activity in habitat patches that provide less cover and increase in those that provide more cover. The cover would act as refuge and reduce the conspicuousness of $M$. musculus. Nocturnal foraging would increase for the same reason. There may be a slight depression in the amounts of food taken as the patches that are utilised more become more depleted and harvesting efficiency decreases.

\section{Methods}

\section{Arena location, construction and dimensions}

Six $23.4 \mathrm{~m}^{2}$ arenas were built amongst rank grass within a fenced area on the brow of a low-lying flat topped ridge $\left(41^{\circ} 14^{\prime} 42.13\right.$ ’'S, $\left.175^{\circ} 29^{\prime} 2.91^{\prime \prime} \mathrm{E}\right)$ between pastoral fields near Martinborough (Figure 3.1). Vegetation within the fenced area was dominated by Chamaecytisus palmensis (Leguminosae) (tree lucerne) and rank pastoral grasses but also consisted of a variety of native and exotic trees, shrubs and flaxes. Livestock pasture surrounded this site with shelter belts nearby (Figure 3.1).

Hexagon shaped arenas were built because of the simplicity of construction and because they could be divided into equal diamond shaped thirds for different internal treatments. Sheets of plywood $(3 \times 0.65 \times 0.025 \mathrm{~m})$ were fixed in a hexagon shape and placed into a narrow trench approximately $50 \mathrm{~mm}$ deep. The loosened sod along the trench was pressed down by foot on the interior side of the wall and compressed down on the exterior side by a hand soil compactor. The entire wall was approximately $50 \mathrm{~mm}$ underground to prevent mice from digging under the wall. The height of the wooden wall was approximately 0.6 metres similar to other arena trials 
(Kotler et al. 1988, Arthur et al. 2004). Strips of corflute plastic $250 \mathrm{~mm}$ wide were nailed to the top of the plywood sheets to prevent mice from climbing over the fence. Joins between corflute sheets were taped together so there were no edges that mice might use to climb the wall. The corflute plastic increased the height of the arena walls to just over $0.8 \mathrm{~m}$. Grass around the internal perimeter was cut to $250 \mathrm{~mm}$ and stalks of seed heads throughout the arena were cut to approximately $500 \mathrm{~mm}$ to prevent mice using the grass to climb over the fence.

\section{Ground cover treatments}

Each third of the arena was randomly assigned a different height of ground cover. The three heights of ground cover used were bare ground, short grass ( $80-130 \mathrm{~mm})$, and rank grass (max. $500 \mathrm{~mm}$ ) (Arthur et al. 2004). To create bare ground, the grass was cut as close as possible to the soil surface (Figure 3.2 and 3.3).An edge-trimmer with a whipping nylon cord was used to cut the grass because it would not dig up the soil or damage the arena walls. Between each trial the grass was trimmed to the appropriate height and any clippings raked and removed from the arena.

One feed tray filled with a litre of sand was placed in the middle of each ground cover treatment. Holes were dug for the $200 \mathrm{~mm}$ round $\mathrm{x} 40 \mathrm{~mm}$ deep trays so the upper edge was flush with ground level. The shortest distance from the tray to the adjacent ground cover type was $1.299 \mathrm{~m}$. This distance prevents the neighbouring patch providing cover. From $1 \mathrm{~m}$ to $1.5 \mathrm{~m}$ has been used previously to separate covered and open foraging patches or as a minimum distance to a refuge (Kotler et al. 1991, Kotler et al. 2001, Orrock et al. 2004). 


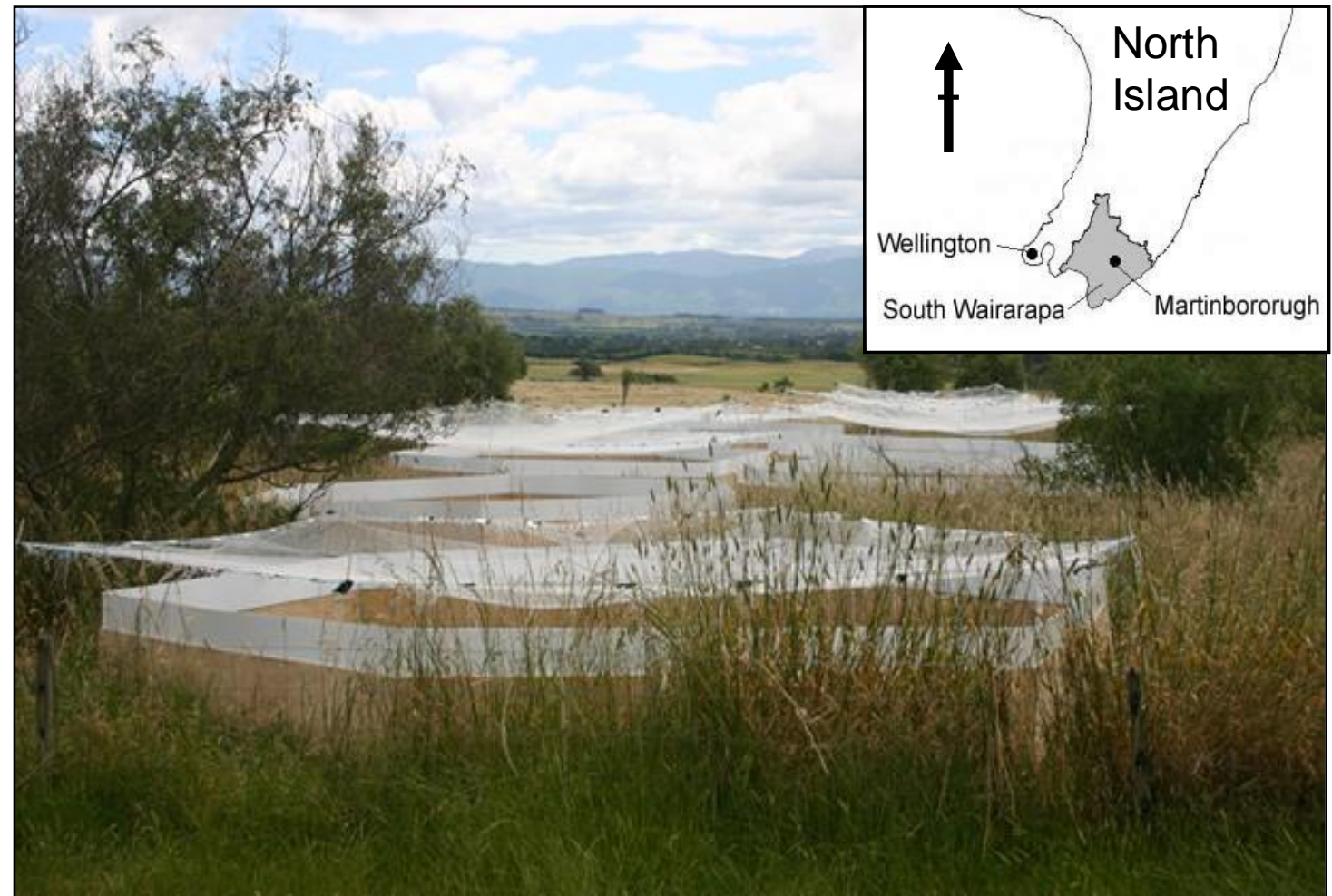

Figure 3.1. Arenas situated in area fenced from livestock and surrounded by trees and rank grass facing west. Inset in the top-right corner displays the location of Martinborough in New Zealand, Martinborough is located beyond the fields in the background. This photo depicts the canopy treatments of chapter 4 that were not part of this chapter's treatment. 


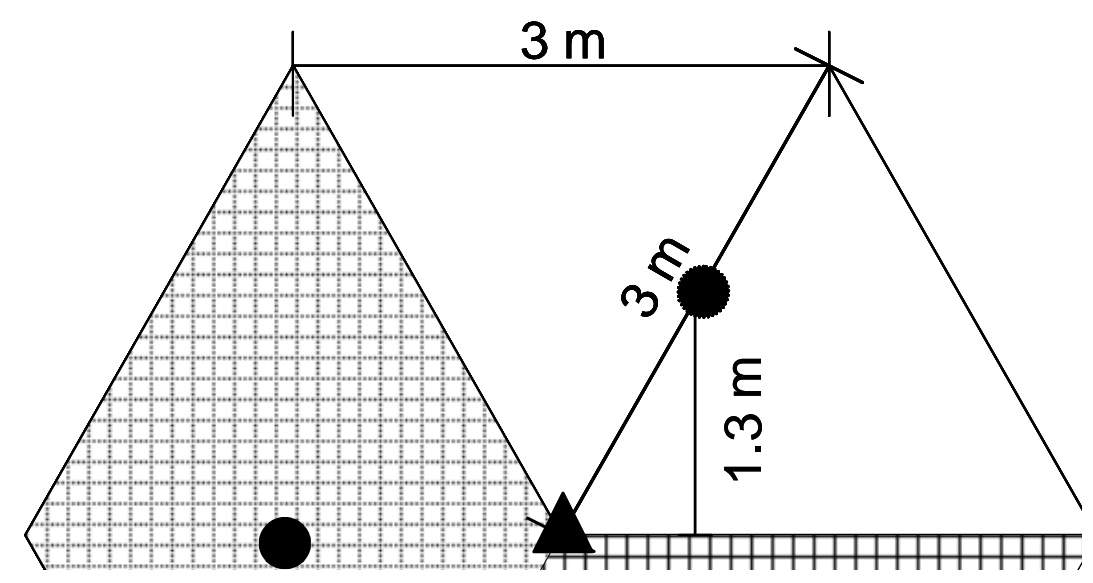


Figure 3.2. Dimensions of hexagon shaped arena with $3 \mathrm{~m}$ sides and 3 ground cover treatments: bare ground $=$ no cover, short grass $=80-130 \mathrm{~mm}$, rank grass $<500 \mathrm{~mm}$ within the arena that M. musculus could move between. In the centre of each ground cover patch is a feed tray. 


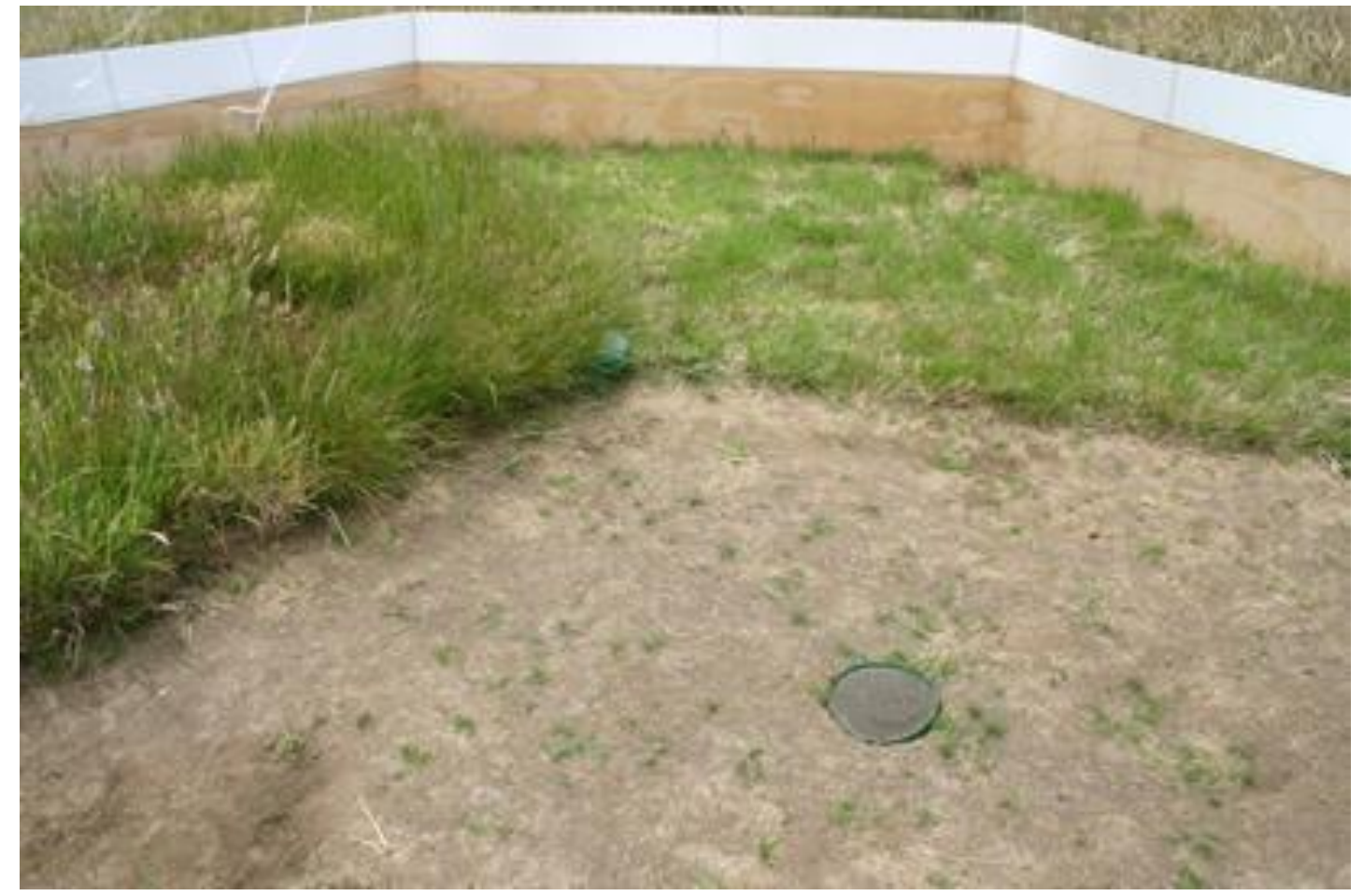

Figure 3.3. Three levels of ground cover as treatments with a feed tray in the foreground within an arena. The scent container was the centre of the arena at the junction of the three ground cover treatments. The three ground cover treatments were: bare ground $=$ no cover, short grass $=80-130 \mathrm{~mm}$, rank grass $<500 \mathrm{~mm}$. 


\section{Dominant competitor treatment}

In the centre of each arena, where the three ground cover treatments converge, a 0.5 litre plastic container was placed. The containers had three evenly spaced 25 × $25 \mathrm{~mm}$ holes cut around their wall near the top so that the lid still remained in place. Sawdust litter from caged $R$. rattus was collected the day before the trial and stored away from the arenas in an air-tight plastic bucket. On the day the trial began three of the arenas were randomly selected and their central container half filled with the scent impregnated sawdust and placed back in the centre of their respective arena. The empty containers remained in the other arenas. Before the containers were put in place, wine vinegar was sprayed in the immediate spot to neutralise any prior odours (pers. comms. Hancock, E. A. Veterinarian). This was important for consecutive trials when the treatments would be swapped between arenas so lingering rat odour would be removed.

The rat scented sawdust in the central containers was refreshed from the stored sawdust every occasion the feed trays were renewed during a trial (see "Quitting harvest rate protocol" below) (Orrock et al. 2004). Refreshing the sawdust after renewing the food prevented the feed trays becoming contaminated with rat odour.

\section{Quitting harvest rate trial protocol}

A method of measuring the quitting harvest rate (QHR) (Schmidt and Ostfeld 2003) was used to examine the habitat preferences of M. musculus (Brown 1988, Brown 1992). A giving up density (GUD) gives more absolute values of habitat quality while QHR gives relative rates of harvesting between the habitats. Trays were filled with a substrate and a designated amount of granule food mixed through it. The rate at which that food was harvested was at a rate relative to the perceived risk and harvesting 
opportunities in surrounding habitats. The rate of harvest decreases as the individual spends more time depleting the food tray. The amount of food remaining gives a value of the minimum harvest rate of an individual for that time period relative to the other available patches. Different harvest rates between different habitats indicate habitat preference. In this study, the food in each tray was limited so that an individual could not be satiated by feeding in only one habitat type. Thus, mice have to select between multiple ground cover types when foraging to meet their metabolic requirements. Nevertheless, food trays were adequately stocked with food such that a mouse would not exhaust itself searching through trays trying to meet its needs. The QHRs taken from trays were relative to harvest rate and perceived risk of the other habitat patches available to the individual over a twelve hour period. The conventional GUD method (Brown 1988) repeatedly leaves trays until they are depleted to a level relative to the surrounding environment, then the amount of food at which the species quits foraging in the patch was averaged.

A preliminary trial was conducted to ensure that an adequate amount of food for the mice to meet their metabolic demands for a twelve hour period was placed in each arena while still requiring the mouse to search between the habitat patches. $M$. musculus require approximately $3 \mathrm{~g}$ of dry matter per day (Crowcroft 1966). One gram mixed through 1 litre of sand in each of the three trays of the arena every 12 hours was therefore thought sufficient and most likely for selective consumption from trays to reflect the influence of treatments. The preliminary trial also created a presence of prior activity in each of the arenas for the first round of trials that were sampled thus creating similar conditions for each of the sampled trials that followed. Sampling every twelve hours would identify any diurnal or nocturnal changes in $M$. musculus foraging activity. 
Every feed tray was stocked from the first morning between 7-7:30am with $1 \mathrm{~g}$ of Sharpes ${ }^{\circledR}$ feed wheat mixed through a litre of sand in each tray. The sand and wheat were mixed in a twenty litre bucket and poured into the feed tray. The tray was gently shaken so that the sand levelled to a smooth surface so that $M$. musculus tracks and foraging activity on its surface could be detected. Trays were replenished with wheat every twelve hours for three days and all at the same time to reduce human activity in the vicinity and within the arenas. Before removing a tray for replenishment they were examined for evidence of track and sign according with previous studies (Arthur et al. 2004, Orrock et al. 2004). Those trays with mice sign were sieved into a twenty litre bucket and any seeds that remained removed and placed into a small labelled paper envelope. Envelopes were labelled detailing; the trial number, arena number, sample period, and ground cover type from which the sample was taken. Seeds from samples were dried in a oven at $60^{\circ} \mathrm{C}$ for seven hours and weighed to the nearest $0.01 \mathrm{~g}$ (Orrock et al. 2004). If sand had been lost from the tray it was replaced so the volume was returned to 1 litre and the next $1 \mathrm{~g}$ of seed mixed through it. Trays that did not have any sign of mice were re-mixed and deposited back into the tray. Trays were put randomly back into the holes in the arenas for another twelve hours. QHRs from the first 24 hours that the mice were in the arena were discarded as habituation time, giving 48 hours of sampling.

\section{Study specimens}

Wild M. musculus from the surrounding farm environment were used in arena trials because they were likely to have been exposed to the local potential predators and competitors. Circus approximans (harrier hawk), Ninox novaeseelandiae (morepork), Mustela erminea (stoat), Mustela nivalis (weasel), Felis catus (feral cat), Canis familiaris (domestic dog) and R. rattus all occurred on the surrounding farmland 
(pers. obs.). The responses of wild M. musculus were more likely to reflect behaviour in a natural setting than the behaviour naïve or commensal mice. M. musculus have been shown to retain anti-predator behaviour when moved to an environment in which predators were absent (Dickman 1992).

Up to seventeen Longworth® live mouse traps were used on the surrounding farmland to catch six mice in one night. Traps were baited with a half teaspoon of Sanitarium ${ }^{\circledR}$ peanut butter and with Nestle® chocolate melt buttons. The traps were placed around shelterbelts, unused timber and stacked debris on the farm and in shade where direct sunlight would not heat the traps. Two nights prior to the night of actual trapping, the traps were baited and placed with the trap door locked open so mice became acclimatised to the traps and feeding from them. About an hour prior to dusk on the day before mice were required, the traps were re-baited and the doors set. All traps were checked the following morning and the mice caught released into the arenas between 7-7:30 am. Only one mouse was released into each arena to prevent dominant-subordinate mouse interactions confounding habitat-use preferences (Dickman et al. 1991). Any surplus mice were released where they were caught. If less than six mice were caught in a single night, the trial would be delayed and trapping continued until six had been caught in a single night so that every arena could be occupied over the same period.

Mice of previous trials were removed from arenas by placing a baited and set live trap while the feed trays from the previous night were sieved. If a mouse was not caught in the arena by the time the new mice were ready to be released, the new mouse was placed in the shade near the assigned arena until the old mouse was caught. 


\section{Analysis}

Data was analysed with SPSS 16.0 (SPSS, Inc., Chicago, IL) general linear models procedure. I used an analysis of variance (ANOVA) with repeated measures to test for the influence of the two R.rattus scent treatments (between subjects factor) on the two levels of diurnal foraging behaviour and three levels ground cover usage (within subject factors). This analysis is generally done for repeated measures over time (Gotelli and Ellison 2004). A repeated measures ANOVA was used because the diurnal and grass cover factors occurred within each of the canopy treatments. Data from both days were pooled for each arena to remove issues of pseudo-replication when sampling was done from the same enclosures with the same mouse and treatment. Pallai's Trace test was used to identify significant treatment effects and interaction after Mauchly's test of sphericity showed that the assumption of sphericity was met.

\section{Results}

Foraging activity in arenas differed significantly temporally and between ground cover treatments. M. musculus foraged $78 \%$ more at night (Pillai's Trace, $\mathrm{F}_{1,10}=$ $131.5, \mathrm{P}=0.000$ ) and at least $60 \%$ more in the rank grass ground cover than the other ground cover patches (Pillai's Trace, $\mathrm{F}_{2,9}=79.509, \mathrm{P}<0.001$ ). The presence of $R$. rattus scent in arenas did not alter the amount of day time activity by $M$. musculus, but nocturnal feeding was reduced by $24 \%$, although the reduction was only approaching significance (Pillai's Trace, $\mathrm{F}_{1,10}=4.297, \mathrm{P}=0.065$ ) (Figure 3.4).

The presence of $R$. rattus scent significantly altered $M$. musculus habitat preferences (Pillai's Trace, $\mathrm{F}_{2,9}=8.692, \mathrm{P}=0.008$ ). Rank grass was still the preferred 
ground cover but the order of preference for short grass and bare ground had reversed due to foraging activity in the short grass patches dropping by 52\% (Figure 3.5).

A three way interaction between the factors temporal activity, ground cover type and rat scent was significant (Pillai's Trace, $\mathrm{F}_{2,9}=6.236, \mathrm{P}=0.020$ ) (Figure 3.6). Rank grass was still preferred over the two other types of ground cover during the day time. However, the presence of $R$. rattus depressed foraging at night at all ground cover types although this difference was largest between the two short grass treatments.

\section{Discussion}

The scent of $R$. rattus, a direct cue from a dominant competitor, modified $M$. musculus foraging activity and habitat use. The introduction of a competitor's direct cue reduced feeding by $M$. musculus at night and foraging activity in patches with short grass ground cover. Rat presence did not affect the amount of food removed during diurnal foraging.

The lack of change in diurnal foraging with the addition of $R$. rattus scent was possibly due to $M$. musculus and $R$. rattus being predominantly nocturnal so a change in M. musculus behaviour might be more apparent when they are both more 


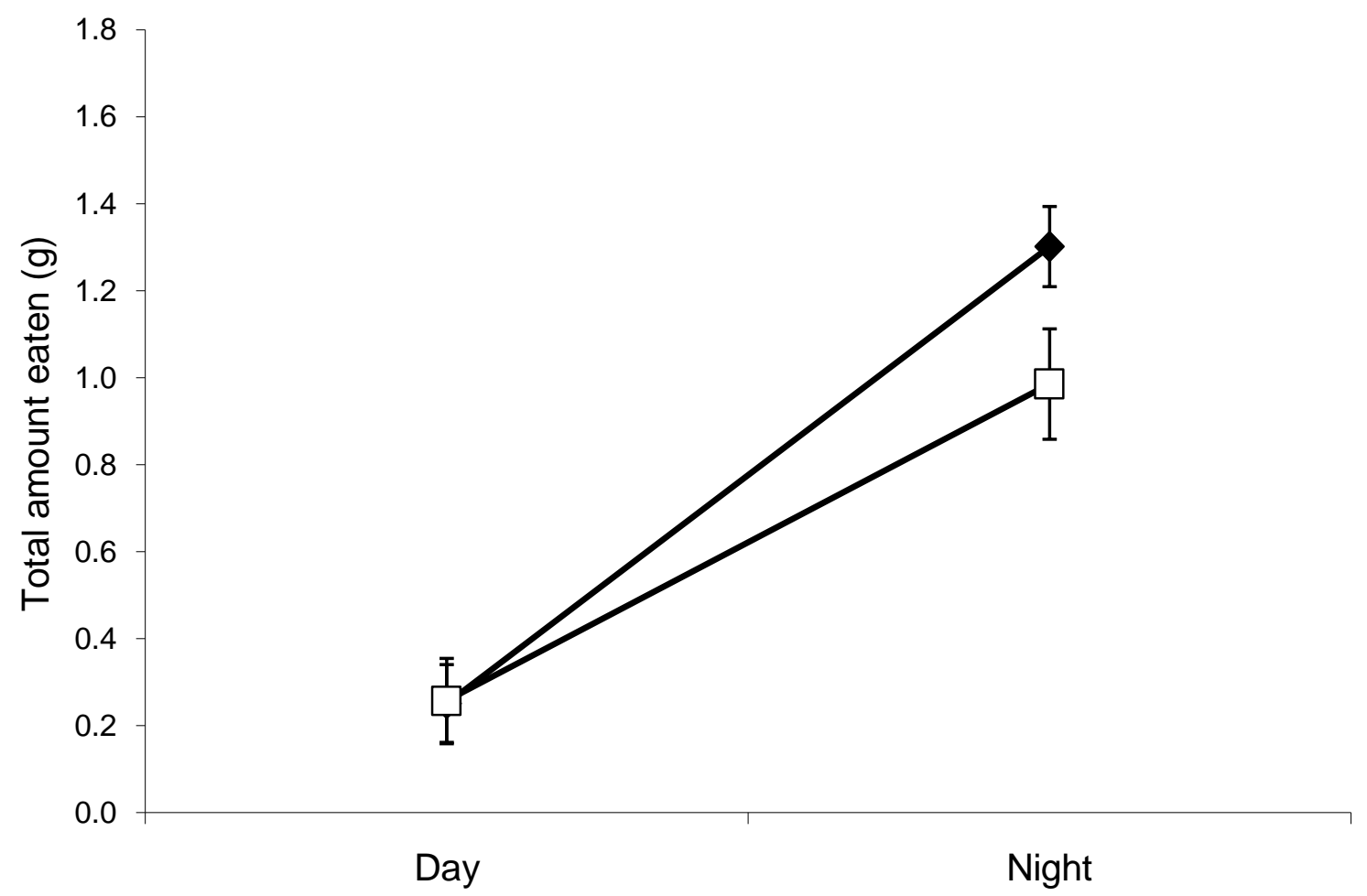

Figure 3.4. Total amount eaten $(\mathrm{g})$ in control $\diamond$ and rat presence $\square$ treatments, displaying the influence of the perceived presence of $R$. rattus on temporal $M$. musculus foraging activity $\left(\mathrm{F}_{1,10}=4.297, \mathrm{P}=0.065\right)(\mathrm{n}=18)$ 


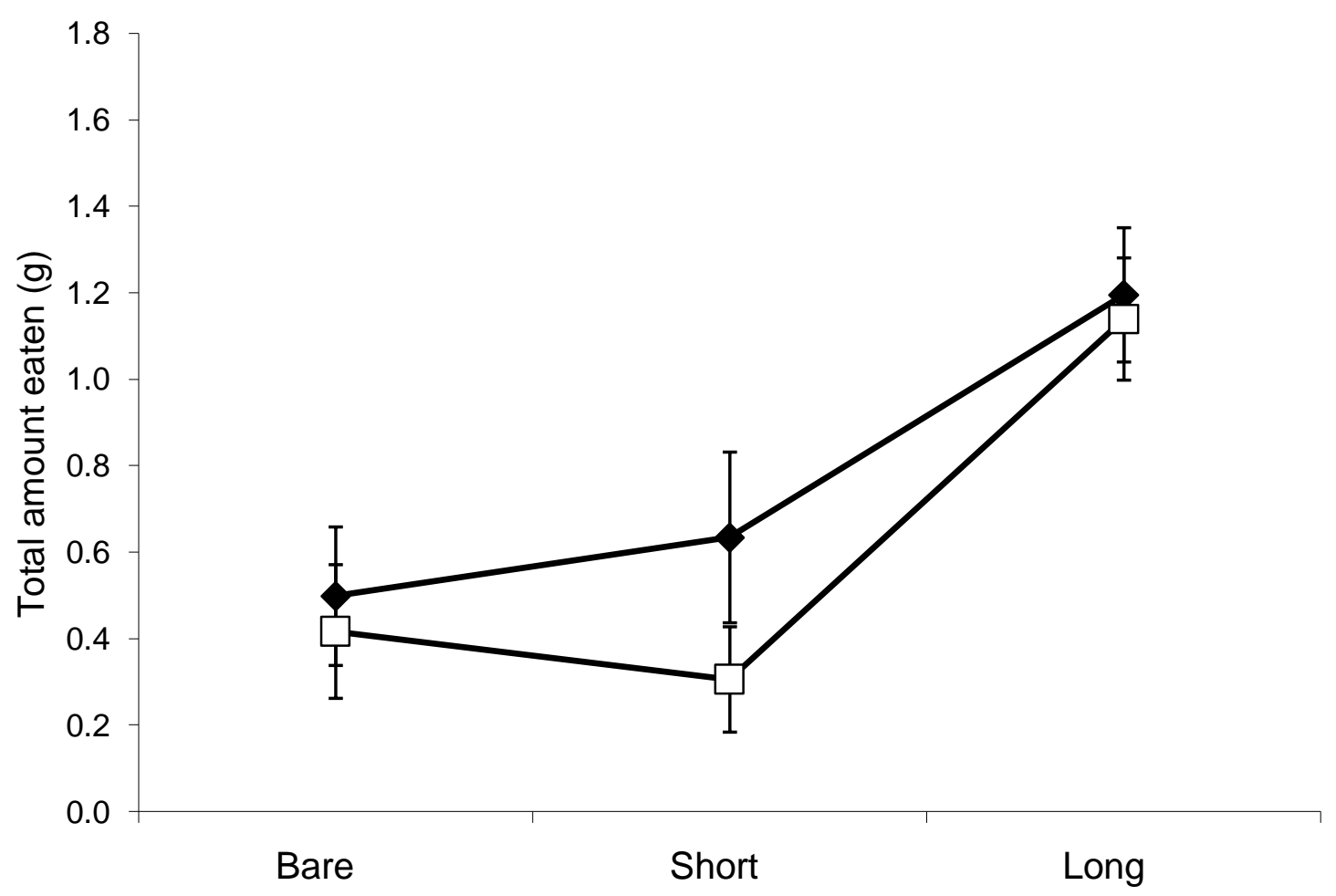

Figure 3.5. Total amount eaten $(\mathrm{g})$ in control $\diamond$ and rat presence $\square$ treatments, displaying the influence of the perceived presence of $R$. rattus on M. musculus use of ground cover while foraging $\left(F_{2,9}=8.692, P=0.008\right)(n=24)$. 


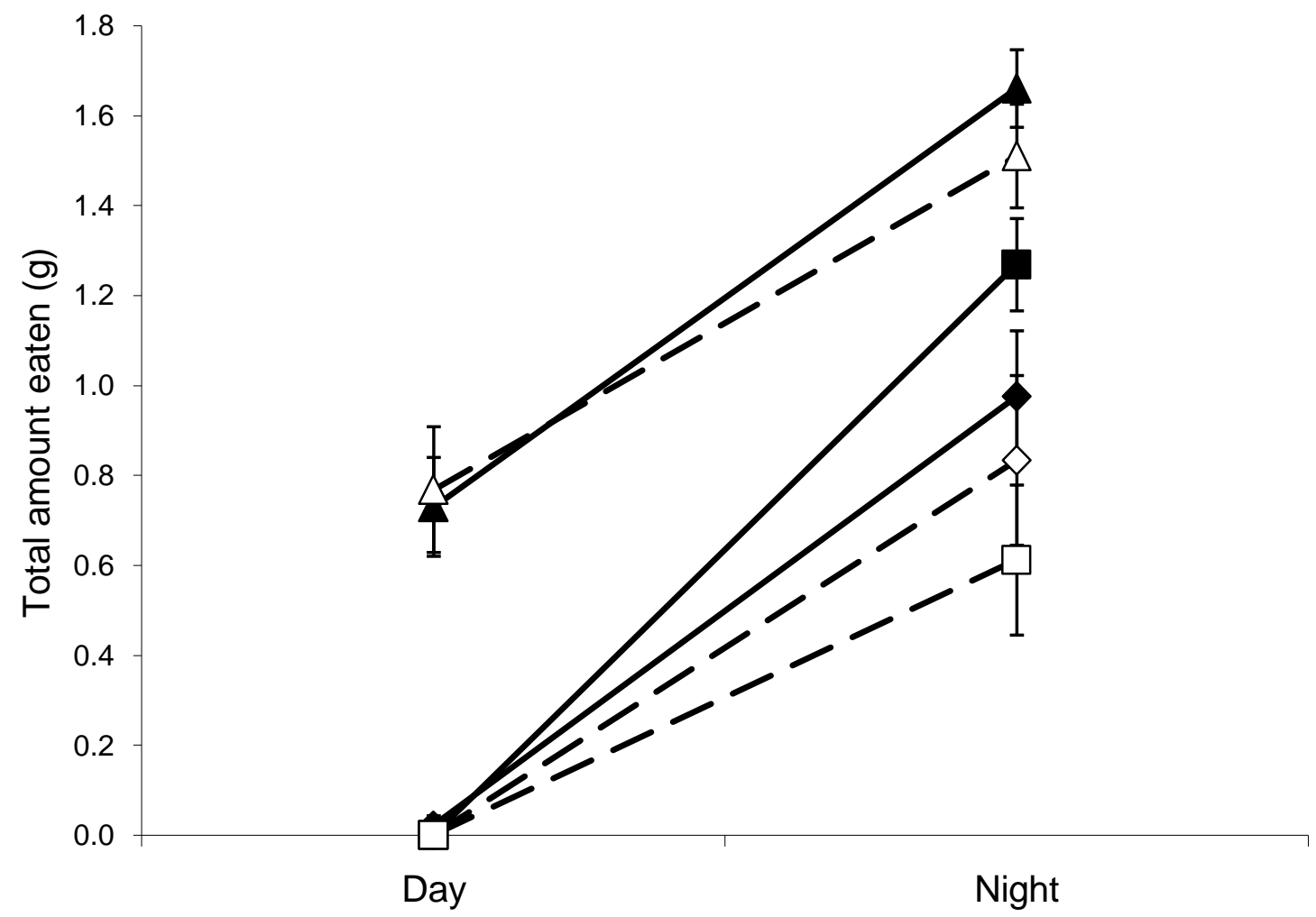

Figure 3.6 Total amount eaten (g) in control-no ground cover $\diamond$, rat presence-no ground cover $-\diamond$-, control-short grass cover $\square$, rat presence-short grass cover $-\square$-, control-rank grass cover $\boldsymbol{\Lambda}$, and rat presence-rank grass $-\Delta$ - treatments, displaying the influence of the perceived presence of $R$. rattus on M. musculus temporal foraging activity and ground cover selection $\left(\mathrm{F}_{2,9}=6.236, \mathrm{P}=0.020\right)(\mathrm{n}=6)$ 
active (Hooker and Innes 1995) and likely to come into contact with each other. Alternatively, $M$. musculus may already take a minimum amount of food over the diurnal period in the absence of the scent cue so it could not be lowered without the individual perishing. If $M$. musculus were restricting themselves during the day to the minimum amount of food required to subsist on throughout the day when they are less active (Mackintosh 1981), then the level of food harvested would not have been reducible. This would have meant that $R$. rattus presence could not reduce the amount of food harvested from control arenas unless the individual mouse perished due to the necessary metabolic requirements not being met.

A similar depression of foraging activity was demonstrated in the interaction between $R$. rattus scent and ground cover treatments. Foraging activity in the bare ground and rank grass ground cover patches did not differ significantly between the $R$. rattus scent treatment and control arenas. But foraging activity in the short grass ground cover went from being lower than bare ground in the presence of $R$. rattus scent to being higher than the bare ground cover patches in arenas without $R$. rattus scent. The decrease of foraging activity in a time period or habitat patch without an increase in an alternative time or patch was predicted if individuals were required to allocate time to activities other than foraging. Increased vigilance was a probable explanation for the decrease in foraging at night or in short grass (Brown et al. 1999, Abramsky et al. 2002), because the introduction of a dominant competitor cue was the only change in the series of balanced trials. There was no direct exclusion from the trays in the short grass patches so the decrease in food is not an analogous situation to Abramsky et al. (2001) where a subordinate competitor, Gerbillus allenbyi (Allenby's gerbil) was physically excluded by a dominant rodent species, G. pyramidum (Egyptian sand gerbil). The situation is more comparable to Abramsky et al. (2002) 
where under increased predation risk, G. allenbyi foraging was reduced and vigilance behaviour increased. The likelihood of M. musculus partaking in other activities was limited because the mice were alone and unable to interact socially and the mice of both treatments were given equal time to acclimatise to the enclosures.

The three-way interaction between $R$. rattus scent treatments, temporal foraging activity, and ground cover patches displayed the small increase of nocturnal M. musculus foraging activity in the short grass when the $R$. rattus scent was introduced. Short grass was originally designed to be an intermediate habitat and the other two habitat patches as extremes, this held true when foraging activity was considered in the absence of $R$. rattus scent. In the presence of $R$. rattus scent, short grass became a patch that $M$. musculus became vulnerable because detection of $R$. rattus was limited without providing refuge and restricted their ability to evade, a combination of the negatives of the other two ground cover types with none of the benefits.

In patches of bare ground there are no visual obstructions so detection of $R$. rattus would be sooner and escape quicker. The short grass may have restricted $M$. musculus line of sight and their ability to detect $R$. rattus which would decrease their flight distance from $R$. rattus. When individuals were released into the arena mice would occasionally run across the bare ground quickly in a fluid motion compared to individuals that initially ran into the short grass patches that had to hop incrementally over the short grass (pers. obs.). While the short grass probably did provide some cover, suggested by the higher foraging activity in the absence of $R$. rattus scent, it may not have been sufficient refuge to elude the dominant competitor. Vigilance and escape methods are important to successfully reach refuge and avoid confrontation 
with $R$. rattus. Foraging and escape substrate have been shown to be important to species and community assemblage (Lima 1998, Kotler et al. 2001).

An alternative explanation to the reduced foraging activity in the short grass ground cover in the presence of $R$. rattus was that $M$. musculus spent less time in the patch. That would have meant that individuals would have had to spend more time in other patches. If this was occurring then it would have been expected that more food was taken from the other patches, which did not happen.

M. musculus could be flexible in their foraging behaviour by shifting their temporal or spatial activity (Dell'Omo et al. 2000). There was no increase in foraging in any habitat patch or time period in the presence of a competitors cue, despite the nocturnal foraging activity in short grass patches being decreased. This may have been due to another cause that had a stronger influence than the potential competitive interference from $R$. rattus. The threat of predation by a diurnal species could explain the lack of shift to daytime foraging when nocturnal foraging was reduced. Circus approximans (harrier hawk) is a diurnal predator of $M$. musculus that visually detects prey and was present in the area (Baker-Gabb 1981a, b). The lack of diurnal foraging activity in the two habitat patch types with reduced cover and higher conspicuousness provides support for this hypothesis. A shift in activity spatially may not have been possible if $M$. musculus were already harvesting as much food as they were prepared to take from a habitat patch or the tray was depleted so it was not energetically viable to harvest more.

The response of $M$. musculus would indicate that in short grass they expect to encounter $R$. rattus or are more vulnerable to $R$. rattus than in the other two patch types. M. musculus appeared to treat the rank grass patches as refuge because of the higher amount of activity at all times, fitting with other arena trials involving rodents 
(Kotler et al. 2001, Arthur et al. 2004) and observations of mice retreating there when they were introduced into arenas (pers. obs.).

A different hypothesis for the result is that $R$. rattus act as an indirect cue for higher predation risk from rodent predators. Increased vulnerability may only alter behaviour in short grass where M. musculus decrease foraging because $R$. rattus are more likely to occur there and therefore attract predators to the habitat. It could be postulated that $R$. rattus would prefer the short grass habitat. In Kotler (1991) the larger G. pyramldurn (39 g) was hindered by dense cover more than the smaller $G$. allenbyi ( $25 \mathrm{~g}$ ). It would fit that $R$. rattus would also be encumbered by the dense cover of the rank grass habitat patches due to their size. $R$. rattus would be conspicuous in open areas because of their size thus attracting predators. Their increased mass may help them move through the short grass habitat by pushing through the blades of grass. King et al. (1996) found M. musculus and M. nivalis (weasel) occurred in similar habitats, as did $R$. rattus and M. erminea (stoat). $M$. nivalis are not as common in New Zealand as M. erminea (Murphy et al. 1998b, King et al. 2001), and $R$. rattus can make up a large portion of M. erminea diet (Murphy and Bradfield 1992, Murphy et al. 1998b). It is plausible that $R$. rattus could attract M. erminea and increase the predation risk for M. musculus. Consequently, direct cues of $R$. rattus could be used by M. musculus as an indirect cue of $M$. erminea, and modify their foraging behaviour as observed in the trials.

The direct effect of $R$. rattus suppressing M. musculus foraging behaviour in the short grass habitat patches could have flow on indirect negative effects on $M$. musculus individual growth rates, population breeding success and population density (Arthur et al. 2004). Population viability of M. musculus might increase without the direct presence of $R$. rattus in habitats that would otherwise be marginal, potentially 
more than in habitats already inhabited. This prediction would imply that the removal of $R$. rattus would benefit $M$. musculus by increasing fitness in a wider range of habitats. In instances where both species have been removed $R$. rattus have been shown to lag behind M. musculus when recovering from pest control operations (Innes et al. 1995, Blackwell et al. 2003, Tompkins and Veltman 2006). This may be because $M$. musculus are able to utilise more habitats in the absence of $R$. rattus in addition to their shorter life history and compensating recruitment (Bronson 1979, Innes et al. 1995). These predictions fit with previous observations involving removal of $R$. rattus across landscapes (Clout et al. 1995, Innes et al. 1995, Gillies and Pierce 1999, Murphy et al. 1999).

The change of order in preference for different habitat patches could be a concern for pest control managers. Not only was the short grass ground cover used more in the absence of a $R$. rattus cue but it was preferred more than the bare ground patch (Figure 3.5). This could imply that not only does M. musculus fitness improve in a wider range of habitats but that they may be more successful than in some of their previous range.

The differing levels of grass cover within the arenas could be used as proxies of habitat disturbance that could have important implications for pastoral and forest management. Rank grass cover could be treated as a low disturbance habitat, short grass cover as a habitat with an intermediate level of disturbance, and bare ground representing a highly disturbed habitat. Multiple studies have investigated the role of habitat disturbance plays in the community assemblage of rodents (Howe and Brown 1999, Malcolm and Ray 2000, Avenant and Cavallini 2007). There are fewer rodents in New Zealand but disturbance may still play a role in rodent communities. 
Disturbances within or surrounding forests which create gaps in the canopy would initiate early successional vegetation forming dense low cover, suiting the habitat preferences of M. musculus. $R$. rattus are known to prefer arboreal habitats (Hooker and Innes 1995, King et al. 1996) so a forested landscape mosaic (Lertzman et al. 1996) could support both species. The community relationships of rodents would change in unforested areas. Further investigation is needed of the terrestrial habitat preferences of $R$. rattus, but from the interpretation of this study intermediate disturbance may benefit them. Undisturbed habitats or severely disturbed habitats with frequent refuge would be preferred by M. musculus. Singleton et al. (2007) investigated the relationship between landscape ecology and mouse plagues in Australia, where permanent refuge combined with cereal crops that have low disturbance rates and supply food augmented population outbreaks. Ylönen et al. (2002) explored trade-offs through varying population densities between safety afforded by habitat and food availability where mice used feeding trays in the open near the refuge around fences more readily than further away in the pasture. The findings of my study correspond with and support both of these studies.

Commercial logging is a widespread industry throughout New Zealand, which disturbs the forest by selective logging or clear felling. The findings of this study would suggest that skid sites, logging tracks and clear felling would be preferred by M. musculus. King et al. (1996) showed that M. musculus abundance was higher in roadsides and young stands of Pinus radiata where the canopy was not continuous, a exotic species widely used in timber plantations. If patches of forest remain intact near areas that have been logged then both $M$. musculus and $R$. rattus could persist. This was observed in King et al. (1996) and logging has promoted diversity in small mammal communities elsewhere (Malcolm and Ray 2000). 
Another large scale disturbance of forest in New Zealand that could alter the rodent communities is fire. New Zealand's forests have not evolved to mitigate the effects of fire so the damage can be severe and succession slow (Ogden et al. 1998). Disturbance of habitats by fire has been shown to promote species diversity (Haim and Izhaki 1994, Valone and Kelt 1999). Although the restricted distribution of $R$. norvegicus and $R$. exulans, and the use of arboreal habitats by $R$. rattus and possible avoidance of open areas means that fire disturbance would likely only benefit $M$. musculus, thus reducing the diversity of rodent communities in New Zealand.

In pastoral agricultural systems $M$. musculus populations may be suppressed by livestock grazing where pasture is generally kept a low level throughout the year without completely removing the grass. This intermediate level of grass could restrict $M$. musculus use of this habitat if $R$. rattus were present, and $R$. rattus are often seen around livestock carcasses (pers. obs.). A probable scenario of bare ground occurring in a pastoral system is during drought conditions, this highly disturbed situation may favour M. musculus if sufficient refuge was available. In the arenas, M. musculus showed a slight preference for bare ground over short grass ground cover but pastoral paddocks are larger areas without regular reachable refuge. If refuge was nearby it would be expected that bare ground would be utilised as observed in Ylönen et al. (2002).

Further investigation of small mammal communities in New Zealand would be required before findings from this study could be implemented into practice. Understanding the influence of mustelids on the behaviour of M. musculus and the habitat preferences of R.rattus would improve the knowledge base of these communities, and then accurate predictions of their dynamics could be made to advance management of these pest species. 
Chapter 4:

The role of canopy as an indirect cue in house mouse (Mus musculus) habitat selection 


\section{Abstract}

How a species interacts with its surrounding habitat and associated species is a fundamental element of ecology. Individuals can use features of the environment as indirect cues to indicate vulnerability and occurrence of adverse species. Mus musculus have been shown to be abundant in habitats with dense ground cover and infrequent in habitats with continuous canopy where a dominant arboreal competitor, Rattus rattus, occurs. Both species are introduced to New Zealand and many other island ecosystems, negatively impacting the native flora and fauna. Arenas were created for the mice with variations of ground cover and canopy treatments. Feed trays within different combinations of ground cover and canopy treatments were sampled to acquire quitting harvest rates (QHR), which indicate habitat preferences. Canopy treatments did not appear to significantly influence habitat preferences of $M$. musculus though two possible patterns of canopy influence did emerge. As canopy provided more direct cover (low canopy or understory), diurnal foraging increased. Nocturnal foraging was decreased in the potentially hazardous short grass cover under high canopy, which may indicate $R$. rattus presence to $M$. musculus. These patterns provide possible evidence contrary to previous accounts of house mice not considering higher vegetation when selecting suitable habitat. The relationship of $M$. musculus using dense ground cover use and higher nocturnal activity complements the current literature. Combining the possible use of canopy cover with investigations of more specific community interactions may strengthen and clarify the use of indirect cues by M. musculus. 


\section{Introduction}

Understanding the relationship between the physical structure of the environment and habitat-use by species within is an important goal for ecology. The physical structure of a rodents environment has been shown to be important for providing refuge from predators (Brown et al. 1992), foraging (Brown 1988), reproduction (Arthur et al. 2004), intra-specific interactions (Dickman et al. 1991), and inter-specific interactions (Kotler et al. 1988, Kotler et al. 2001).

By evaluating features of a habitat structure, species can reduce contact with a dominant competitor or predator (Stamps and Krishnan 2005). These features, indirect cues, are not created by the competitor or predator but indicate higher vulnerability or are associated with their presence. Structural complexity, escape substrate or a habitat type suitable for dominant competitor or predator species are features that species could use as indirect cues. Indirect cues have been shown to be important in habitat selection by various species of rodents (Roche et al. 1999, Mandelik et al. 2003, Orrock et al. 2004). Alternative to indirect cues are direct cues such as sight, sound and smell from the competitor or predator (Orrock et al. 2004). The presence of the competitor or predator inhibits the activity of the species or displaces them from the habitat.

Rattus rattus and Mus musculus have been shown to be abundant in different habitats. M. musculus are more common in dense ground cover and non-continuous canopy while $R$. rattus are more common in natural habitat with continuous canopy (King et al. 1996) and are predominantly arboreal (Hooker and Innes 1995). R. rattus are considered the dominant competitor in this relationship (Caut et al. 2007). The use of indirect cues by M. musculus may be one reason for the lack of overlap in habitat 
use between these species, though vegetation above $1 \mathrm{~m}$ has been considered not to influence Mus domesticus (Dickman 1992).

By isolating and examining $M$. musculus responses to variations of habitat structure, insight into how communities with $M$. musculus are assembled can be gained. Comprehension of these relationships improves the understanding of how rodents have adapted to New Zealand's environment and tools to managing these invasive pests.

$R$. rattus and $M$. musculus are the most widespread small mammals in New Zealand (Innes 2005b, Ruscoe and Murphy 2005) and also occur on other islands of the Pacific, Indonesia, sub-Antarctic, and Madagascar (Caut et al. 2007). Historically, the focus of ecological research has been on the detrimental ecological effects and management of $R$. rattus (Towns et al. 2006, Caut et al. 2007) with limited consideration of the ramifications with M. musculus persisting (Caut et al. 2007). M. musculus populations have increased with the reduction or removal of $R$. rattus populations (Innes et al. 1995, Miller and Miller 1995, Caut et al. 2007). M. musculus have been shown to directly and indirectly impact on New Zealand's avifauna (King 1983), herpetofauna (Newman 1994, Lettink and Cree 2006), flora (Fitzgerald et al. 1996, Duthie et al. 2006), freshwater vertebrates (Baker 2006), invertebrates (Fitzgerald et al. 1996), and forest succession (Wilson et al. 2007).

If $M$. musculus were to use indirect cues for $R$. rattus occurrence then it would be expected that canopy cover may be used as a cue because $R$. rattus are known to utilise arboreal habitats (Hooker and Innes 1995). This is likely to be important to $M$. musculus ecology because $R$. rattus are a widely distributed species (Ruscoe 2001) and dominant competitor (Caut et al. 2007). The use of canopy as an indirect cue by M. musculus would be inferred if they were less active or avoided habitats under 
canopy. M. musculus could respond to indirect cues by spending more time in safer habitat patches (Dickman 1992), becoming more active at times when R. rattus is less active (Jones et al. 2001), or putting more effort into behaviours such as vigilance at the cost of other behaviours like foraging (Abramsky et al. 2002, Arthur et al. 2004). Forced changes in habitat choice and activity may be mitigated if refuge or a favourable habitat occurred under the canopy cover, such as long rank grass (King et al. 1996), whereas a lack of response to habitat features might be due to M. musculus using direct cues or R. rattus not influencing M. musculus ecology. A lack of influence is unlikely because $R$. rattus removal benefits populations of M. musculus, although if their use of habitat is so different that M. musculus may not need to readily avoid $R$. rattus. Alternatively, predator species of $M$. musculus may have greater influence on $M$. musculus distribution and activity, overriding any responses to cues of $R$. rattus.

In this chapter, I investigate the interactions between ground and aerial cover on $M$. musculus foraging activity and habitat choice. Based on the role that $R$. rattus appears to play in M. musculus population dynamics and their use of arboreal habitats, I predict that high canopy cover will affect $M$. musculus activity and habitat-use in a similar pattern that the direct presence of $R$. rattus does. 


\section{Methods}

In this chapter the arenas and ground cover treatments are retained from chapter 3, though instead of the $R$. rattus scent treatment varying canopy heights were introduced.

\section{Arena location, construction and dimensions}

Six $23.4 \mathrm{~m}^{2}$ arenas were built amongst rank grass within a fenced area on the brow of a low-lying flat topped ridge $\left(41^{\circ} 14^{\prime} 42.13\right.$ 'S, $\left.175^{\circ} 29^{\prime} 2.91^{\prime \prime} \mathrm{E}\right)$ between pastoral fields near Martinborough (Figure 3.1). Vegetation within the fenced area was dominated by Chamaecytisus palmensis (Leguminosae) (tree lucerne) and rank pastoral grasses but also consisted of a variety of native and exotic trees, shrubs and flaxes. Livestock pasture surrounded this site with shelter belts nearby (Figure 3.1).

Hexagon shaped arenas were built because of the simplicity of construction and because they could be divided into equal diamond shaped thirds for different internal treatments. Sheets of plywood $(3 \times 0.65 \times 0.025 \mathrm{~m})$ were fixed in a hexagon shape and placed into a narrow trench approximately $50 \mathrm{~mm}$ deep. The loosened sod along the trench was pressed down by foot on the interior side of the wall and compressed down on the exterior side by a hand soil compactor. The entire wall was approximately $50 \mathrm{~mm}$ underground to prevent mice from digging under the wall. The height of the wooden wall was approximately 0.6 metres similar to other arena trials (Kotler et al. 1988, Arthur et al. 2004). Strips of corflute plastic $250 \mathrm{~mm}$ wide were nailed to the top of the plywood sheets to prevent mice from climbing over the fence. Joins between corflute sheets were taped together so there were no edges that mice might use to climb the wall. The corflute plastic increased the height of the arena walls to just over $0.8 \mathrm{~m}$. Grass around the internal perimeter was cut to $250 \mathrm{~mm}$ and 
stalks of seed heads throughout the arena were cut to approximately $500 \mathrm{~mm}$ to prevent mice using the grass to climb over the fence.

\section{Ground cover treatments}

Each third of the arena was randomly assigned a different height of ground cover. The three heights of ground cover used were bare ground, short grass (80-130 mm), and rank grass (max. $500 \mathrm{~mm}$ ) (Arthur et al. 2004). To create bare ground, the grass was cut as close as possible to the soil surface (Figure 3.2 and 3.3).An edge-trimmer with a whipping nylon cord was used to cut the grass because it would not dig up the soil or damage the arena walls. Between each trial the grass was trimmed to the appropriate height and any clippings raked and removed from the arena.

One feed tray filled with a litre of sand was placed in the middle of each ground cover treatment. Holes were dug for the $200 \mathrm{~mm}$ round $\mathrm{x} 40 \mathrm{~mm}$ deep trays so the upper edge was flush with ground level. The shortest distance from the tray to the adjacent ground cover type was $1.299 \mathrm{~m}$. This distance prevents the neighbouring patch providing cover. From $1 \mathrm{~m}$ to $1.5 \mathrm{~m}$ has been used previously to separate covered and open foraging patches or as a minimum distance to a refuge (Kotler et al. 1991, Kotler et al. 2001, Orrock et al. 2004). 


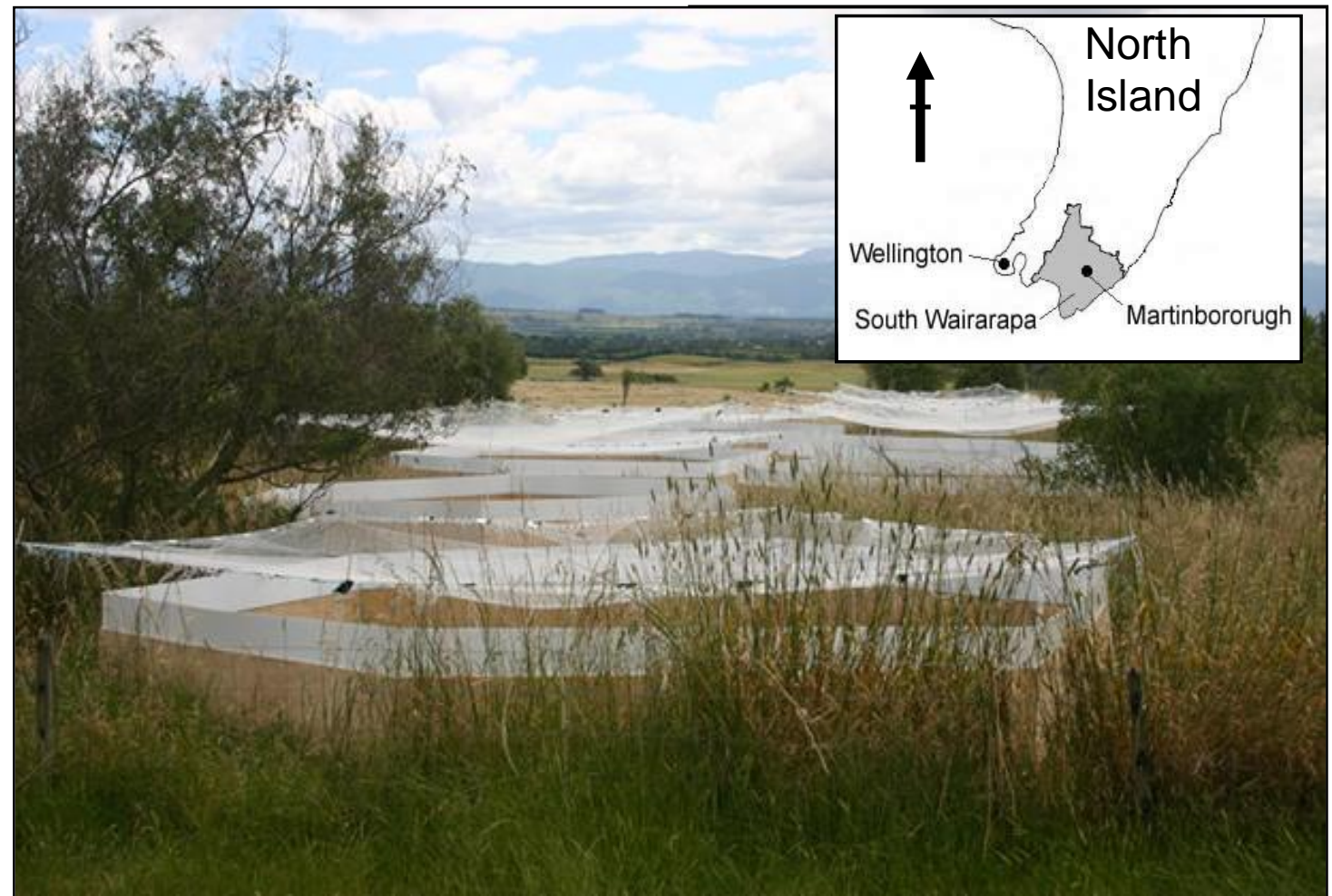

Figure 4.1. Arenas situated in area fenced from livestock and surrounded by trees and rank grass facing west. Inset in the top-right corner displays the location of Martinborough in New Zealand, Martinborough is located beyond the fields in the background. 


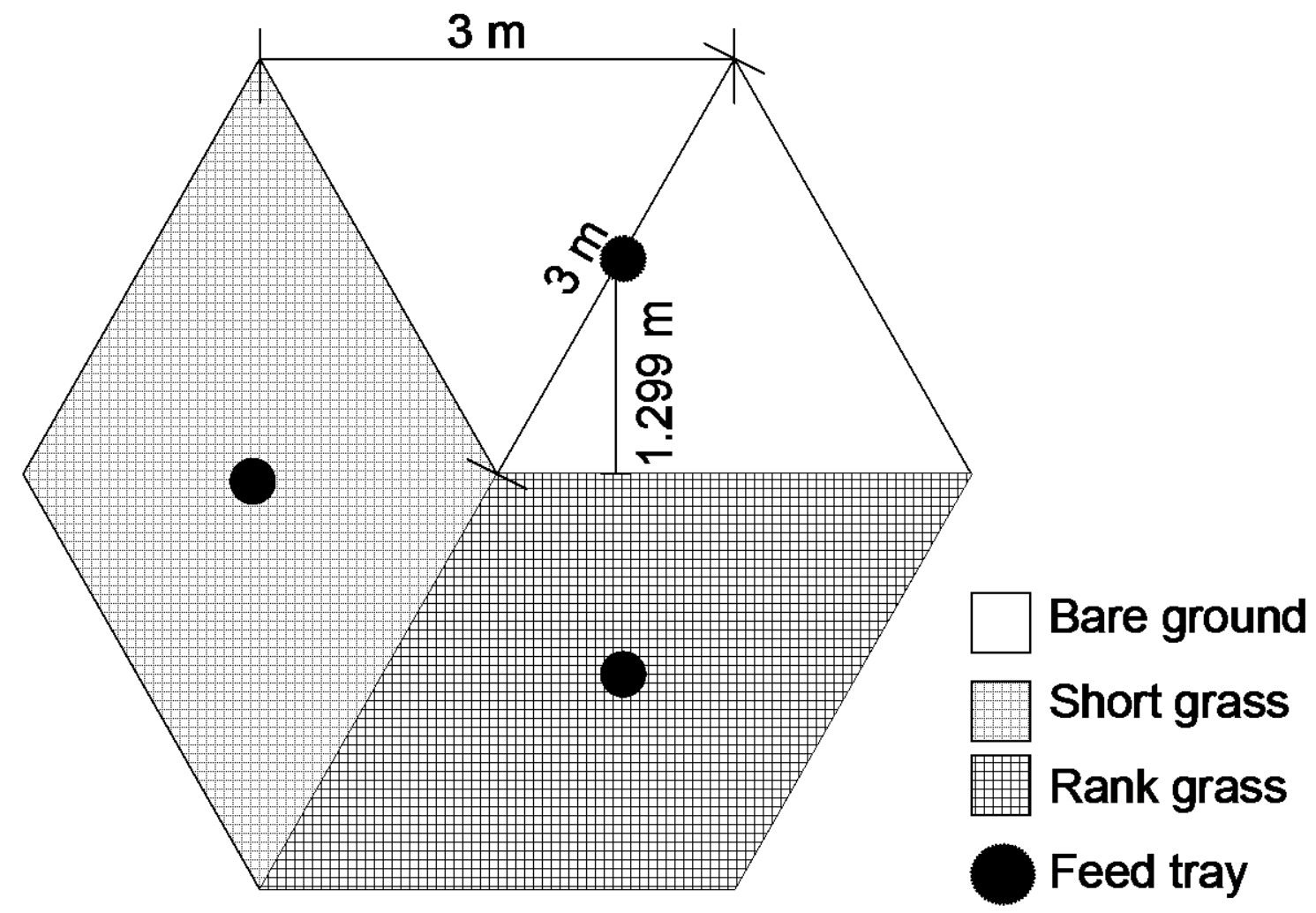

Figure 4.2. Dimensions of hexagon shaped arena with $3 \mathrm{~m}$ sides and 3 ground cover treatments: bare ground $=$ no cover, short grass $=80-130 \mathrm{~mm}$, rank grass $<500 \mathrm{~mm}$ within the arena that $M$. musculus could move between. In the centre of each ground cover patch is a feed tray. 


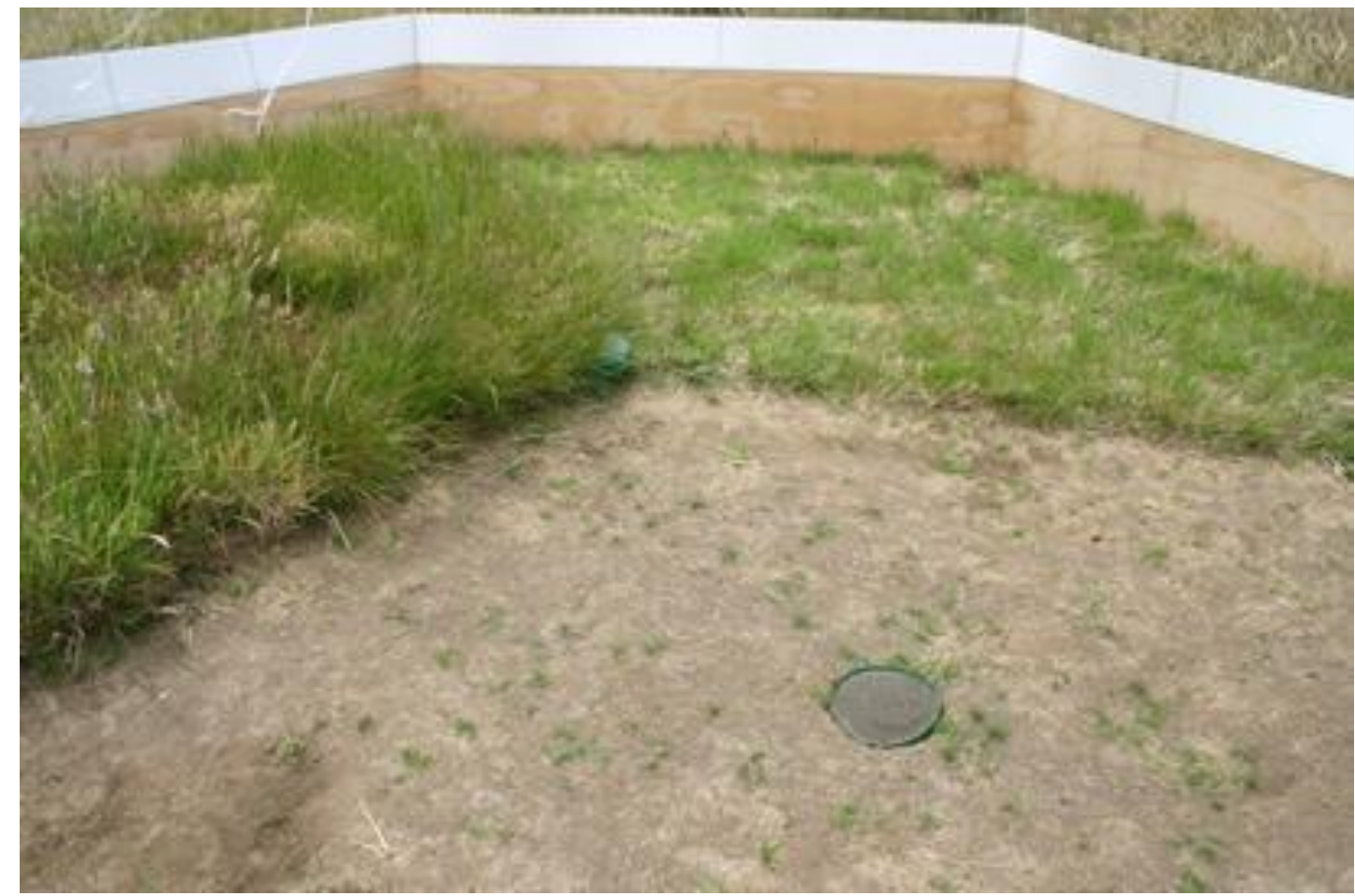

Figure 4.3. Three levels of ground cover as treatments with a feed tray in the

foreground within an arena. The three ground cover treatments were: bare ground = no cover, short grass $=80-130 \mathrm{~mm}$, rank grass $<500 \mathrm{~mm}$. 


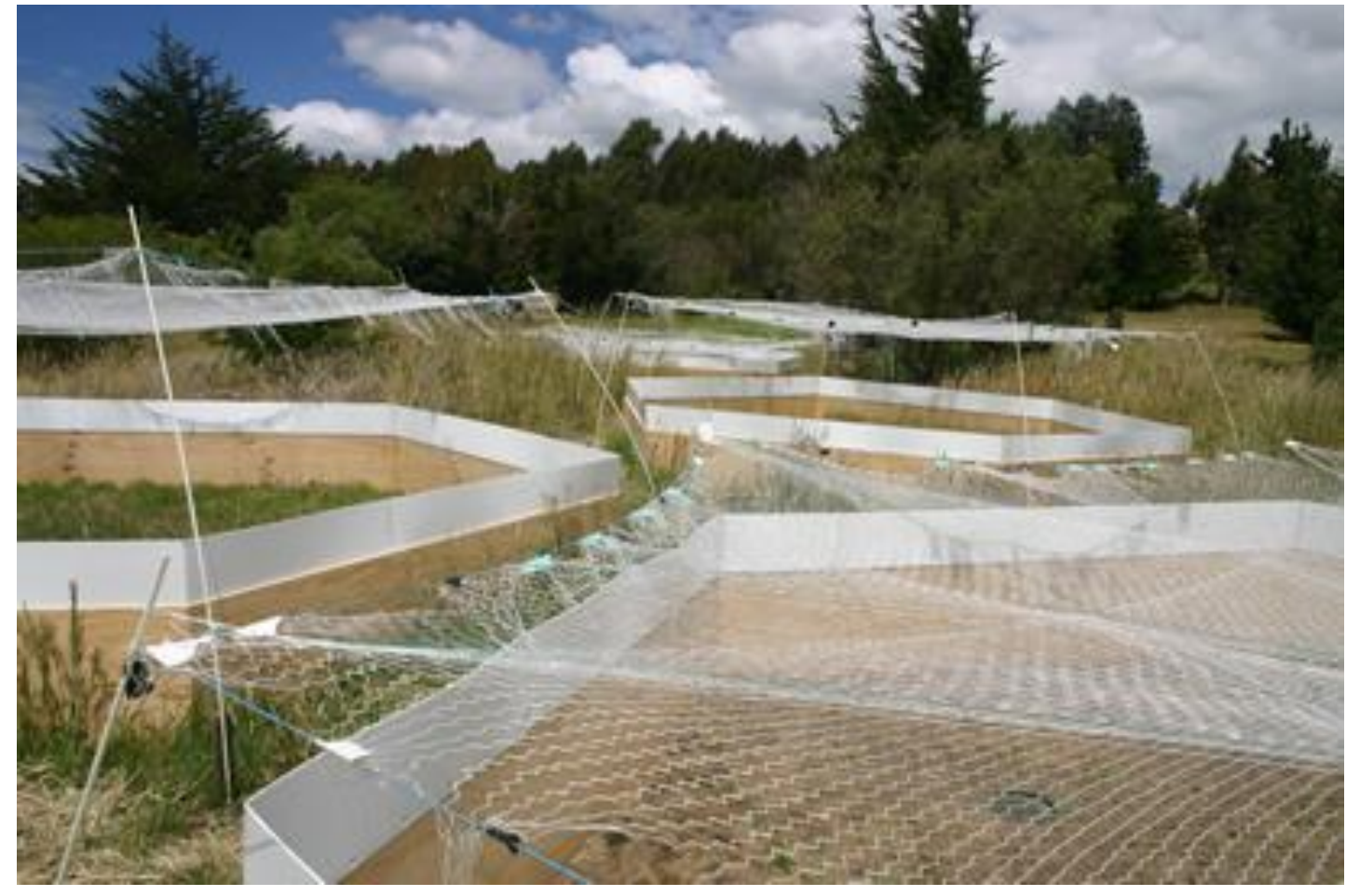

Figure 4.4. Four arenas with canopy treatments made of baleage netting are shown.

The low canopy treatment $(0.8-1 \mathrm{~m})$ above an arena in the foreground and two arenas with the high canopy treatments $(1.75-1.9 \mathrm{~m})$ behind, arenas with no canopy treatment are not shown 


\section{Canopy cover treatment}

Canopy cover treatments were placed at different heights to represent three natural canopy cover conditions. Dickman (1992) deemed vegetation over $1 \mathrm{~m}$ was not used in habitat selection by M. musculus so one canopy treatment was set just below this level $(0.8-1 \mathrm{~m})$, one clearly above this level $(1.75-1.9 \mathrm{~m})$ and one treatment without any form of canopy cover (Figure 4.4). The canopy covers were made of baleage wrap (a white, light weight netting that is conventionally used to bind bales of green grass feed) and supported by fibreglass rods. Each canopy treatment was randomly assigned to two of the six arenas, once a round of trials was complete the artificial canopies were rotated between arenas.

\section{Quitting harvest rate trial protocol}

A method of measuring the quitting harvest rate (QHR) (Schmidt and Ostfeld 2003) was used to examine the habitat preferences of M. musculus (Brown 1988, Brown 1992). A giving up density (GUD) gives more absolute values of habitat quality while QHR gives relative rates of harvesting between the habitats.Trays were filled with a substrate and a designated amount of granule food mixed through it. The rate at which that food was harvested was at a rate relative to the perceived risk and harvesting opportunities in surrounding habitats. The rate of harvest decreases as the individual spends more time depleting the food tray. The amount of food remaining gives a value of the minimum harvest rate of an individual for that time period relative to the other available patches. Different harvest rates between different habitats indicate habitat preference. In this study, the food in each tray was limited so that an individual could not be satiated by feeding in only one habitat type. Thus, mice have to select between multiple ground cover types when foraging to meet their metabolic requirements. 
Nevertheless, food trays were adequately stocked with food such that a mouse would not exhaust itself searching through trays trying to meet its needs. The QHRs taken from trays were relative to harvest rate and perceived risk of the other habitat patches available to the individual over a twelve hour period. The conventional GUD method (Brown 1988) repeatedly leaves trays until they are depleted to a level relative to the surrounding environment, then the amount of food at which the species quits foraging in the patch was averaged.

A preliminary trial was conducted to ensure that an adequate amount of food for the mice to meet their metabolic demands for a twelve hour period was placed in each arena while still requiring the mouse to search between the habitat patches. $M$. musculus require approximately $3 \mathrm{~g}$ of dry matter per day (Crowcroft 1966). One gram mixed through 1 litre of sand in each of the three trays of the arena every 12 hours was therefore thought sufficient and most likely for selective consumption from trays to reflect the influence of treatments. The preliminary trial also created a presence of prior activity in each of the arenas for the first round of trials that were sampled thus creating similar conditions for each of the sampled trials that followed. Sampling every twelve hours would identify any diurnal or nocturnal changes in $M$. musculus foraging activity.

Every feed tray was stocked from the first morning between 7-7:30am with $1 \mathrm{~g}$ of Sharpes ${ }^{\circledR}$ feed wheat mixed through a litre of sand in each tray. The sand and wheat were mixed in a twenty litre bucket and poured into the feed tray. The tray was gently shaken so that the sand levelled to a smooth surface so that M. musculus tracks and foraging activity on its surface could be detected. Trays were replenished with wheat every twelve hours for three days and all at the same time to reduce human activity in the vicinity and within the arenas. Before removing a tray for 
replenishment they were examined for evidence of track and sign according with previous studies (Arthur et al. 2004, Orrock et al. 2004). Those trays with mice sign were sieved into a twenty litre bucket and any seeds that remained removed and placed into a small labelled paper envelope. Envelopes were labelled detailing; the trial number, arena number, sample period, and ground cover type from which the sample was taken. Seeds from samples were dried in a oven at $60^{\circ} \mathrm{C}$ for seven hours and weighed to the nearest $0.01 \mathrm{~g}$ (Orrock et al. 2004). If sand had been lost from the tray it was replaced so the volume was returned to 1 litre and the next $1 \mathrm{~g}$ of seed mixed through it. Trays that did not have any sign of mice were re-mixed and deposited back into the tray. Trays were put randomly back into the holes in the arenas for another twelve hours. QHRs from the first 24 hours that the mice were in the arena were discarded as habituation time, giving 48 hours of sampling.

\section{Study specimens}

Wild M. musculus from the surrounding farm environment were used in arena trials because they were likely to have been exposed to the local potential predators and competitors. Circus approximans (harrier hawk), Ninox novaeseelandiae (morepork), Mustela erminea (stoat), Mustela nivalis (weasel), Felis catus (feral cat), Canis familiaris (domestic dog) and $R$. rattus all occurred on the surrounding farmland (pers. obs.). The responses of wild M. musculus were more likely to reflect behaviour in a natural setting than the behaviour naïve or commensal mice. M. musculus have been shown to retain anti-predator behaviour when moved to an environment in which predators were absent (Dickman 1992).

Up to seventeen Longworth ${ }^{\circledR}$ live mouse traps were used on the surrounding farmland to catch six mice in one night. Traps were baited with a half teaspoon of Sanitarium ${ }^{\circledR}$ peanut butter and with Nestle ${ }^{\circledR}$ chocolate melt buttons. The traps were 
placed around shelterbelts, unused timber and stacked debris on the farm and in shade where direct sunlight would not heat the traps. Two nights prior to the night of actual trapping, the traps were baited and placed with the trap door locked open so mice became acclimatised to the traps and feeding from them. About an hour prior to dusk on the day before mice were required, the traps were re-baited and the doors set. All traps were checked the following morning and the mice caught released into the arenas between 7-7:30 am. Only one mouse was released into each arena to prevent dominant-subordinate mouse interactions confounding habitat-use preferences (Dickman et al. 1991). Any surplus mice were released where they were caught. If less than six mice were caught in a single night, the trial would be delayed and trapping continued until six had been caught in a single night so that every arena could be occupied over the same period.

Mice of previous trials were removed from arenas by placing a baited and set live trap while the feed trays from the previous night were sieved. If a mouse was not caught in the arena by the time the new mice were ready to be released, the new mouse was placed in the shade near the assigned arena until the old mouse was caught.

\section{Analysis}

Data was analysed with SPSS 16.0 (SPSS, Inc., Chicago, IL) general linear models procedure. I used an analysis of variance (ANOVA) with repeated measures to test for the influence of the three canopy treatments (between subjects factor) on the two levels of diurnal foraging behaviour and three levels ground cover usage (within subject factors). This analysis is generally done for repeated measures over time 
(Gotelli and Ellison 2004). Repeated measures ANOVA was used because the diurnal and grass cover factors occurred within each of the canopy treatments. Data from both days were pooled for each arena to remove issues of pseudo-replication when sampling was done from the same enclosures with the same mouse and treatment. Pallai's Trace test was used to identify significant treatment effects and interaction after Mauchly's test of sphericity showed that the assumption of sphericity was met.

\section{Results}

Contrary to expectations, the canopy treatments did not appear to affect the foraging behaviour of $M$. musculus during these trials. There were no significant interactions between canopy cover treatments and ground cover use (Pillai's trace, $\mathrm{F}_{4,24}=1.017, \mathrm{P}$ $=0.418$, Figure 4.5$)$ or between canopy cover treatments and temporal activity (Pillai's trace, $\mathrm{F}_{2,12}=0.920, \mathrm{P}=0.425$, Figure 4.6).

Overall, the strongest effect was ground cover (Pillai's trace, $F_{2,11}=49.256, \mathrm{P}$ $<0.001)$. M. musculus harvested 55\% more seed in rank grass than in short grass, and $26 \%$ times more in short grass than on bare ground (Figure 4.5). During nocturnal foraging 59\% more seed was harvested than during diurnal foraging (Pillai's trace, $\mathrm{F}_{1}$, $12=49.256, \mathrm{P}<0.001)($ Figure 4.6).

M. musculus foraging activity was higher at night for each ground cover type than during the day but the magnitude of change between each ground type varied (Pillai's trace, $F_{2,11}=6.841, P=0.012$, Figure 4.7$)$. Foraging activity in short grass cover was higher than on bare ground throughout the day and night and both increased by similar amounts at night (0.90 $\mathrm{g}$ and $1.04 \mathrm{~g}$ more harvested respectively). In the short 
grass, $M$. musculus harvested only $20 \%$ of the amount harvested from the rank grass cover than the short grass cover, though at night this increased to $71 \%$.

A three-way interaction between the canopy cover treatments, use of different ground cover types and temporal activity was not significant (Pillai's trace, $\mathrm{F}_{4,24}=1.808, \mathrm{P}=$ 0.160) but the sample size for each combination of factors for this analysis was low (n =5). Two possible trends (Figure 4.8) warranted consideration. The change in foraging activity in rank grass ground cover under different canopy treatments between night and day, and the low increase in seed harvested in short grass cover under high canopy treatments from day to night.

In rank grass ground cover, there was greater variation in foraging activity between canopy treatments diurnally than at night ( $0.73 \mathrm{~g}$ diurnal range of the seed harvested compared with $0.07 \mathrm{~g}$ range at night) (Figure 4.8). When excluding the rank grass ground cover from consideration, the short grass ground cover and high canopy combination had the most of food removed during the day but the lowest at night (day, $0.29 \mathrm{~g}$ eaten compared with $0.92 \mathrm{~g}$ at night) (Figure 4.8). The change of $0.63 \mathrm{~g}$ between night and day was the smallest of the short grass and bare ground cover treatments, the next smallest was $0.93 \mathrm{~g}$ (bare ground and no canopy treatment). Though three-way interaction was not significant, short grass ground cover under high canopy was the most preferred ground cover outside of rank grass during the day but becomes the least preferred combination overall at night. 


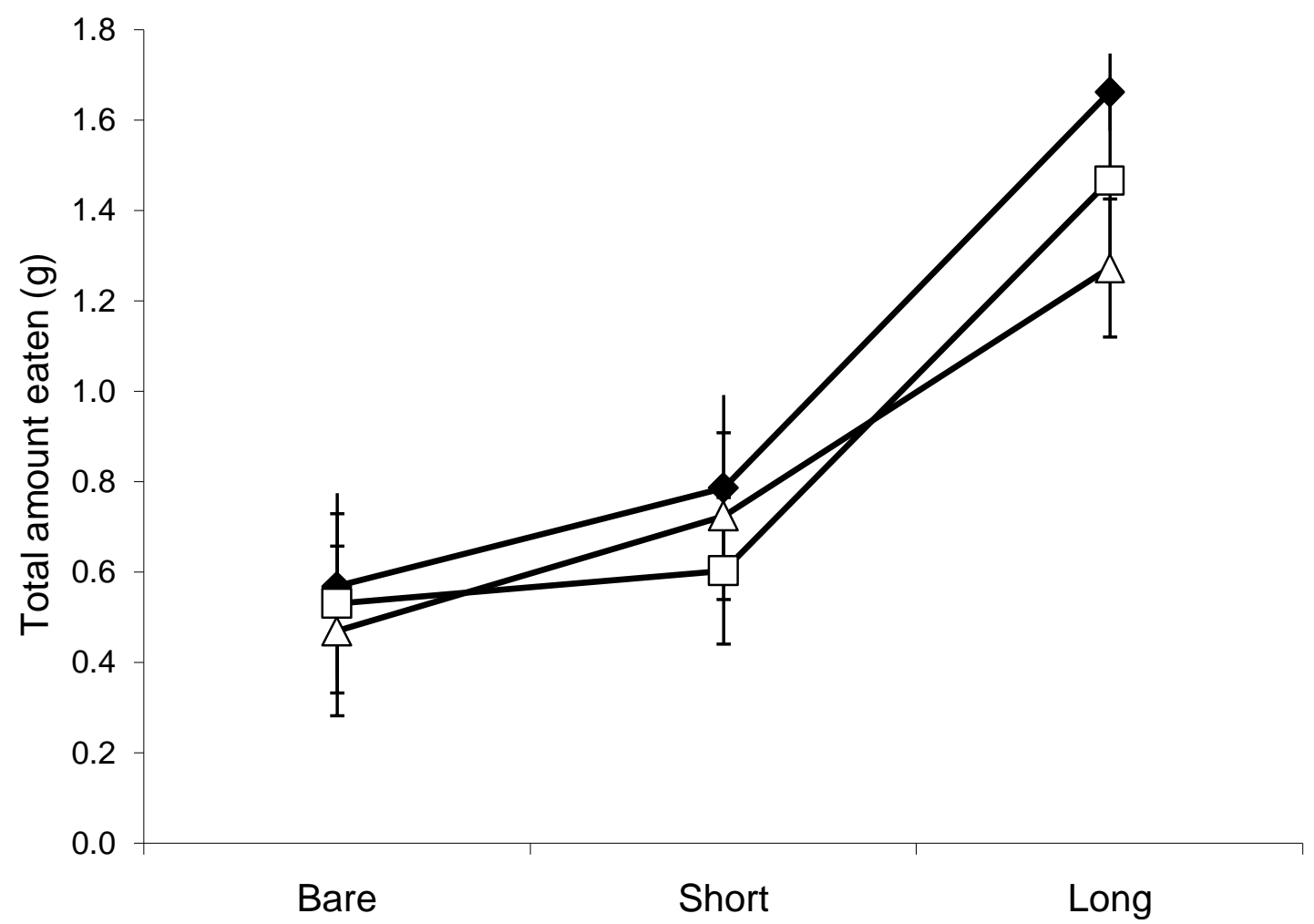

Figure 4.5 Total amount eaten (g) in low canopy cover $\diamond$, high canopy cover $\square$, and no canopy cover $\Delta$ treatments, displaying the interaction between canopy cover height and use of ground cover of $M$. musculus during foraging $\left(\mathrm{F}_{4,24}=1.017, \mathrm{P}=\right.$ $0.418)(n=10)$. 


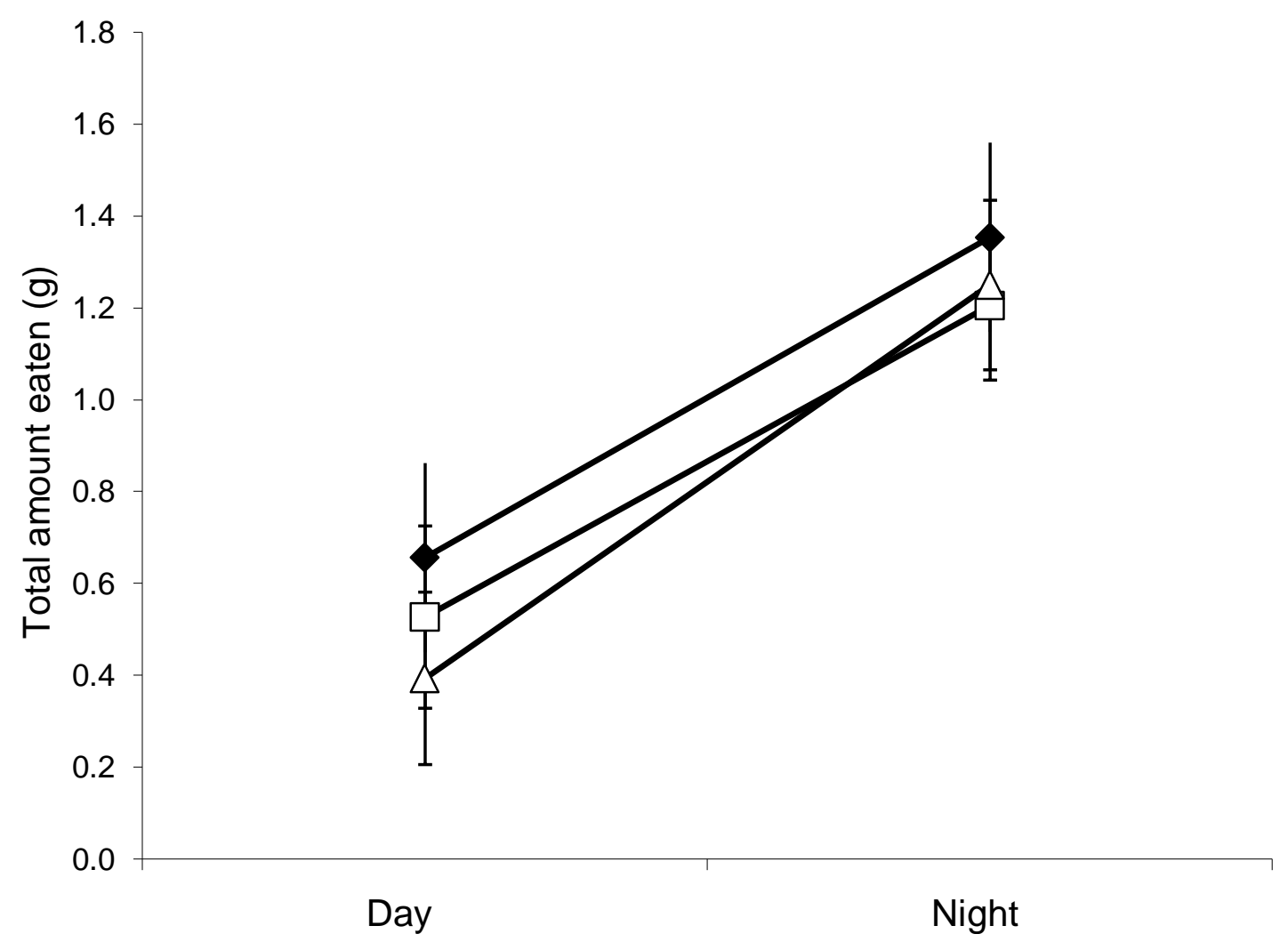

Figure 4.6 Total amount eaten (g) in low canopy cover $\diamond$, high canopy cover $\square$, and no canopy cover $\Delta$ treatments, displaying the interaction between canopy cover height and temporal $M$. musculus foraging activity $\left(\mathrm{F}_{2,12}=0.920, \mathrm{P}=0.425\right)(\mathrm{n}=15)$ 


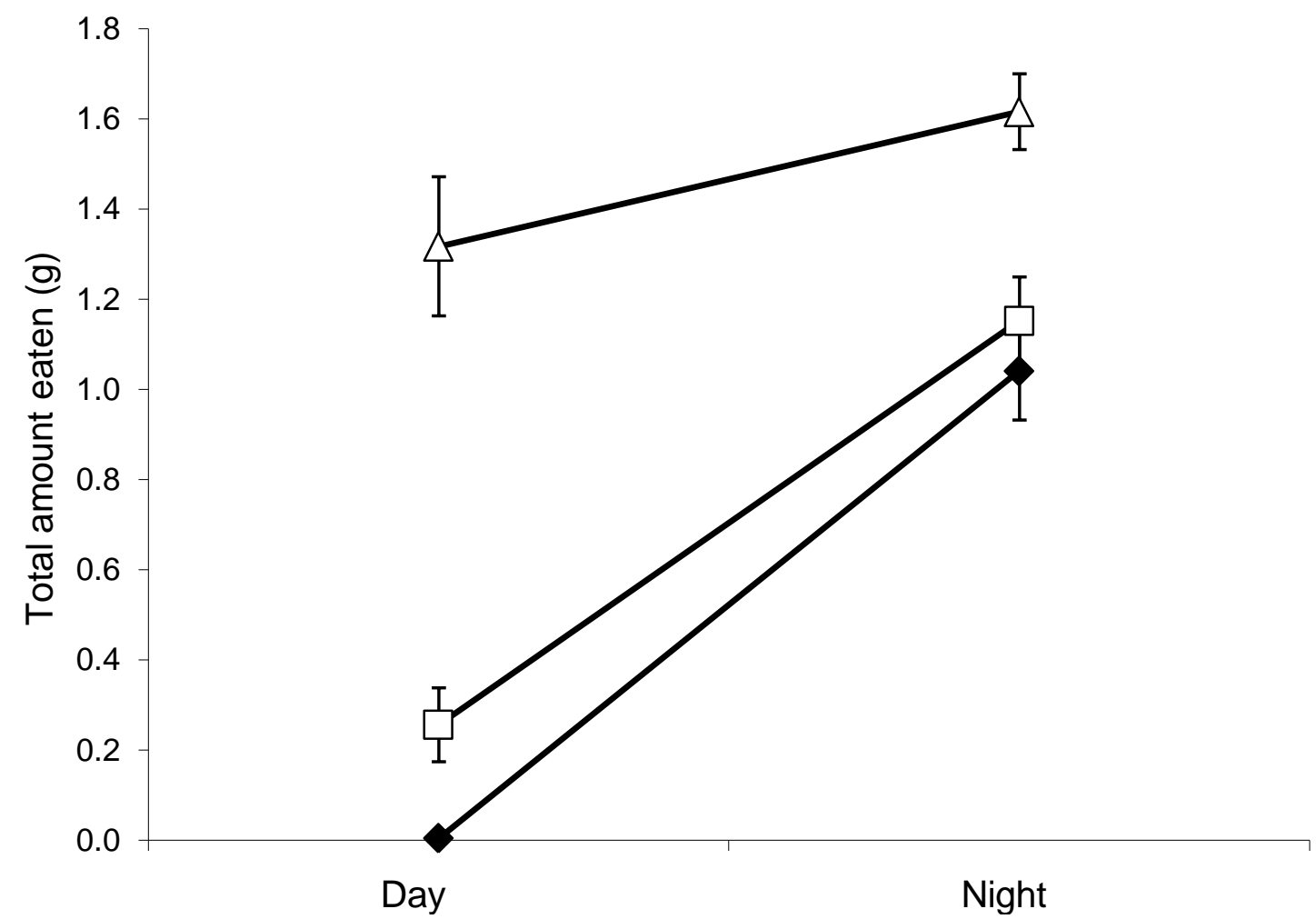

Figure 4.7 Total amount eaten (g) in no ground cover $\diamond$, short grass cover $\square$, and rank grass cover $\Delta$ treatments, displaying the interaction between ground cover and temporal M. musculus foraging activity $\left(\mathrm{F}_{2,11}=6.841, \mathrm{P}=0.012\right)(\mathrm{n}=15)$. 


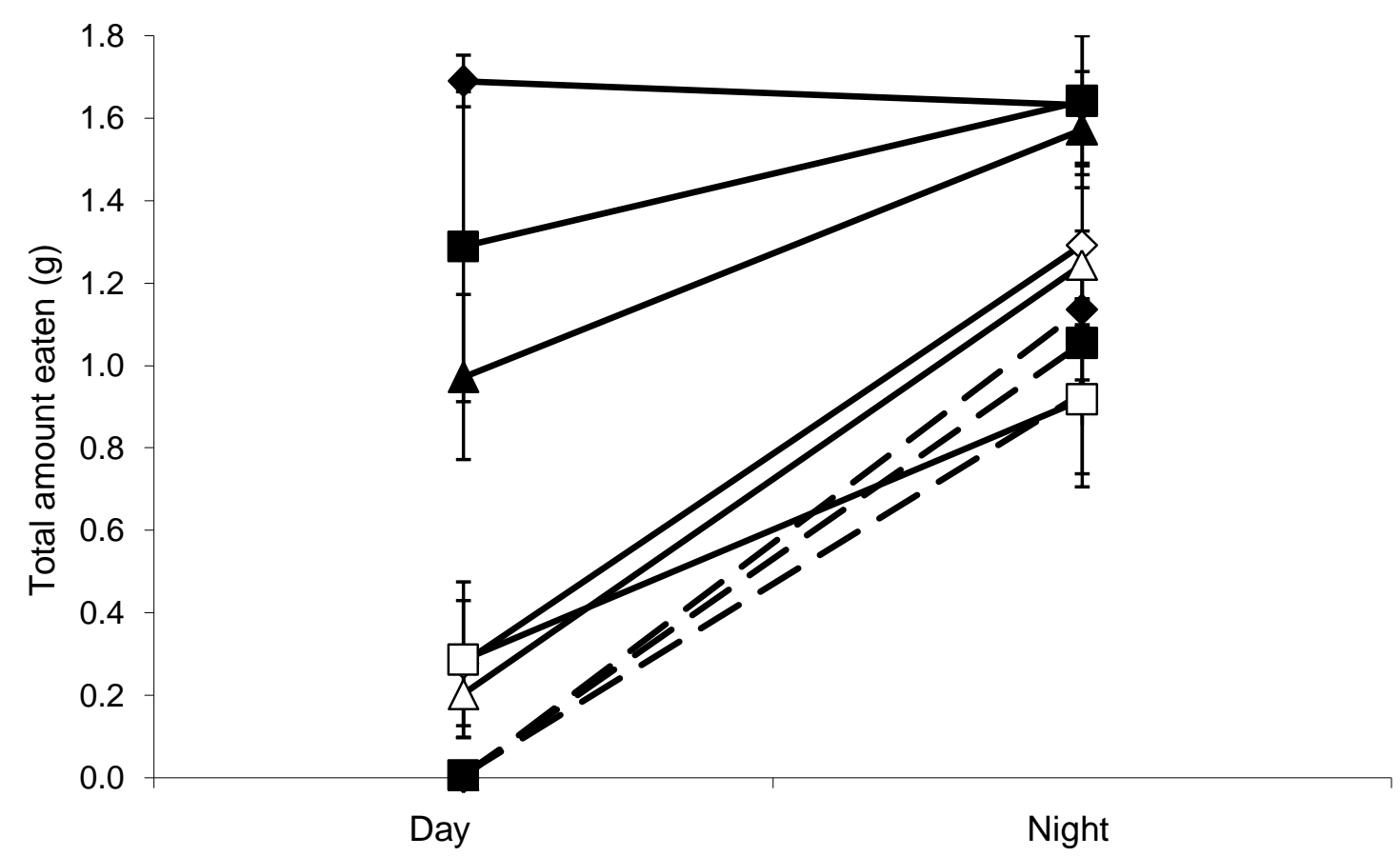

Figure 4.8 Total amount eaten (g) in no ground-low canopy cover - $\bullet-$, no ground-

high canopy cover - $\mathbf{-}$-, no ground-no canopy cover - $\mathbf{A}-$, short grass-low canopy cover $\diamond$, short grass-high canopy cover $\square$, short grass-no canopy cover $\Delta$, rank grass-low canopy cover $\bullet$, rank grass-high canopy cover $\mathbf{r a n k}$ grass-no canopy cover $\boldsymbol{\Delta}$ treatments, displaying the interaction between canopy cover height and both ground cover use and temporal behaviour of $M$. musculus during foraging $\left(\mathrm{F}_{4,24}=\right.$ $1.808, \mathrm{P}=0.160)(\mathrm{n}=5)$ 


\section{Discussion}

The high amounts of nocturnal foraging and use of the rank grass habitat observed here fits with the two previous chapters and the literature (Dickman et al. 1991, Dickman 1992, King et al. 1996, Singleton et al. 2007). Canopy treatment had no significant effects on the foraging activity of $M$. musculus but the trends of both diurnal and nocturnal foraging did give reason to examine further.

The lack of a significant influence of canopy treatments on the foraging behaviour of $M$. musculus was unexpected considering the habitat partitioning previously observed (King et al. 1996). Because R. rattus and M. musculus use habitats that differ in canopy cover (King et al. 1996), it was predicted that $M$. musculus would use aerial cover as an indirect cue to reduce encounters with their dominant competitor, $R$. rattus (Caut et al. 2007).

When focussing on the nocturnal short grass interactions displayed in Figure 4.8 there are possible indications of high canopy as an indirect cue for $R$. rattus. Foraging activity under the high canopy treatment increases less at night time relative to the two other short grass interactions. The low canopy treatment represents a level of low vascular vegetation or sub-canopy in a natural environment, whereas the high canopy treatment provided an imitation of higher arboreal canopy.

Chapter 3 provided evidence that short grass at night was a ground cover treatment that was less preferred in the presence of $R$. rattus scent, suggesting that they may be more prone in this habitat when both species are more active. Orrock et al. (2004) showed an example of rodents using vegetation as an indirect cue of predation risk over direct scent cues of predator species when considering habitat preferences, though does not appear to occur here. The combination of short grass, a 
ground cover type that was not preferred in the presence of $R$. rattus, and high canopy cover, a habitat that $R$. rattus are abundant in, may create an environment that $M$. musculus may be apprehensive in but does not significantly avoid.

The patterns of foraging activity observed in rank grass patches during the daytime was likely due to lower canopy providing more direct cover and therefore more protection from avian predators. Diurnal Circus approximans (Harrier hawks) were considered the main form of avian predation because of their diet (Baker-Gabb 1981b) and were common in the area (pers. obs.). The other diurnal raptor species of New Zealand, Falco novaeseelandiae (New Zealand falcon), was not present (pers. $o b s$.) and $M$. musculus are not a frequent constituent of $F$. novaeseelandiae diet (Lawrence and Gay 1991, Barea et al. 1999). C. approximans hunts for prey by soaring or hovering then dropping to the prey (Baker-Gabb 1981a). Therefore, canopy treatments would provide cover for $M$. musculus from $C$. approximans. The lower the canopy the more direct the cover was and more foraging activity resulted.

The patterns of $M$. musculus ground cover use and the weaker relationship with canopy cover suggest that ground cover may be a more significant (primary) factor in M. musculus habitat choices and canopy cover a secondary factor. Preference for rank grass remained clear whereas possible choices of canopy were not so apparent. These findings provide possible support for the use of indirect cues by $M$. musculus as secondary features in habitat selection.

Dickman (1992) stated that $M$. domesticus did not use vegetation over $1 \mathrm{~m}$ high when selecting habitat. Dickman (1992) was conducted in an Australian environment where there are more mammalian, avian and reptilian predator species (MacDonald 1992, Menkhorst 2001, Wilson and Swan 2003) as well as more rodentia species (Menkhorst 2001). The community relationships with different predators and 
competitors may have altered the processes and value of certain habitat preferences. In this study, increased ground cover was preferred (Figure 4.5) but there are two examples shown in these arena trials that display potential examples of $M$. musculus evaluating canopy cover. Evaluation of canopy features by M. musculus may need more study with more natural canopy materials and choices of canopy heights available within an arena.

If the ungulates were removed then regeneration may benefit from $R$. rattus presence and the absence of $M$. musculus. There are no native ungulate species to New Zealand and their abundance has been negatively correlated with understory and seedling density (Sweetapple and Nugent 2004). Low amounts of ground cover due to ungulate browsing and $R$. rattus presence because of a continuous arboreal habitat (Hooker and Innes 1995) would be alike the combination of short grass and high canopy that was not preferred by at night $M$. musculus. Post-dispersal seed predation would decrease without $M$. musculus and with the removal of ungulates seedling survival would increase, aiding regeneration of the forest. Though this would be counteracted by pre-dispersal destruction of fruits, flowers, buds and seedlings by $R$. rattus (Towns et al. 2006), and as the forest regenerates, the habitat would become more suited to M. musculus.

The interaction between rank grass and canopy treatments during the day may suggest that the relationship between $M$. musculus and $C$. approximans is a $\mu$-type predator-prey relationship. A $\mu$-type relationship is a system where the prey species avoids contact with another species through behavioural changes (e.g. habitat shift, diet change, diverting time from foraging to vigilance or altering foraging times). If individuals are physically removed from a habitat through direct contact with a predator species then it is treated as an N-type system (Brown et al. 1999). There was 
the possibility that $M$. musculus avoided the habitat where they are prone to $C$. approximans, though none were depredated. A study looking directly at this relationship would be more conclusive.

The presence of canopy cover may have promoted some diurnal foraging and limited some nocturnal foraging by M. musculus. M. musculus are more active nocturnally and so the negative effects of canopy at night time may have a stronger influence on their overall habitat choice. The decrease of foraging activity in short grass ground cover under high canopy would add further detail to the distribution patterns of M. musculus and $R$. rattus in King et al. (1996).

The main effects of high activity in dense ground cover and at night are aligned with previous studies. Nocturnal behaviours of $M$. musculus and other rodent species are inherent whether in natural or artificial environments to reduce activity when they more visually conspicuous (Mackintosh 1981). The high use of ground cover is widely supported in the literature (Brown 1988, Dickman 1992, Krebs et al. 1995, Arthur et al. 2004, Singleton et al. 2007) and adds to the correlation found in King et al. (1996) of high mice abundance in dense ground cover and absence in closed canopy habitat. The patterns found in King et al. (1996) were partially explained from these arena trials. Foraging increased amongst rank grass ground cover and decreased under canopy and with low level ground cover. Other benefits provided by the dense ground cover could be refuge, nesting habitat or food resources that relate to success of the population and fitness of the individual (Brown 1988, Krebs et al. 1995, King et al. 1996, Gray et al. 2000, Arthur et al. 2004, Singleton et al. 2007). In Chapter 2, ground cover was found to be a strong estimable parameter of mouse abundance and was also a contributor to the second strongest model that concerned suitable breeding habitat. Chapter 3 suggested that the complex ground 
cover substrate that does not provide refuge for $M$. musculus can be a hindrance for vigilance and escape.

Further trials could be done to support the evidence from the interactions of nocturnal foraging use of short grass under different canopy treatments and the effect of canopy treatment on daytime foraging behaviour. Arenas with consistent levels of ground cover throughout and varying levels of canopy treatment over each arena may clarify the canopy preferences of $M$. musculus. M. musculus are more active nocturnally (Mackintosh 1981) so the changes of activity due canopy cover at night this may play a bigger role in the patterns of preference displayed than during diurnal foraging.

The use of canopy as an indirect cue was not conclusive though there was potentially a weak response. There may be other environmental features that $M$. musculus use not only for $R$. rattus but other species, i.e. soil moisture or proximity to bodies of water may act as cues of the larger Rattus norvegicus (Norway rat), (King et al. 1996). There is scope for further investigation of indirect cues by M. musculus for $R$. rattus, whether with canopy cover of alternative features, or other species that are part of M. musculus ecology. 
Chapter 5:

Conclusions 
The objective of this study was to examine the competitive relationship between $M u s$ musculus and Rattus rattus. I expected that $R$. rattus would have affected M. musculus habitat preferences via direct and indirect cues of $R$. rattus presence because of the degree of influence that $R$. rattus appears to have on $M$. musculus populations (Innes et al. 1995, Miller and Miller 1995, King et al. 1996, Caut et al. 2007).

The common theme from the three investigations was that ground cover in the form of rank grass was preferred by $M$. musculus. From the observations on the landscape scale, rank grass was the strongest parameter for estimating M. musculus abundance. During both arena experiments rank grass was used the most regardless of the time of day or treatments of canopy cover and $R$. rattus presence. The use of dense ground cover is by no means a novel concept for $M$. musculus or a majority of small mammal species (Dickman et al. 1991, Dickman 1992, Twigg and Kay 1994, King et al. 1996, Kotler et al. 2001, Singleton et al. 2007), although there are some species that have adapted to foraging in open micro-habitats (Randall 1992, Kotler et al. 2001). This habitat preference fits with King et al. (1996) where in Pureora Forest Park $R$. rattus were more abundant in continuous canopy habitats and $M$. musculus were more common in areas of rank grass and broken canopy.

The point of interest throughout the study was how the relationship with $R$. rattus influenced $M$. musculus habitat prefences. There has been a demand for further work to be done to improve our grasp of the dynamics between these two rodent species (Innes et al. 1995, Brown et al. 1996, Sweetapple and Nugent 2005, Caut et al. 2007). Increases in M. musculus populations have been recorded after the removal of $R$. rattus (Innes et al. 1995, Miller and Miller 1995, Murphy et al. 1999) but it has been suggested that these increases were not solely due to removal of a competitor. 
Behavioural changes may play a role in the increased detection of M. musculus (Brown et al. 1996, Sweetapple and Nugent 2005, Caut et al. 2007).

During the arena trials where scent, a direct cue of $R$. rattus presence, was introduced there was evidence supporting a behavioural change in M. musculus. Mice in the arenas with the scent of $R$. rattus present decreased their foraging activity in short grass patches but did not increase activity in the other patches, suggesting that their foraging activity was suppressed. Therefore, it is possible that increases in foraging activity in the absence $R$. rattus of could incite higher reproductive rates (Arthur et al. 2004). The increase of M. musculus populations benefiting from the removal of $R$. rattus maybe due to higher reproductive rates with improved access to food resources (Brown et al. 1996) but also higher detection rates of M. musculus (Sweetapple and Nugent 2005), as they are more active.

Combining the findings of $M$. musculus behavioural changes due to $R$. rattus presence in the arena trials and with similar suggestions of behavioural changes (Brown et al. 1996, Sweetapple and Nugent 2005) it would be reasonable to be wary of estimates of the extent and number of M. musculus where $R$. rattus densities are modified or different. It is probable that in the presence of $R$. rattus in natural settings M. musculus populations are underestimated. The potential impacts of M. musculus may not be apparent in the presence of $R$. rattus because their activity, particularly foraging behaviour, are suppressed. The negative impacts of M. musculus may be attributed to $R$. rattus because the true extent $M$. musculus abundance is not apparent in natural settings where both species occur. Moreover, studies of behaviour solely on one of these species isolated from the other have to consider how the results would be represented in natural environments where both species are present. 
A finding with potentially important ramifications was the shared preference of $M$. musculus and $R$. rattus for warm dry slopes. A management focus on the removal of rats (Towns et al. 2006, Caut et al. 2007) may not be sufficient to conserve or restore native species and habitats because of the potential increase of the impact of M. musculus in these preferred habitats (Tompkins and Veltman 2006). The strongest parameter in the landscape scale observations was the aspect of slopes with $M$. musculus abundance positively correlated with north facing slopes and negatively correlated with slopes facing north-east around to the west. King et al. (1996) found that $R$. rattus were also more abundant on warmer and dryer slopes. Regeneration of forest communities and species adapted to warmer dryer areas might be restricted by rodents.

Imagine a forest flora adapted to warm dry sites that have suffered a decrease in range and a survey of pests in the area showing an abundance of $R$. rattus but, perhaps mistakenly, low levels of $M$. musculus. A management plan aimed at reducing the $R$. rattus population without considering $M$. musculus could lead to population irruptions of M. musculus (Innes et al. 1995, Miller and Miller 1995, Tompkins and Veltman 2006, Caut et al. 2007). Therefore, the management for this forest would be ineffective at promoting the forest species regeneration because high M. musculus numbers would not benefit seed or seedling survival and possibly invertebrates involved with regeneration of the forest (Miller and Miller 1995, Fitzgerald et al. 1996, Duthie et al. 2006, Wilson et al. 2007).

Reoccurring increases of $M$. musculus abundance with the removal of $R$. rattus (Innes et al. 1995, Miller and Miller 1995, Ruscoe 2001, Caut et al. 2007) and the increase of Mustela erminea (stoat) with irruptions of $M$. musculus and their subsequent prey-swapping (King 1983, O'Donnell and Phillipson 1996, King and 
White 2004) create cause for concern for pest management programs without adequate foresight. For example, if $M$. erminea and $R$. rattus are removed from an area or habitat to protect a species that is prone to predation from these species, it would be expected that M. musculus populations would benefit from their absence. However, an abundance of $M$. musculus would benefit the reinvasion of $M$. erminea to the area, potentially nullifying the gains made by removing the predators. The relationships within these communities need to be understood and considered to improve the efficiency and long-term success of controlling mammalian pests.

In New Zealand plagues of mice like those that occur in Australian grain growing regions (Singleton and Redhead 1990) have not taken place, but there have been irruptions of $M$. musculus populations coinciding with mast seeding of New Zealand beech forests (Nothofagus spp) (King 1983). These irruptions lead to an increase in rodent predators, particularly M. erminea (King 1983, O'Donnell and Phillipson 1996), increasing predation on Mohoua ochrocephala (mohua, yellowhead) (King 1983, O'Donnell et al. 1996) an endangered species (O'Donnell et al. 2001).

Those conserving $M$. ochrocephala may be able to pre-empt these irruptions to minimize the impact of M. musculus irruptions. Between plagues in Australia, Mus domesticus persist in refuge sites, but expand their range when the conditions are suitable (Singleton et al. 2007). Outside of mast seasons M. musculus are scarce in Nothofagus forest (Fitzgerald et al. 1981) so are likely to persist in the area at refuge sites. By concentrating on potential refuge sites in the lead up to a mast year the irruption of $M$. musculus populations may be reduced. From this study the northern facing sites with dense cover would be conducive as refuge sites. Singleton et al. (2007) observed that habitats previously utilised rarely by $M$. domesticus became centres of source populations (positive emigration) in favourable conditions. Pre- 
empting M. musculus irruptions may limit their increase initially but would not stop them completely. The behavioural preferences shown here, combined with demographic and spatial studies of M. musculus (Fitzgerald et al. 1981, Dickman 1992, Arthur et al. 2004, Singleton et al. 2007) begin to draw a picture of potential source-sink dynamics (Pulliam 1988).

Consideration of $M$. musculus when conserving cold blooded vertebrates is also imperative. M. musculus have previously been recorded impacting on native reptiles in New Zealand (Newman 1994, Lettink and Cree 2006). Reptiles need external sources of warmth and utilise habitats with dense ground cover (East et al. 1995) so they could overlap in habitat with M. musculus and suffer from $R$. rattus eradication that does not factor in the response of M. musculus.

Other vertebrates may need to be considered when managing rodent species. Galaxias maculatus (inanga, whitebait) eggs have been depredated by $M$. musculus (Baker 2006). Their eggs are laid on the banks generally minor waterways (Baker 2006), where contact with M. musculus might ordinarily be low because of the damp conditions. Reducing the $R$. rattus densities may increase $M$. musculus activity and increase egg predation.

Extant species of frog that are endemic to New Zealand, Leiopelma hamiltoni (Hamilton's frog), L. pakeka (Maud Island frog), L. archeyi (Archey's frog) and L. hochstetteri (Hochstetter's frog) are all threatened species (Daugherty et al. 1994). M. musculus have not been shown to be a cause of decline in native frogs (Towns and Daugherty 1994, Baber et al. 2006), despite their varying degrees of terrestrial habitat use that could make them prone. Perhaps M. musculus avoid their damp cool habitats. This is potentially supported by the most aquatic species, L. hochstetteri, which would 
be less likely to come into contact with M. musculus is also the most widespread frog species (Daugherty et al. 1994).

There was weak evidence from the arena trials that $M$. musculus used physical features of the habitat other than ground cover as cues to preferred foraging habitats. The possible use of differing levels of canopy cover differs from Dickman's (1992) suggestion that cover over $1 \mathrm{~m}$ did not influence $M$. musculus habitat choice. There was a trend for nocturnal foraging activity to decrease in short grass under the high canopy treatment. This fitted with the decreased foraging activity in short grass with the scent of $R$. rattus present. The use of indirect cues did not only concern the relationship with $R$. rattus but also diurnal avian predators. There was potentially a predation risk created by Circus approximans (Australasian harrier), this was the most probable explanation of higher diurnal foraging activity as canopy cover treatments became lower and provided direct cover. These patterns were not seen at night which suggests that Ninox novaeseelandiae (morepork, ruru) may not be a major predator of M. musculus though they were present in the area (pers. obs.). The lack of predatory risk posed $N$. novaeseelandiae is supported by the low proportion of M. musculus in their diet (Haw and Clout 1999, Haw et al. 2001). Ground cover has repeatedly been shown to be important in habitat use for M. musculus and other rodent species but my arena trials show that there may have been a secondary preference for canopy cover.

Nocturnal foraging behaviour in rank grass patches by M. musculus was not affected by canopy treatments during the arena trials. This suggests that there was the potential for coexistence with $R$. rattus where dense ground cover exists under continuous canopy. Overlap in both of these rodents species diet (Miller and Miller 1995) was not factored in the arena trials. At higher $R$. rattus densities, it would be expected that $M$. musculus would be excluded from some of the food resources 
(Brown et al. 1996, Caut et al. 2007). At lower densities coexistence of both species could arise with less competition for food (Caut et al. 2007).

The change in foraging behaviour of $M$. musculus during the arena trials was assumed to be caused by $R$. rattus, which compete with M. musculus in natural settings (Brown et al. 1996, Caut et al. 2007). It is feasible that $R$. rattus also attract predators of both species, such as M. erminea. King et al. (1996) reported a correlation in abundance between $M$. erminea and $R$. rattus and between Mustela nivalis (weasel) and $M$. musculus. M. nivalis are not common throughout New Zealand and M. erminea are more numerous (Murphy et al. 1998a, King et al. 2001). Therefore, an overlap in habitat with $R$. rattus may increase $M$. musculus contact with M. erminea and reduce M. musculus activity. $R$. rattus may be used by $M$. musculus as an indirect cue for $M$. erminea causing the reduction in foraging activity, not the competitive relationship between $M$. musculus and $R$. rattus supposed. The behavioural responses of $M$. musculus to $M$. erminea need to be investigated exclusively to make more precise conclusions on their relationship. Similar but larger arena experiments with $R$. rattus physically present may comprehensively clarify the type of relationship between $R$. rattus and M. musculus. Additional research into the dynamics between more invasive small mammal species, whether competitive or predatory, would further our comprehension of these communities and improve the management of them.

The arena trials made it possible to control the access to the feed trays that were interfered with by other species in the giving up density trials on the landscape scale (Chapter 2). This made it possible to identify the preferences of M. musculus. Excluding other species and individuals from the enclosures meant that the responses of $M$. musculus may not have been completely representative of a natural setting but 
did provide insight that can help to explain patterns that are observed in the environment.

By advancing our understanding of $M$. musculus habitat preferences the amount of effective effort put into pest management can be improved. Depending on the habitat preferences and ecology of the species of conservation interest, the degree of M. musculus eradication required can be determined or whether control is needed at all. If management of $M$. musculus is required, then effort can be asserted more effectively in habitats favoured by $M$. musculus. Further investigations into sourcesink dynamics of M. musculus would strengthen this concept as a tool for conservation. 


\section{References}

Abramsky, Z., M. L. Rosenzweig, and A. Subach. 2001. The cost of interspecific competition in two gerbil species. Journal of Animal Ecology 70:561-567.

Abramsky, Z., M. L. Rosenzweig, and A. Subach. 2002. The costs of apprehensive foraging. Ecology 83:1330-1340.

Alterio, N., H. Moller, and K. Brown. 1999. Trappability and densities of stoats (Mustela erminea) and ship rats (Rattus rattus) in a South Island Nothofagus forest, New Zealand. New Zealand Journal of Ecology 23:95-100.

Andersen, M. C., H. Adams, B. Hope, and M. Powell. 2004. Risk assessment for invasive species. Risk Analysis 24:787-793.

Arthur, A. D., R. P. Pech, and C. R. Dickman. 2004. Habitat structure mediates the non-lethal effects of predation on enclosed populations of house mice. Journal of Animal Ecology 73:867-877.

Atkinson, I. A. E. 1996. Introductions of wildlife as a cause of species extinctions. Wildlife Biology 2:135-141.

Avenant, N. L., and P. Cavallini. 2007. Correlating rodent community structure with ecological integrity, Tussen-die-Riviere Nature Reserve, Free State province, South Africa. Integrative Zoology 2:212-219.

Baber, M., H. Moulton, C. Smuts-Kennedy, N. Gemmel, and M. Crossland. 2006. Discovery and spatial assessment of a Hochstetter's frog (Leiopelma hochstetteri) population found in Maungatautari Scenic Reserve, New Zealand. New Zealand Journal of Zoology 33:147-156. 
Baker-Gabb, D. J. 1981a. Breeding behaviour and ecology of the Australasian harrier (Circus approximas) in the Manawatu-Rangitikei sand country, New Zealand. Notornis 28:103-119.

Baker-Gabb, D. J. 1981b. The diet of the Australasian harrier (Circus approximans) in the Manawatu-Rangitikei sand country, New Zealand. Notornis 28:241-254.

Baker, C. F. 2006. Predation of inanga (Galaxias maculatus) eggs by field mice (Mus musculus). Journal of the Royal Society of New Zealand 36:143-147.

Barea, L. P., J. R. Waas, K. Thompson, and N. H. Hyde. 1999. Diet provided for chicks by New Zealand falcons (Falco novaeseelandiae) nesting in forested habitat. Notornis 46:257-267.

Basse, B., I. Flux, and J. Innes. 2003. Recovery and maintenance of North Island kokako (Callaeas cinerea wilsoni) populations through pulsed pest control. Biological Conservation 109:259-270.

Bell, B. D. 1978. The Big South Cape Islands rat irruption in P. Dingwall, I. A. E. Atkinson, and H. R., editors. The Ecology and Control of Rodents in New Zealand Nature Reserves. Department of Lands and Survey, Wellington, New Zealand.

Blackwell, G. L. 2005. Another world: the composition and consequences of the introduced mammal fauna of New Zealand. Australian Zoologist 33:108-118.

Blackwell, G. L., and W. L. Linklater. 2003. Unique and valuable but untouched research opportunities using exotic mammals in Australasia. Australian Zoologist 32:420-430.

Blackwell, G. L., M. A. Potter, J. A. McLennan, and E. O. Minot. 2003. The role of predators in ship rat and house mouse population eruptions: drivers or passengers? Oikos 100:601-613. 
Bossuyt, B., M. Heyn, and M. Hermy. 2002. Seed bank and vegetation composition of forest stands of varying age in central Belgium: consequences for regeneration of ancient forest vegetation. Plant Ecology 162:33-48.

Brand, C. J., L. B. Keith, and C. A. Fischer. 1976. Lynx responses to changing snowshoe hare densities in central Alberta. The Journal of Wildlife Management 40:416-428.

Bronson, F. H. 1979. The reproductive ecology of the house mouse. The Quarterly Review of Biology 54:265-299.

Brown, J. S. 1988. Patch use as an indicator of habitat preference, predation risk, and competition. Behavioral Ecology and Sociobiology 22:37-47.

Brown, J. S. 1992. Patch use under predation risks. I: models and predictions. Annales Zoologici Fennici 29:301-309.

Brown, J. S., J. W. Laundre, and M. Gurung. 1999. The ecology of fear: optimal foraging, game theory, and trophic interactions. Journal of Mammalogy 80:385-399.

Brown, J. S., R. A. Morgan, and B. D. Dow. 1992. Patch use under predation risk: II. a test with fox squirrels, Sciurus niger. Annales Zoologici Fennici 29:311-318.

Brown, K. P., H. Moller, J. Innes, and N. Alterio. 1996. Calibration of tunnel tracking rates to estimate relative abundance of ship rats (Rattus rattus) and mice (Mus musculus) in a New Zealand forest. New Zealand Journal of Ecology 20:271275.

Brown, K. P., and S. C. Urlich. 2005. Aerial 1080 operations to maximise biodiversity protection. New Zealand Department of Conservation Research Series no. 216. Department of Conservation, Wellington, New Zealand. 
Buckley, Y. M. 2008. The role of research for integrated management of invasive species, invaded landscapes and communities. Journal of Applied Ecology 45:397-402.

Burnham, K. P., and D. R. Anderson. 2002. Model selection and multimodel inference: a practical information-theoretic approach 2nd edition. Springer, New York, USA.

Caut, S., J. G. Casanovas, E. Virgos, J. Lozano, G. W. Witmer, and F. Courchamp. 2007. Rats dying for mice: modelling the competitor release effect. Austral Ecology 32:858-868.

Charnov, E. L. 1976. Optimal foraging, the marginal value theorem. Theoretical Population Biology 9:129-136.

Choquenot, D., and W. A. Ruscoe. 2000. Mouse population eruptions in New Zealand forests: the role of population density and seedfall. Journal of Animal Ecology 69:1058-1070.

Clout, M. N., K. Denyer, R. E. James, and McFadden. 1995. Breeding success of New Zealand pigeons (Hemiphaga novaeseelandiae) in relation to control of introduced mammals. New Zealand Journal of Ecology 19:209-212.

Crowcroft, P. 1966. Mice all over. Foulis, London, United Kingdom.

Cunningham, D. M., and P. J. Moors. 1993. Guide to the identification and collection of New Zealand rodents. 2nd edition. Department of Conservation, Wellington, New Zealand.

Daniel, M. J. 1973. Seasonal diet of the ship rat (Rattus r. rattus) in lowland forest in New Zealand. Proceedings of the New Zealand Ecological Society 20:21-30. 
Daniel, M. J. 1990. Order Chiroptera. Pages 114-137 in C. M. King, editor. The handbook of New Zealand mammals. Oxford University Press, Auckland, New Zealand.

Daugherty, C. H., G. B. Patterson, and R. A. Hitchmough. 1994. Taxonomic and conservation review of the New Zealand herpetofauna. New Zealand Journal of Zoology 21:317-323.

Day, T. D., and R. J. MacGibbon. 2007. Multiple-species exclusion fencing and technology for mainland sites. Pages 418-433 in Proceedings of the managing vertebrate invasive species, Fort Collins, Colorado, USA.

Dell'Omo, G., L. Ricceri, D. P. Wolfer, I. I. Poletaeva, and H.-P. Lipp. 2000. Temporal and spatial adaptation to food restriction in mice under naturalistic conditions. Behavioural Brain Research 115:1-8.

Diamond, J. M., and C. R. Veitch. 1981. Extinctions and introductions in the New Zealand avifauna: cause and effect? Science 211:499-501.

Dickman, C. R. 1992. Predation and habitat shift in the house mouse, Mus domesticus. Ecology 73:313-322.

Dickman, C. R., M. Predavec, and A. J. Lynam. 1991. Differential predation of size and sex classes of mice by the barn owl, Tyto alba. Oikos 62:67-76.

Dulloo, M. E., S. P. Kell, and C. G. Jones. 2002. Impact and control of invasive alien species on small islands. International Forestry Review 4:277-285.

Duthie, C., G. Gibbs, and K. C. Burns. 2006. Seed dispersal by weta. Science 311:1575.

East, K. T., M. R. East, and C. H. Daugherty. 1995. Ecological restoration and habitat relationships of reptiles on Stephens Island, New Zealand. New Zealand Journal of Zoology 22:249-261. 
Ecroyd, C. E., R. A. Franich, H. W. Kroese, and D. Steward. 1995. Volatile constituents of Dactylanthus taylorii flower nectar in relation to flower pollination and browsing by animals. Phytochemistry 40:1387-1389.

Efford, M. G., B. J. Karl, and H. Moller. 1988. Population ecology of Mus musculus on Mana Island, New Zealand. Journal of Zoology 216:539-563.

Fitzgerald, B. M., M. J. Daniel, A. E. Fitzgerald, B. J. Karl, M. J. Meads, and P. R. Notman. 1996. Factors affecting the numbers of house mice (Mus musculus) in hard beech (Nothofagus truncata) forest. Journal of the Royal Society of New Zealand 26:237-249.

Fitzgerald, B. M., B. J. Karl, and H. Moller. 1981. Spatial organization and ecology of a sparse population of house mice (Mus musculus) in a New Zealand forest. The Journal of Animal Ecology 50:489-518.

Gillies, C. A., and R. J. Pierce. 1999. Secondary poisoning of mammalian predators during possum and rodent control operations at Trounson Kauri Park, Northland, New Zealand. New Zealand Journal of Ecology 23:183-192.

Gotelli, N. J., and A. M. Ellison. 2004. A primer of ecological statistics. Sinauer Associates, Sunderland, USA.

Gray, S. J., S. P. Jensen, and J. L. Hurst. 2000. Structural complexity of territories: preference, use of space and defence in commensal house mice, Mus domesticus. Animal Behaviour 60:765-772.

Gurevitch, J., and D. K. Padilla. 2004. Are invasive species a major cause of extinctions? Trends in Ecology \& Evolution 19:470-474.

Haim, A., and I. Izhaki. 1994. Changes in rodent community during recovery from fire: relevance to conservation. Biodiversity and Conservation 3:573-585. 
Hamilton, W. J., Jr. 1942. Winter reduction of small mammal populations and its probable significance. The American Naturalist 76:216-218.

Haw, J. M., and M. N. Clout. 1999. Diet of morepork (Ninox novaeseelandiae) throughout New Zealand by analysis of stomach contents. Notornis 46:333345.

Haw, J. M., M. N. Clout, and R. G. Powlesland. 2001. Diet of moreporks (Ninox novaeseelandiae) in Pureora Forest determined from prey remains in regurgitated pellets. New Zealand Journal of Ecology 25:61-67.

Herbst, M., J. M. Roberts, P. T. W. Rosier, M. E. Taylor, and D. J. Gowing. 2007. Edge effects and forest water use: a field study in a mixed deciduous woodland. Forest Ecology and Management 250:176-186.

Heske, E. J., J. H. Brown, and S. Mistry. 1994. Long-term experimental study of a Chihuahuan Desert rodent community: 13 years of competition. Ecology 75:438-445.

Holdaway, R. N. 1989. New Zealand's pre-human avifauna and its vulnerability. New Zealand Journal of Ecology 12:11-25.

Holdaway, R. N., and N. R. Beavan. 1999. Reliable ${ }^{14}$ C AMS dates on bird and Pacific rat (Rattus exulans) bone gelatin, from a $\mathrm{CaCO}_{3}$-rich deposit. Journal of the Royal Society of New Zealand 29:185-211.

Holland, P. G., and D. G. Steyn. 1975. Vegetational responses to latitudinal variations in slope angle and aspect. Journal of Biogeography 2:179-183.

Hooker, S., and J. Innes. 1995. Ranging behaviour of forest-dwelling ship rats, Rattus rattus, and effects of poisoning with broadifacoum. New Zealand Journal of Zoology 22:291-304. 
Howe, H. F., and J. S. Brown. 1999. Effects of birds and rodents on synthetic tallgrass communities. Ecology 80:1776-1781.

Hughes, J. J., and D. Ward. 1993. Predation risk and distance to cover affect foraging behaviour in Namib Desert gerbils. Animal Behaviour 46:1243-1245.

Innes, J. 2001. Advances in New Zealand mammalogy 1990-2000: european rats. Journal of the Royal Society of New Zealand 31:111-125.

Innes, J. 2005a. Norway rat. Pages 174-187 in C. M. King, editor. The handbook of New Zealand ammals. Oxford University Press, Auckland, New Zealand.

Innes, J. 2005b. Ship rat. Pages 187-204 in C. M. King, editor. The handbook of New Zealand mammals. Oxford University Press, Auckland, NewZ ealand.

Innes, J., and G. Barker. 1999. Ecological consequences of toxin use for mammalian pest control in New Zealand - an overview. New Zealand Journal of Ecology 23:111-127.

Innes, J., B. Warburton, D. Williams, H. Speed, and P. Bradfield. 1995. Large-scale poisoning of ship rats (Rattus rattus) in indigenous forests of the North Island, New Zealand. New Zealand Journal of Ecology 19:5-17.

Jones, M., Y. Mandelik, and T. Dayan. 2001. Coexistence of temporally partitioned spiny mice: roles of habitat structure and foraging behavior. Ecology 82:21642176

Juliano, S. A., and L. Philip Lounibos. 2005. Ecology of invasive mosquitoes: effects on resident species and on human health. Ecology Letters 8:558-574.

King, C. M. 1983. The Relationships between beech (Nothofagus Sp.) seedfall and populations of mice (Mus musculus), and the demographic and dietary responses of stoats (Mustela erminea), in three New Zealand forests. The Journal of Animal Ecology 52:141-166. 
King, C. M., K. Griffiths, and E. C. Murphy. 2001. Advances in New Zealand mammalogy 1990-2000: stoat and weasel. Journal of the Royal Society of New Zealand 31:165-183.

King, C. M., J. G. Innes, M. Flux, M. O. Kimberley, J. R. Leathwick, and D. S. Williams. 1996. Distribution and abundance of small mammals in relation to habitat in Pureora Forest Park. New Zealand Journal of Ecology 20:215-240.

King, C. M., and P. C. L. White. 2004. Decline in capture rate of stoats at high mouse densities in New Zealand Nothofagus forests. New Zealand Journal of Ecology 28:251-258.

Kotler, B. P., J. S. Brown, and O. Hasson. 1991. Factors affecting gerbil foraging behavior and rates of owl predation. Ecology 72:2249-2260.

Kotler, B. P., J. S. Brown, A. Oldfield, J. Thorson, and D. Cohen. 2001. Foraging substrate and escape substrate: patch use by three species of gerbils. Ecology 82:1781-1790.

Kotler, B. P., J. S. Brown, R. J. Smith, and W. O. Wirtz Ii. 1988. The effects of morphology and body size on rates of owl predation on desert rodents. Oikos 53:145-152.

Krebs, C. J., A. J. Kenney, and G. R. Singleton. 1995. Movements of feral house mice in agricultural landscapes. Australian Journal of Zoology 43:293-302.

Lawrence, S. B., and C. G. Gay. 1991. Behaviour of fledgling New Zealand falcons (Falco novaeseelandiae). Notornis 38:173-182.

Legendre, P., and M. J. Fortin. 1989. Spatial pattern and ecological analysis. Plant Ecology 80:107-138. 
Lertzman, K. P., G. D. Sutherland, A. Inselberg, and S. C. Saunders. 1996. Canopy gaps and the landscape mosaic in a coastal temperate rain forest. Ecology 77:1254-1270.

Lettink, M., and A. Cree. 2006. Predation, by the feral house mouse (Mus Musculus), of McCann's skinks (Oligosoma maccanni) constrained in pittfall traps. Herpetofauna 36:61-62.

Lima, S. L. 1998. Nonlethal effects in the ecology of predator-prey interactions. BioScience 48:25-34.

MacDonald, J. D. 1992. Birds of Australia: a summary of information Reed Books, West Chatswood, Australia.

Mackintosh, J. 1981. Behaviour of the house mouse. Pages 337-366 in R. Berry, editor. Biology of the House Mouse. Academic Press, London, United Kingdom.

Malcolm, J. R., and J. C. Ray. 2000. Influence of timber extraction routes on Central African small-mammal commnunities, forest structure, and tree diversity. Conservation Biology 14:1623-1638.

Mandelik, Y., M. Jones, and T. Dayan. 2003. Structurally complex habitat and sensory adaptations mediate the behavioural responses of a desert rodent to an indirect cue for increased predation risk. Evolutionary Ecology Research 5:501-515.

Marra, M. J. 2003. Last interglacial beetle fauna from New Zealand. Quaternary Research 59:122-131.

McGlone, M. S. 1989. The Polynesian settlement of New Zealand in relation to environmental and biotic changes. New Zealand Journal of Ecology 12:115129. 
Menkhorst, P. 2001. A field guide to the mammals of Australia. Oxford University Press, Melbourne, Australia.

Miller, C. J., and T. K. Miller. 1995. Population dynamics and diet of rodents on Rangitoto Island, New Zealand, including the effect of a 1080 poison operation. New Zealand Journal of Ecology 19:19-27.

Moffat, M., and E. O. Minot. 1994. Distribution and abundance of forest birds in the Ruamahanga Ecological Area, North Island, New Zealand. New Zealand Journal of Zoology 21:135-150.

Murphy, E. C., and P. Bradfield. 1992. Change in diets of stoats following pois oning of rats in a New Zealand forest. New Zealand Journal of Ecology 16:137-140.

Murphy, E. C., B. K. Clapperton, P. Bradfield, and H. J. Speed. 1998a. Effects of ratpoisoning operations on abundance and diet of mustelids in New Zealand podocarp forests. New Zealand Journal of Zoology 25:315-328.

Murphy, E. C., B. K. Clapperton, P. M. F. Bradfield, and H. J. Speed. 1998 b. Brodifacoum residues in target and non-target animals following large-scale poison operations in New Zealand podocarp-hardwood forests. New Zealand Journal of Zoology 25:307-314.

Murphy, E. C., L. Robbins, J. B. Young, and J. E. Dowding. 1999. Secondary poisoning of stoats after an aerial 1080 poison operation in Pureora Forest, New Zealand. New Zealand Journal of Ecology 23:175-182.

Newman, D. G. 1994. Effects of a mouse, Mus musculus, eradication programme and habitat change on a lizard populations of Mana Island, New Zealand, with special reference to McGregor's skink, Cyclodina macgrregor. New Zealand Journal of Ecology 21:443-456. 
Nicholson, A. J. 1933. Supplement: the balance of animal populations. The Journal of Animal Ecology 2:131-178.

Nunes, S. 2007. Dispersal and philopatry. Pages 150-162 in J. O. Wolff and P. W. Sherman, editors. Rodent Societies: An Ecological and Evolutionary Perspective. The University of Chicago Press, Chicago, USA.

O'Donnell, C. F. J. 1996. Predators and the decline of New Zealand forest birds: an introduction to the hole-nesting bird and predator programme. New Zealand Journal of Zoology 23:213-219.

O'Donnell, C. F. J., P. J. Dilks, and G. P. Elliot. 1996. Control of a stoat (Mustela erminea) population irruption to enhance mohua (yellowhead) (Mohoua ochrocephala) breeding success in New Zealand. New Zealand Journal of Zoology 23:279-286.

O'Donnell, C. F. J., and S. M. Phillipson. 1996. Predicting the incidence of mohua predation from the seedfall, mouse, and predator fluctuations in beech forests. New Zealand Journal of Zoology 23:287-293.

O'Donnell, C. F. J., A. Roberts, and J. Lyall. 2001. Mohua (yellowhead) recovery plan. Threatened species recovery plan series 6. Department of Conservation, Wellington.

Ogden, J., L. E. S. Basher, and M. McGlone. 1998. Botanical briefing. Fire, forest regeneration and links with early human habitation: evidence from New Zealand. Annals of Botany 81:687-696.

Orrock, J. L., B. J. Danielson, and R. J. Brinkerhoff. 2004. Rodent foraging is affected by indirect, but not by direct, cues of predation risk. Behavioral Ecology 15:433-437. 
Pimentel, D., R. Zuniga, and D. Morrison. 2005. Update on the environmental and economic costs associated with alien-invasive species in the United States. Ecological Economics 52:273-288.

Pulliam, H. R. 1988. Sources, sinks, and population regulation. The American Naturalist 132:652-661.

Randall, J. A. 1992. Behavioural adaptations of desert rodents (Heteromyidae). Animal Behaviour 45:263-287.

Ricklefs, R. E., and G. L. Miller. 1999. Ecology. 4th edition. W.H. Freeman, New York, USA.

Roche, B. E., A. I. Schulte-Hostedde, and R. J. Brooks. 1999. Route choice by deer mice (Peromyscus maniculatus): reducing the risk of auditory detection by predators. American Midland Naturalist 142:194-197.

Rogers, G. M., and M. S. McGlone. 1994. A history of Kaiparoro clearing and the limits of Nothofagus in the northern Tararua Range, New Zealand. New Zealand Journal of Botany 32:463-482.

Ruscoe, W. A. 2001. Advances in New Zealand mammalogy 1990-2000: house mouse. Journal of the Royal Society of New Zealand 31:127-134.

Ruscoe, W. A., R. Goldsmith, and D. Choquenot. 2001. A comparison of population estimates and abundance indices for house mice inhabiting beech forests in New Zealand. Wildlife Research 28:173-178.

Ruscoe, W. A., and E. C. Murphy. 2005. House mouse. Pages 204-221 in C. M. King, editor. The handbook of New Zealand mammals. Oxford University Press, Auckland, New Zealand.

Saunders, A., and D. A. Norton. 2001. Ecological restoration at mainland Islands in New Zealand. Biological Conservation 99:109-119. 
Schauber, E. M., D. Kelly, P. Turchin, C. Simon, W. G. Lee, R. B. Allen, I. J. Payton, P. R. Wilson, P. E. Cowan, and R. E. Brockie. 2002. Masting by eighteen New Zealand plant species: the role of temperature as a synchronizing cue. Ecology 83:1214-1225.

Schmidt, K. A., and R. S. Ostfeld. 2003. Mice in space: space use predicts the interaction between mice and songbirds. Ecology 84:3276-3283.

Schoener, T. W. 1983. Field experiments on interspecific competition. The American Naturalist 122:240-285.

Singleton, G. R., and T. D. Redhead. 1990. Structure and biology of house mouse populations that plague irregularly: an evolutionary perspective. Biological Journal of the Linnean Society 41:285-300.

Singleton, G. R., C. R. Tann, and C. J. Krebs. 2007. Landscape ecology of house mouse outbreaks in south-eastern Australia. Journal of Applied Ecology 44:644-652.

Stamps, J., and V. V. Krishnan. 2005. Nonintuitive cue use in habitat selection. Ecology 86:2860-2867.

Stringer, I., and R. Montefiore. 2000. Distribution and biology of the endangered kauri snail, Paryphanta busbyi watti. Science for Conservation 163:5-35

Sweetapple, P. J., and G. Nugent. 2004. Seedling ratios: a simple method for assessing ungulate impacts on forest understories. Wildlife Society Bulletin 32:137-147.

Sweetapple, P. J., and G. Nugent. 2005. When the rats are away the mice will play! Kararehe Kino: Vertebrate Pest Research: 9-10. 
Sweetapple, P. J., and G. Nugent. 2007. Ship rat demography and diet following possum control in a mixed podocarp-hardwood forest. New Zealand Journal of Ecology 31:186-201.

Tait, A., R. Bell, S. Burgess, R. Gorman, W. Gray, H. Larsen, B. Mullan, S. Reid, J. Sansom, C. Thompson, D. Wratt, and M. Harkness. 2002. Meteorological hazards and the potential impacts of climate change in Wellington Region. Wellington Regional Council Meteorological Hazards and Climate Change Report. Wellington Regional Council, Wellington.

Taylor, R. H. 1975. What limits kiore (Rattus exulans) distribution in New Zealand? New Zealand Journal of Zoology 2:473-477.

Tompkins, D. M., and C. J. Veltman. 2006. Unexpected consequences of vertebrate pest control: predictions from a four-species community model. Ecological Applications 16:1050-1061.

Towns, D. R., I. A. E. Atkinson, and C. H. Daugherty. 2006. Have the harmful effects of introduced rats on islands been exagerated? Biological Invasions 8:863-891.

Towns, D. R., and K. G. Broome. 2003. From small Maria to massive Campbell: forty years of rat eradications from New Zealand islands. New Zealand Journal of Zoology 30:377-398.

Towns, D. R., and C. H. Daugherty. 1994. Patterns of range contractions and extinctions in the New Zealand herpetofauna following human colonisation. New Zealand Journal of Zoology 21:325-339.

Twigg, L. E., and B. J. Kay. 1994. The effects of microhabitat and weather on house mouse (Mus domesticus) numbers and the implications for management. The Journal of Applied Ecology 31:651-663. 
Valone, T. J., and J. H. Brown. 1995. Effects of competition, colonization, and extinction on rodent species diversity. Science 267:880-883.

Valone, T. J., and D. A. Kelt. 1999. Fire and grazing in a shrub-invaded arid grassland community: independent or interactive ecological effects? Journal of Arid Environments 42:15-28.

Weihong, J., C. R. Veitch, and J. L. Craig. 1999. An evaluation of the efficiency of rodent trapping methods: the effect of trap arrangement, cover type, and bait. New Zealand Journal of Ecology 23:45-51.

White, P. C. L., and C. M. King. 2006. Predation on native birds in New Zealand beech forests: the role of functional relationships between stoats (Mustela erminea) and rodents. Ibis 148:765-771.

Wiener, J. G., and M. H. Smith. 1972. Relative efficiencies of four small mammal traps. Journal of Mammalogy 53:868-873.

Wilmshurst, J. M., and T. F. G. Higham. 2004. Using rat-gnawed seeds to independently date the arrival of Pacific rats and humans in New Zealand. The Holocene 14:801-806.

Wilson, D. J., E. F. Wright, C. D. Canham, and W. A. Ruscoe. 2007. Neighbourhood analyses of tree seed predation by introduced rodents in a New Zealand temperate rainforest. Ecography 30:105-119.

Wilson, S. K., and G. Swan. 2003. A complete guide to reptiles of Australia Reed New Holland, Frenchs Forrest, Australia.

Yeaton, R. I., and M. L. Cody. 1974. Competitive release in island song sparrow populations. Theoretical Population Biology 5:42-58.

Ylönen, H., J. Jacob, M. J. Davies, and G. R. Singleton. 2002. Predation risk and habitat selection of Australian house mice (Mus domesticus) during an 
incipient plague: desperate behaviour due to food depletion. Oikos 99:284289.

Yom-Tov, Y., S. Yom-Tov, and H. Moller. 1999. Competition, coexistence, and adaptation amongst rodent invaders to Pacific and New Zealand islands. Journal of Biogeography 26:947-958.

Young, A., and N. Mitchell. 1994. Microclimate and vegetation edge effects in a fragmented podocarp-broadleaf forest in New Zealand. Biological Conservation 67:63-72.

Zavaleta, E. S., R. J. Hobbs, and H. A. Mooney. 2001. Viewing invasive species removal in a whole-ecosystem context. Trends in Ecology \& Evolution 16:454-459. 